\title{
Zur Kenntnis der Erscheinungen bei der Elektrolyse von Alkalichloridlösungen mit Diaphragma.
}

\author{
Von \\ F. Foerster und F. JoRke.
}

Mit 3 Figuren im Text.

\section{Einleitung.}

Die Elektrolyse von Alkalichloridlösungen mit Diaphragma hat eine hohe wirtschaftliche Bedeutung, da sie kaustisches Alkali und Chlor gesondert zu liefern vermag. Es ist daher selbstverständlich, dafs die Technik seit Jahren diesen Vorgang mit grofsem Eifer und entsprechenden Erfolgen studiert hat; ob es ebenso selbstverständlich ist, dals aus den hierbei geleisteten grolsen Summen wissenschaftlicher Forschung die Wissenschaft selbst so wenig unmittelbaren oder mittelbaren Nutzen gezogen hat, wie es der Fall ist, mufs dahingestellt bleiben.

Im Anschlufs an die im Dresdener Laboratorium durchgeführten Untersuchungen über die Elektrolyse der Alkalichloridlösungen ohne Diaphragma lag es viel zu nahe, die hierbei gewonnenen Erkenntnisse an einem eingehenderen Studium des Diaphragmenprozesses zu prüfen, als dals wir an diesem hätten vorbeigehen können. Wir haben daher ein solches unternommen und wollen im Folgenden die dabei gewonnenen Ergebnisse mitteilen, so wenig diese auch den Anspruch machen, das von uns betretene Gebiet in abgeschlossener Behandlung vorzuführen, und so sehr wir uns dabei bewulst sind, den beteiligten Kreisen der Technik nicht viel Neues zu bringen. 


\section{Theoretischer Teil.}

Wenn auch über die Grundzüge der Erscheinungen bei der Elektrolyse von Alkalichloriden mit Diaphragma mancherlei Mitteilungen vorliegen, $u$. a. in den Untersuchungen von $F_{O G H}{ }^{1}$ und auch die eine oder andere Erfahrung der Technik im Laufe der Zeit bekannt geworden ist, so ist doch eine eingehendere Theorie dieser Dinge unseres Wissens bisher nicht veröffentlicht worden.

\section{A. Die chemischen Vorgänge im Kathoden- und im Anodenraum.}

Bei der Elektrolyse einer Alkalichloridlösung, bei welcher Kathoden- und Anodenraum durch ein poröses Diaphragma von einander getrennt sind, entsteht in jenem, der aufgewandten Strommenge entsprechend, Alkalihydrat und freier Wasserstoff, und dieser verteilt das Erstere rasch in der Kathodenlösung. So gelangt Alkalihydroxyd an das Diaphragma und dringt durch dieses in einem gewissen Betrage in den Anodenraum ein, und zwar teils auf dem Wege der Stromleitung, teils durch einfache Diffusionsvorgänge. Die Alkalichloridelektrolyse mit Diaphragma unterscheidet sich also von derjenigen ohne ein solches eigentlich nur graduell, und zwischen den Erscheinungen bei beiden Vorgängen müssen Zusammenhänge existieren. In einem Fall verschwindet sehr nahe alles an der Kathode gebildete Alkali und an der Anode frei werdende Chlor, und es entstehen als Produkte der Elektrolyse in der früher dargelegten Weise ${ }^{2}$ Chlorsauerstoffverbindungen. Beim Diaphragmenprozels aber gehen nur gewisse Teile des kathodisch entstehenden Alkalis und des anodischen Chlors als solche verloren, und der von ihnen verbleibende Rest stellt den wertvollsten Teil der Stromausbeute dar. Wodurch diese Verluste beeinflufst werden, soll unten in Abschnitt B behandelt werden; hier soll nun zunächst das Schicksal der in den Anodenraum gelangenden Hydroxylionen verfolgt werden.

Es soll dabei, um die Betrachtungen und die später zu deren Prüfung vorzunehmenden Experimente möglichst einfach zu gestalten, davon ausgegangen werden, dafs die Anoden völlig unangreifbar sind, aus Platiniridium bestehen. Ferner soll in dieser Arbeit die Erörterung des Temperatureinflusses auf die Vorgänge unterlassen, und es sollen diese als bei gewöhnlicher Temperatur, etwa bei $20^{\circ}$, sich abspielend allgemein angenommen werden.

\footnotetext{
1 Dissertation. Jena 1889.

${ }^{2} Z$. anorg. Chem. 22, 1.
} 
Bei hoher Chloridkonzentration im Anfang der Elektrolyse wird im Anodenraum zunächst so gut wie ausschliefslich rom Strom durch Entladen von Chlorionen freies Chlor gebildet. Dieses sättigt die Anodenlauge und entweicht dann aus der Anodenzelle, deren Inhalt dauernd durchmischend. Gleichzeitig wandern Alkaliionen durch das Diaphragma aus, und so verarmt die Anodenlösung im Verlauf der Elektrolyse verhältnismälsig schnell an Alkalichlorid. Anders ist es bei der diaphragmenlosen Elektrolyse, wo anfangs infolge der Hypochloritbildung die Hälfte, später durch die Chloratbildung $5 / 6$ des entladenen Chlors wieder in den Ionenzustand zurückkehren, die Chloridkonzentration also viel langsamer abnimmt.

Ein weiterer sehr wichtiger Unterschied beider Arbeitsweisen besteht darin, dals, da die Löslichkeit des freien Chlors in wässerigen Chloridlösungen eine nicht unerhebliche ist, die bei Beginn der Elektrolyse durch das Diaphragma in geringer Menge eindringenden Hydroxyle sich in der Anodenzelle einem Überschufs von Chlor gegenüber befinden. Alsdann erfolgt nach unseren früheren Angaben $^{1}$ im Sinne der Gleichung:

$$
\stackrel{+}{\mathrm{R}}+\mathrm{OH}+\mathrm{Cl}_{2}=\stackrel{+}{\mathrm{R}}+\overrightarrow{\mathrm{Cl}}+\mathrm{HOCl}
$$

die Bildung von freier unterchloriger Säure. Dieser Reaktionsverlauf wurde bisher nur aus theoretischen Gründen gefordert; dals diese Vermutung aber der Wirklichkeit entspricht, zeigt der folgende Versuch: $50 \mathrm{ccm}$ eines Chlorwassers, welche eine $0.0632 \mathrm{~g}$ Sauerstoff äquivalente Menge an freiem Chlor enthielten, wurden mit so viel Normalnatronlauge versetzt $(4.0 \mathrm{ccm})$, dals der Gleichung(1) entsprechend auf zwei Äquivalente Chlor ein Äquivalent Alkali kam, und unmittelbar darauf 10 Minuten lang mit einem kräftigen Luftstrome behandelt. Dieser hätte alles etwa frei gebliebene Chlor austreiben müssen; nach der Behandlung mit Luft fand sich aber in der Lösung $0.0632 \mathrm{~g}$ Hypochloritsauerstoff, sie hatte also nach dem Alkalizusatz kein ungebundenes Chlor mehr enthalten, und der gesamte aktive Sauerstoff war in ihr als freie unterchlorige Säure vorhanden, wovon wir uns nach dem weiter unten zu beschreibenden Verfahren überzeugen konnten.

Im weiteren Verlauf der Elektrolyse dringt nun immer mehr Alkali in die Anodenzelle, während in dieser die Lösung in dem Malse, als ihre Chloridkonzentration geringer wird, immer grölsere

' Journ. pr. Chem. 59, 88. 
Chlormengen zu lösen vermag. Diese Zunahme der letzteren aber erfolgt langsamer als die der einwandernden Alkalimengen, so dals diese einem immer geringeren Chlorüberschufs entgegentreten können. Wenn nun hierbei der Punkt erreicht wird, an welchem die Menge der vom Diaphragma her einwandernden Hydroxyle so grofs wird, dafs je eines derselben weniger als zwei Äquivalente freien Chlors beim Eintritt in die Anodenlauge vorfindet, so beginnt auch unterchlorigsaures Salz in der Lösung zu entstehen. Dieses tritt nun aber einem inzwischen verhältnismälsig sehr grols gewordenen Überschusse von freier unterchloriger Säure gegenüber und diese oxydiert es schnell zu Chlorat.

Da der Vorgang nach der Gleichung

$$
2 \mathrm{HOCl}+\stackrel{+}{\mathrm{R}}+\mathrm{OCl}=\stackrel{+}{\mathrm{R}}+\mathrm{O}_{3} \overline{\mathrm{Cl}}+2 \stackrel{+}{\mathrm{H}}+2 \overline{\mathrm{Cl}}
$$

erfolgt, und die frei werdende Salzsäure wieder unterchlorige Säure abscheidet, so erreicht or sein Ende, wenn $1 / 3$ des Hypochlorits der Oxydation anheimgefallen ist. Die Menge der verbrauchten unterchlorigen Säure wird dabei wieder ersetzt, und das Endergebnis ist so, dals aller dann noch vorhandene Hypochloritsauerstoff als freie unterchlorige Säure vorliegt, und der anfangs in Form von unterchlorigsaurem Salz anwesende aktive Sauerstoff nachher als Chloratsauerstoff sich in der Lösung befindet.

Diese Verhältnisse werden durch folgenden $\nabla$ ersuch beleuchtet: Eine nach BALARD hergestellte Lösung von freier unterchloriger Säure enthielt in $100 \mathrm{ccm}$ neben $0.0352 \mathrm{~g}$ Chloratsauerstoff $0.4584 \mathrm{~g}$ Hypochloritsauerstoff, d. h. ungefähr soviel, wie sich in Gestalt von unterchloriger Säure bei der Elektrolyse von Chlorkalium mit Diaphragma und Platinanoden in $100 \mathrm{ccm}$ der Anodenlauge ansammelt. Diese Lösung wurde mit Chlor gesättigt, und nahm soviel davon auf, als $0.1104 \mathrm{~g}$ Sauerstoff äquivalent war. Von ihr wurden $50 \mathrm{ccm}$, welche also enthielten:

$$
\begin{aligned}
& 0.2292 \mathrm{~g} \text { Sauerstoff in Form von } \mathrm{HOCl} \\
& 0.0176 \mathrm{~g} " \# \# \# \# \mathrm{HO}_{3} \mathrm{Cl} \\
& 0.0552 \mathrm{~g} \\
& \hline 0.3020 \mathrm{~g} \text { insgesamt, }
\end{aligned}
$$

mit soviel Normalnatronlauge $(6.9 \mathrm{ccm})$ versetzt, als gerade hinreicht, sämtliches gelöstes Chlor in unterchlorigsaures Salz zu verwandeln, und dann sofort eine Viertelstunde lang mit einem Luftstrom behandelt.

Z. anarg. Chem. XXIII. 
Hierauf enthielt die Lösung:

$0.2294 \mathrm{~g}$ Sauerstoff in Form von $\mathrm{HOCl}$
$0.0687 \mathrm{~g}, \quad, \quad, \quad, \quad \mathrm{RO} C \mathrm{Cl}$
$0.0041 \mathrm{~g} \quad " \quad, \quad, \quad \mathrm{ROCl}$
$0.3022 \mathrm{~g}$ insgesamt.

Es war also die Menge der unterchlorigen Säure unverändert geblieben, und das anfänglich aus der Einwirkung des Alkalis auf das freie Chlor hervorgegangene Hypochlorit hatte sich fast vollständig in Chlorat verwandelt. Nach 2 Stunden enthielt die Lösung gar kein unterchlorigsaures Salz mehr.

Wenn nun die im Laufe der Elektrolyse durch das Diaphragma gelangenden Alkalimengen immer grölser werden, wird die unterchlorige Säure immer langsamer zunehmen, indem das eindringende Hydroxyd allmählich in grölserem Umfange zur Bildung von Hypochlorit als zu derjenigen von unterchloriger Säure führt. Entsteht schliefslich jenes ausschliefslich, so hat damit die Konzentration der unterchlorigen Säure in der Anodenlauge ein Maximum erreicht; denn von nun an wird eine weitere Steigerung des eindringenden Hydroxyds auch gewisse Teile der vorher angehäuften unterchlorigen Säure neutralisieren und somit in die Chloratbildung mit hineinbeziehen; von jetzt ab wird die Menge der unterchlorigen Säure stetig sinken.

Es kann, wie man sieht, auch dann noch aller Hypochloritsauerstoff als unterchlorige Säure in der Anodenlösung bleiben, wenn alles eindringende Hydroxyl zur Bildung unterchlorigsauren Salzes verbraucht wird.

Soweit Letzteres der Fall ist, werden auf zwei in den Anodenraum einwandernde Hydroxylionen zwei Äquivalente des freigewordenen Chlors verschwinden, also die Chlorausbeute in gleichem Mafse abnehmen wie die Alkaliausbeute. So lange aber noch freie unterchlorige Säure neu entsteht, müssen nach Gleichung (1) auf je ein in die Anodenlösung gelangendes Hydroxylion zwei Äquivalente Chlor verbraucht werden, und in dem hierdurch gegebenen Umfange mufs die Chlorausbeute hinter der Alkaliausbeute zurückbleiben. Das wird nach dem eben Dargelegten besonders in der ersten Zeit der Elektrolyse der Fall sein, und später wird sich die Chlorausbeute der Alkaliausbeute immer mehr nähern.

Hierzu kommt, dafs aufser dem leicht und schnell oxydierbaren Hypochlorit auch das in der Anodenlösung vorhandene Chlorid mit 
der Zeit und in geringem Umfange der Einwirkung der unterchlorigen Säure anheimfällt. Diese verläuft nach der Gleichung

$$
3 \mathrm{HOCl}+\stackrel{+}{\mathrm{R}}+\overline{\mathrm{Cl}}=\stackrel{+}{\mathrm{R}}+\mathrm{ClO}_{3}+3 \stackrel{+}{\mathrm{H}}+3 \overrightarrow{\mathrm{Cl}},
$$

und die hierbei freiwerdende Salzsäure giebt mit anderer unterchloriger Säure freies Chlor:

$$
3 \stackrel{+}{\mathrm{H}}+3 \overline{\mathrm{Cl}}+3 \mathrm{HOCl}=3 \mathrm{H}_{2} \mathrm{O}+3 \mathrm{Cl}_{2} .
$$

Dabei würden aber auf 12 verschwindende Äquivalente Hypochloritsauerstoff 6 Äquivalente Chlor frei, also gerade soviel, als vorher bei der Bildung jener zuviel verbraucht waren. Es wird also auch durch diese als sekundär zu bezeichnende Chorentwickelung die Chlorausbeute der Alkaliausbeute wieder genähert.

Andererseits findet eine Verminderung der Chlorausbeute dadurch statt, dals ClŌ-Ionen, so gering auch ihre Konzentration in der Lösung der freien unterchlorigen Säure ist, an den anodischen Entladungsvorgängen teilnehmen. Dadurch wird sonst zur Chlorabscheidung benutzte Stromarbeit zur Entwickelung von Sauerstoff und zur Rückbildung freier unterchloriger Säure aufgewandt, ohne dafs dadurch die auch sonst stattfindende Bindung des in der Anodenlauge gelösten Chlors durch die einwandernden Hydroxyle eingeschränkt würde.

Die vorangehenden Betrachtungen haben solche Arbeitsbedingungen zur Voraussetzung, bei denen, dem praktischen Zweck des Diaphramenprozesses zufolge, die Gewinnung von Alkalihydrat und Chlor noch einigermalsen erfolgreich betrieben werden kann. In je mehr überwiegendem Mafse das im Kathodenraum entstehende Alkali in den Anodenraum dringt, um so weniger sind jene Vorbedingungen erfüllt. Es lälst sich aber ohne weiteres voraussagen, dals - unverminderte Chloridkonzentration vorausgesetzt - dann allmählich die freie unterchlorige Säure verschwinden und immer gröfsere Anteile von ihrem Salz in der Lösung bleiben werden, wodurch hier die Konzentration der $\mathrm{Cl} \overline{\mathrm{O}}$-Ionen eine starke Vermehrung erleidet. Die bei ihrer anodischen Entladung frei werdende unterchlorige Säure wird dann immer mehr an Stelle der anfänglich durch den Chlorüberschufs erzeugten bei der Chloratbildung treten. Bei unseren Versuchen sind wir diesen, offenbar den Uebergang zur diaphragmenlosen Alkalichloridelektrolyse bildenden Vorgängen fern geblieben. 
Für die anodischen Entladungsvorgänge kommen nun aber neben den Clō-Ionen noch die Anionen des Wassers und, bei länger fortgesetzter Elektrolyse, auch diejenigen des dabei sich stetig anreichernden Chlorats in Betracht.

Auf der Entladung einer gewissen Menge von $\mathrm{OH}-$ Ionen beruht, wie HABER und GRINBERG ${ }^{1}$ als sehr wahrscheinlich dargethan haben, die anodische Sauerstoffentwickelung bei der Elektrolyse von Salzsäurelösungen. Sind diese noch reichlich konzentriert, so treten nur Spuren von Sauerstoff auf; erst bei etwa normaler Salzsäure wurde bei den Versuchen der genannten Forscher die Sauerstoffentwickelung so erheblich, dafs sie praktisch in Betracht kommt. Ihre uns hier besonders interessierenden Ergebnisse sind im folgenden zusammengestellt:

\begin{tabular}{|c|c|c|}
\hline \multirow{2}{*}{$\begin{array}{l}\text { Konzentration, bezw. Sättigungsgrad } \\
\text { der Salzsäure }\end{array}$} & \multicolumn{2}{|c|}{$\begin{array}{c}\text { Anteil der Hydroxylentladung an der } \\
\text { anodischen Stromarbeit in } \% \text { bei der } \\
\text { Stromdichte von }\end{array}$} \\
\hline & $0.2 \mathrm{Amp} . / \mathrm{qm}$ & $0.02 \mathrm{Amp} . / \mathrm{qcm}$ \\
\hline $\begin{array}{l}1 / 1 \text {-norm. Salzsäure }(3.65 \mathrm{~g} \mathrm{HCl} \text { in } \\
100 \mathrm{ccm})\end{array}$ & 1.7 & 0.9 \\
\hline $\begin{array}{l}1 / 1 \text {-norm. Salzsäure, } \mathrm{zu}^{2} / 3 \text { mit Natrium } \\
\text { gesättigt }(1.22 \mathrm{~g} \mathrm{HCl}+3.90 \mathrm{~g} \mathrm{NaCl} \\
\text { in } 100 \mathrm{ccm})\end{array}$ & 5.6 & 4.4 \\
\hline $\begin{array}{c}1 / \mathrm{s} \text {-norm. Salzsäure }(1.22 \mathrm{~g} \mathrm{HCl} \text { in } \\
100 \mathrm{ccm})\end{array}$ & 16.9 & 9.8 \\
\hline $\begin{array}{c}1 / 10 \text {-norm. Salzsäure }(0.365 \mathrm{~g} \mathrm{HCl} \text { in } \\
100 \mathrm{ccm})\end{array}$ & 33.5 & 34.8 \\
\hline
\end{tabular}

Diese Versuche zeigen, wie die anodische Sauerstoffentladung bei der Elektrolyse verdünnter Salzsäure ihrem Umfange nach bestimmt ist durch das Anodenpotential und das Konzentrationsverhältnis der $\overline{\mathrm{Cl}}$ - und der $\mathrm{O} \overline{\mathrm{H}}$-Ionen in der Lösung.

In einer neutralen Alkalichloridlösung ist nun die Gelegenheit zur Sauerstoffentladung günstiger als in einer äquivalenten Salzsäurelösung. Die Konzentration der Chlorionen ist zwar in beiden Fällen sehr nahe gleich. Dagegen ist in der Salzsäure die Konzentration der Hydroxylionen durch die grolse Menge der $\stackrel{+}{\mathrm{H}}-\mathrm{Ionen}$ gegenüber derjenigen in reinem Wasser und in neutralen Lösungen aufserordentlich vermindert

\footnotetext{
${ }^{1} Z$. anorg. Chem. 16, 198 u. 329.
} 
In einer neutralen Alkalichloridlösung wird daher bei höherer Molekularkonzentration als in einer Salzsäurelösung bei der Elektrolyse an der Anode Hydroxylentladung eintreten. Thr entgegen vermag die Anwesenheit von unterchloriger Säure zu wirken, und zwar sowohl durch die verhältnismälsig leichte Entladbarkeit ihrer Anionen als auch durch die von ihr der Lösung erteilte geringe Wasserstoffionenkonzentration. Sofern aber Hydroxylionen des Wassers anodisch entladen werden, bleiben Wasserstoffionen in entsprechender Menge in der Lösung und zwar Chlorionen gegenüber; es entsteht also in der ursprünglich neutralen Flüssigkeit freie Salzsäure, während die äquivalente Menge Sauerstoff entweicht.

Eine solche anodische Salzsäurebildung mufs natürlich in gewissem, freilich wohl nur sehr geringem Umfange auch bei der diaphragmenlosen Elektolyse von Alkalichloridlösungen vor sich gehen. Dabei aber wird die Salzsäure aus dem vorhandenen Hypochlorit alsbald unterchlorige Säure abscheiden, es wird also auf 1 entladenes Hydroxyl 1 Äquivalent unterchlorige Säure frei werden, d. h. genau dasselbe eintreten, was geschehen wäre, wenn statt einem $\mathrm{O} \overline{\mathrm{H}}$ ein $\mathrm{ClO}$ entladen worden wäre. Auf den Verlauf des Vorganges wird daher eine etwaige Salzsäurebildung ohne nennenswerten Einflufs sein, und sie konnte bei der Betrachtung der diaphragmenlosen Elektrolyse neutraler Alkalichloridlösungen ganz vernachlässigt werden.

Etwas anderes ist es aber in dem hier zur Erörterung stehenden Falle; denn hier findet die Salzsäure nur freie unterchlorige Säure in der Lösung vor; mit dieser mufs sie alsbald nach Gleichung (4) wieder freies Chlor liefern. Es wird dabei aus $1 \mathrm{Mol}$. $\mathrm{HOCl}$ die bei ihrer Bildung verbrauchte Menge Chlor, also $1 \mathrm{Mol}$. $\mathrm{Cl}_{2}$, wieder abgeschieden, während an der Anode statt eines $\overline{\mathrm{Cl}}$ ein $O \overline{\mathrm{H}}$ entladen wird. Auf die Chlorausbeute hat also die anodische Salzsäurebildung dieselbe Wirkung, als wenn das zur Entstehung von $1 \mathrm{Mol}$. HOCl erforderliche Hydroxylion gar nicht mit Chlor reagierte, sondern von einem an der Anode entstandenen Molekül HCl sofort neutralisiert worden wäre. Durch etwa eintretende Salzsäurebildung wird also der durch die Entstehung freier unterchloriger Säure hervorgerufene besondere Chlorverlust verkleinert, die Chlorausbeute der Alkaliausbeute genähert. Die auf der Entladung von $\mathrm{OH}$-ionen beruhende anodische Sauerstoffentwickelung hat also im vorliegenden Falle, zum Unterschiede von der durch 
die ClO--Ionenentladung hervorgerufenen, . keinen besonderen Mehrverlust an der Chlorausbeute zur Folge.

Wird die Chloridmenge in der Anodenzelle bei langer Fortsetzung der Elektrolyse sehr gering, während das Chlorat inzwischen, zuletzt gleichzeitig mit dem Auftreten reichlicherer Salzsäuremengen wohl auch durch primäre Bildung, sich immer stärker angereichert hat, so kann auch die Abscheidung der schwerst entladbaren Anionen, derjenigen der Chlorate, möglich werden. Sie kehren aber, während Sauerstoff entweicht, wieder in die Lösung zurück, und diese erhält dabei in entsprechendem Mafse einen Gehalt an freien Wasserstoffionen. So lange noch in einer dieser äquivalenten Menge Chlorionen vorhanden sind, ist die Wirkung dieses Vorganges keine andere, als wenn statt der $\mathrm{Cl}_{3}$-Ionen $\mathrm{OH}$-Ionen des Wassers entladen worden wären. Wird die Chloridmenge gar zu gering, so bleibt freie Chlorsäure in der Anodenlösung, wir haben dann keine Chlorid-, sondern eine Chloratelektrolyse. Das dürfte aber nur dann eintreten, wenn vom Kathodenraum die Zuwanderung der Chlorionen fast ganz durch diejenige von Hydroxylionen verdrängt ist. Denn als wir $500 \mathrm{ccm}$ einer bei $20^{\circ}$ gesättigter Kaliumchloratlösung in einer als Anodenraum dienenden Thonzelle einer 20\% igen Kaliumchloridlösung gegenüber mit 5 Amp. elektrolysierten, enthielt das aus der Anodenzelle entweichende Gas schon nach $1 / 2$ Stunde $50 \%$ Chlor; so leicht kann schon eine kleine zuwandernde Chloridmenge die Entladung von Chlorationen zurückdrängen.

Wie immer nun diese verwickelten Verhältnisse zusammenwirken werden, so ist doch klar, dafs die Chlorausbeute bei der Elektrolyse neutraler Alkalichloridlösungen mit der Alkaliausbeute nicht übereinzustimmen braucht, dafs sie im allgemeinen etwas niedriger sein wird als diese, wofern überhaupt Hypochloritsauerstoff in der Anodenlauge sich zu halten vermag. Würde man aber während der Elektrolyse von aufsen dauernd freie Salzsäure zufügen, so würde sie die aus dem Kathodenraum eindringende Hydroxyle neutralisieren, ohne dafs diesen ein Chlorverlust zu entsprechen hätte. Alsdann könnte man höhere Chlorausbeuten als Alkaliausbeuten erzielen. Jene werden am grö[sten sein, wenn an der Anode so viel Äquivalente Salzsäure in einer bestimmten Zeit zugeführt werden, als in dieser Hydroxyle in die Anodenzelle einwandern, und wenn hier die Konzentration der Chlorionen immer so grofs ist, dals eine Entladung von Hydroxylen des Wassers dadurch möglichst verhindert wird. 
In der That macht die Technik hierron, soviel bekannt ist, gelegentlichen Gebrauch. ${ }^{1}$

Die bisher erörterten Vorgänge in den Anodenzellen müssen nun gewisse Abänderungen erfahren, wenn statt der unangreifbaren Anoden aus Platiniridium solche von Kohle benutzt werden. Ehe aber diese für die Praxis des Diaphragmenprozesses so wichtigen Verhältnisse besprochen werden können, mufs zunächst durch Versuche an Platiniridiumanoden entschieden werden, ob wirklich, unserer Vermutung nach, die anodische Salzsäurebildung in neutralen Chloridlösungen so gering ist, dals sie das Verbleiben von Chlorsauerstoffsalzen in der Anodenlauge erlaubt.

\section{B. Die Wirkungsweise des Diaphragmas.}

Die Trennung der Kathoden- und der Anodenlösung, welche für die Herstellung von Alkalihydrat und Chlor durch Elektrolyse von Alkalichlorid notwendig ist, erfolgt bei dem hier in Rede stehenden technischen Prozels durch ein poröses Diaphragma, welches heute im Grofsbetriebe wohl zumeist aus Cement besteht, dem man künstlich eine gewisse Porosität erteilt.

Um die Wirkungsart einer solchen porösen Zwischenwand etwas näher zu betrachten, soll sie zunächst als unendlich dünn angenommen werden, und ihre Poren sollen gestatten, dafs der Strom die Ionen, welche er in der Lösung vorfindet, herüber und hinüber nach den betreffenden Elektroden befördert; sie seien aber zunächst als so fein gedacht, dals bei der herrschenden Stromstärke ein anderweitiger Austausch der Kathoden- und Anodenlösung nicht stattfindet.

Im Anfange der Elektrolyse kommen allein die Alkali- und die Chlorionen für den Stromtransport in Betracht. Sei die Überführungszahl der letzteren $n$, die der ersteren also $1-n$, so werden, wenn 1 Mol. Alkalichlorid an den Elektroden vom Strome zerlegt wird, also 1 Äquivalent Chlor an der Anode frei wird, $n$ Chlorionen aus der Kathoden- in die Anodenzelle und $(1-n)$ Alkaliionen in der entgegengesetzten Richtung durch das Diaphragma wandern. Dadurch wird sich die Alkalichloridmenge in der Anodenzelle um $1-n \ddot{A} q u i v a l e n t e$ vermindern, und in der Kathodenzelle, wo gleichzeitig 1 Äquivalent Alkalihydrat entsteht, um $n$ Äquivalente. Ist

\footnotetext{
Z. B. bei dem Prozels von Le Sugur, Zeitschr. Elektrochem. 5, 293.
} 
wie bei Kaliumchlorid $n$ nahezu 0.5, so verschwindet an der Kathode wie an der Anode fast je die Hälfte des zersetzten Chlorids; ist, wie bei Natriumchlorid, $n>0.5$, so ist die Chloridverminderung in der Kathodenzelle grölser als an der Anode.

Es tritt nun aber sehr schnell eine Änderung der Verhältnisse ein, da das an der Kathode entstehende Alkali von dem aufsteigenden Wasserstoff alsbald im ganzen Kathodenraum verteilt wird, an das Diaphragma gelangt und hier an der Stromleitung in die Anodenzelle hinein teilnimmt. Dadurch wird, ähnlich wie oben für das Chlorid dargethan, auch das Alkalihydrat im Kathodenraum an Menge abnehmen, und infolgedessen wird, wie erwähnt, nicht nur die Alkali-, sondern auch die Chlorausbeute vermindert.

Infolge des Auswanderns von Hydroxylionen aus dem Kathodenraum wird hier die Chloridmenge langsamer abnehmen, als es ohne Dazwischenkunft der Hydroxyle geschehen wäre.

In der Anodenzelle wird für jedes eindringende und alsbald ja wieder verschwindende Hydroxyl ein Chlorion in der Lösung erzeugt, sei es, dafs infolge der Bildung von unterchloriger Säure nach Gleichung (1) ein bereits abgeschiedenes Chloratom in den Ionenzustand zurückkehrt, sei es, dafs für ein sonst abgeschiedenes Chlorion ein Hydroxyl des Wassers entladen wird, und die entstehende Salzsäure das ankommende Hydroxyl neutralisiert. Es wird also für die Chloridkonzentration der Anodenzelle das Ergebnis dasselbe sein, als wenn statt der Hydroxylionen die gleiche Zahl von Chlorionen einwanderten. Da jene aber eine grölsere Wanderungsgeschwindigkeit haben als diese, wird auch in der Anodenzelle die Chloridkonzentration langsamer abnehmen, als wenn die Hydroxylwanderung unterbliebe. Nur soweit ein Teil der Chlorionen in Chlorationen ubbergeht, mufs wiederum eine Steigerung in der Abnahme der Chloridmenge stattfinden.

Von grofser Wichtigkeit ist nun die Frage nach dem Anteil, mit welchem das an der Kathode entstandene Alkalihydrat dem im Elektrolyten vorhandenen Alkalichlorid die Stromleitung abnimmt. Nach HItToRF beteiligen sich zwei gleichzeitig in einer Lösung vorhandene Elektrolyte an der Stromüberführung nach Mafsgabe ihrer Leitvermögen. Sei ursprünglich, ehe Alkalihydrat an das Diaphragma herankam, zur Überführung einer gewissen Elektrizitätsmenge 1 Äquivalent Alkalichlorid notwendig gewesen, so werden nun, wenn Alkali dem Chlorid sich beimischt, $x$ Äquivalente desselben an der Stromleitung teilnehmen und ebensoviel Chloridäquivalente ver- 
drängen, so dafs von diesen nur noch $(1-x)$ Äquivalente die Stromleitung besorgen; es haben sich also Chlorid und Hydroxyd in dem Verhältnis $\frac{1-x}{x}$ in die Stromleitung geteilt.

Bezeichnen wir mit $L_{1}$ das Leitvermögen, welches das Chlorid aufweisen würde, wenn es unter den gegebenen Bedingungen allein in der Lösung wäre, und mit $L_{2}$ die entsprechende Grölse für das Hydroxyd, so ist:

$$
\frac{1-x}{x}=\frac{L_{1}}{L_{3}}
$$

Seien die Molekularkonzentrationen des Chlorids und Hydroxyds $e_{1}$ bezw. $c_{2}$, die Dissoziationsgrade $\alpha_{1}$ und $\alpha_{2}$, so ist

$$
L_{1}=c_{1} \alpha_{1} \lambda_{\infty}^{\prime} \text { und } L_{2}=c_{2} \alpha_{2} \lambda_{\infty}^{\prime \prime},
$$

wenn man mit $\lambda_{\infty}^{\prime}$ bezw. $\lambda_{\infty}^{\prime \prime}$ die molekulare Leitfähigkeit von Chlorid bezw. Hydroxyd bei unendlicher Verdünnung bezeichnet. Daraus folgt:

$$
\frac{1-x}{x}=\frac{c_{1} \alpha_{1} \lambda_{\infty}^{\prime}}{c_{2} \alpha_{2} \lambda^{\prime \prime}}
$$

Die dieser Formel zu Grunde liegende Voraussetzung, dals die Elektrolyte in der Mischung das ihnen in reinem Zustande für die gleiche Konzentration zukommende Leitvermögen beibehalten, ist von SchraDeR ${ }^{1}$ für verdünnte, und von Hopfgartser ${ }^{2}$ auch für konzentriertere Lösungen, zumal von weitgehend dissoziierten Chloriden, als mit den Thatsachen genügend übereinstimmend gefunden worden. MAC GREGoR ${ }^{3}$ hat allerdings darauf hingewiesen, dals die Theorie hinsichtlich des elektrischen Leitvermögens ein rein additives Verhalten gemischter Elektrolyte niemals erlaubt, und hat eine strengere Berechnungsweise des Leitvermögens von Mischungen angegeben. Aber auch mit dieser gelangt man grade bei stark dissoziierten Chloriden zu theoretischen Schlufsfolgerungen, welche mit HOPFGaRTNER's Ergebnissen befriedigend übereinstimmen. ${ }^{4}$ In unserem Falle handelt es sich freilich um noch erheblich stärkere Lösungen, als die bei der letzteren Arbeit benutzten waren, aber man wird auch hier doch wohl in erster Annäherung die Formel (a) als gültig

1 Zeitschr. Elektrochem. 3, 498.

${ }^{2}$ Zeitschr. phys. Chem. 25, 115.

3 Philos. Magaz. 41, (1896), 276.

4 Physical Review 8, (1899), 129. 
ansehen dürfen. Der Bruch $\frac{\lambda_{\infty}^{\prime}}{\lambda_{\infty}^{\prime \prime}}$ hat nach den Untersuchungen von Kohlrausch für Kaliumlösungen bei.18 $18^{\circ}$ den Wert:

und für Natriumlösungen

$$
\frac{\lambda_{\infty}^{\prime}}{\lambda_{\infty}^{\prime \prime}}=\frac{123}{222}=0.554
$$

$$
\frac{\lambda_{\infty}^{\prime}}{\lambda_{\infty}^{\prime \prime \prime}}=\frac{103}{201}=0.512 .
$$

Wir erhalten dann für Kaliumlösungen:

$$
\frac{1-x^{\prime}}{x^{\prime}}=0.554 \frac{c_{1} \alpha_{1}}{c_{2} \alpha_{2}}, \text { also } x^{\prime}=\frac{1}{1+0.554 \frac{c_{1} \alpha_{1}}{c_{2} \alpha_{2}}},
$$

und für Natriumlösungen:

$$
\frac{1-x^{\prime \prime}}{x^{\prime \prime}}=0.512 \frac{c_{1} \alpha_{1}}{c_{2} \alpha_{2}}, \text { also } x^{\prime \prime}=\frac{1}{1+0.512 \frac{c_{1} \alpha_{1}}{c_{2} \alpha_{2}}} .
$$

Das Verhältnis, in welchem sich der Strom zwischen Chlorid und Hydroxyd teilt, ändert sich, wie man sieht, schneller zu Gunsten des letzteren als dasjenige der Konzentrationen der Chlor-und Hydroxylionen.

Wollen wir nun hieraus die Stromausbeute an Alkali finden, so führt dazu folgende Überlegung: Würde die Stromleitung nur durch das Hydroxyd erfolgen, so würden, wenn wir die Überführungszahl des Hydroxyds mit $n^{\prime}$ bezeichnen, in der Zeit, in welcher 1 Äquivalent Alkalihydrat an der Kathode neu entsteht, $n^{\prime}$ Hydroxyde durch das Diaphragma auswandern; die in dieser Zeit herrschende Alkalistromausbeute $A$ betrüge also

$$
A=100\left(1-n^{\prime}\right) \% \text {. }
$$

Beteiligt sich nun statt eines Äquivalents des Hydroxyds von diesem nur der Bruchteil $x$ an der Stromleitung, so wandern nur $x . n^{\prime}$ Åquivalente Alkalihydrat aus, d. h. es wird

$$
A=100\left(1-x n^{\prime}\right)^{\%} \% \text {. }
$$

Die Überführungszahl des Hydroxyds dürfte bei den Alkalisalzlösungen wie diejenige anderer Anionen derselben ${ }^{2}$ von deren Konzentration so wenig abhängig sein, dals wir sie als nahezu konstant betrachten und hier ihre bei grolser Verdünnung gültigen Werte einsetzen können. Diese betragen nach KoHmadusch für

1 Praktisch ist diese Formel nicht zu bewahrheiten, wegen der weiter unten noch zu erörternden, niemals auszuschliefsenden Vorgänge der freiwilligen Diffusion.

${ }^{2}$ Vgl. auch W. BeIN, Zeitschr. phys. Chem. 27, 1. 
Kalihydrat 0.74 und für Natriumhydrat 0.84 . Führen wir diese Zahlen, sowie die oben gefundenen Werte von $x$ in die Formel $\left(b_{1}\right)$ ein, so ergiebt sich:

für Kaliumlösungen $\quad A_{K}=100\left(1-\frac{0.74}{1+0.554 \frac{c_{1} \alpha_{1}}{c_{2} \alpha_{2}}}\right) \%$

und für Natriumlösungen $A_{\mathrm{Na}}=100\left(1-\frac{0.84}{1+0.512 \frac{c_{1} \alpha_{1}}{c_{2} \alpha_{2}}}\right) \%$.

Diese Gleichungen geben die Stromausbeuten an für den Augenblick, in welchem das durch Analyse zu findende Konzentrationsverhältnis $\frac{c_{1}}{c_{2}}$ herrscht. Will man die während einer ganzen Elektrolyse herrschende Gesamtstromausbeute bestimmen so kann man dies nach einem für ähnliche Verhältnisse von OETTEL ${ }^{l}$ angegebenen Verfahren thun. Dazu zeichnet $\operatorname{man}$ eine Kurve, für welche man die Zeiten, zu denen die jeweiligen Ausbeuten nach einer der obigen Formeln gefunden wurden, als Abscissen, die Ausbeuten selbst als Ordinaten auf Millimeterpapier aufträgt, schneidet aus diesem ein Rechteck heraus, dessen eine Seite die Ordinate im Anfangspunkt und dessen andere Seite die Abscissenaxse bis zum letzten Bestimmungspunkt ist, wägt dieses, zerschneidet es dann längs der aufgezeichneten Ausbeutekurve und wägt den von dieser und der Abscissenachse begrenzten Teil des Papiers. Das Verhältnis beider Gewichte mit 100 multipliziert giebt die gesuchte Gesamtstromausbeute in Hundertteilen.

Soweit die für obige Gleichungen notwendigen Werte von $\alpha_{1}$ und $\alpha_{2}$ für unseren Fall von Interesse sind, wurden sie näch der Formel $\alpha=\frac{\lambda}{\lambda_{\infty}}$ aus den vorliegenden Leitfähigkeitsbestimmungen von KoHLRAURCH ${ }^{2}$ berechnet und sind im folgenden zusammengestellt; die Werte von $c_{1}$ und $e_{2}$ beziehen sich auf $100 \mathrm{ccm}$ :

$\begin{array}{ccc}e_{1} & \alpha_{1} \text { für } \mathrm{KCl} & \alpha_{1} \text { für } \mathrm{NaCl} \\ 0.40 & - & 0.447 \\ 035 & 0.655 & 0.490 \\ 0.30 & 0.672 & 0.512 \\ 0.25 & 0.686 & 0.548 \\ 0.20 & 0.701 & 0.587 \\ 0.15 & 0.720 & 0.631 \\ 0.10 & 0.741 & 0.677\end{array}$

1 Zeitschr. Elektrochem. 1, 355.

2 Ostwald's Allgem. Chem. II. (1), 731 u. 741. 


$\begin{array}{ccc}c_{2} & \alpha_{2} \text { für } \mathrm{KOH} & \alpha_{2} \text { für } \mathrm{NaOH} \\ 0.20 & 0.677 & 0.609 \\ 0.10 & 0.775 & 0.740 \\ 0.05 & 0.836 & 0.811 \\ 0.01 & 0.900 & 0.841\end{array}$

Man sieht, der Bruch $\frac{\alpha_{1}}{\alpha_{2}}$ wird um so mehr unter 1 liegen, jemehr $c_{2}$ gegenüber $c_{1}$ zurücktritt, je grölser also der Bruch $\frac{c_{1}}{c_{2}}$ ist. Die Änderungen des Wertes von $\frac{\alpha_{1}}{\alpha_{2}}$ sind aber viel geringer als diejenigen des letzteren Bruches; es wird also nach obigen Formeln das Verhältnis der Konzentration des Alkalihydrates zu derjenigen des Alkalichlorids in erster Linie die Stromausbeute bestimmen, diese also immer mehr abnehmen, je mehr im Verlauf der Elektrolyse das Alkalihydrat steigt und das Chlorid sich vermindert. Bei gleichen Werten von $\frac{e_{1}}{c_{2}}$ wird, wie man sieht, die Stromausbeute für Natriumchloridlösungen niedriger liegen als für Kaliumchloridlösungen.

Da nur immer ein Teil des an der Kathode entstehenden Alkalihydrats durch das Diaphragma dringt, so ergiebt sich, dafs die Anbringung zweier, einen Mittelraum vom Kathoden- und Anodenraum abgrenzender Diaphragmen die Stromausbeute steigern mufs; sie wird dies um so besser thun, je grölser das Volumen des Mittelraumes ist, einen je geringeren Wert für $c_{2}$ hier eine bestimmte, aus dem Kathodenraum einwanderde Hydroxylmenge giebt. Einige Versuche WrNTELER's ${ }^{1}$ bestätigen diese Überlegung. Da aber eine auf diesem Wege herbeigeführte Steigerung der Stromausbeute durch eine Erhöhung der Spannung erkauft werden muls, ist es fraglich, ob es auf diesem Wege gelingen kann, die Energieausbeute an Alkali und Chlor beim Diaphragmenprozefs zu erhöhen.

Die bisherigen Ausführungen bedürfen streng genommen insofern einer kleinen Einschränkung, als die ihnen zu Grunde liegende Voraussetzung, dafs vom Anodenraum her nur die Alkaliionen den Stromtransport besorgen, nicht genau richtig ist, sondern die hier auftretende freie Säure auch Wasserstoffionen dem Strome bietet. Diese müssen sich wieder mit den Alkaliionen in die Stromleitung teilen, und zwar in dem Malse, wie es durch das Verhältnis der Konzentrationen und Dissoziationgrade der beiden in Frage kommenden Leiter und ihrer

${ }^{1}$ Zeitschr. Elektrochem. 5, 15 u. 49. 
Leitfähigkeiten bei unendlicher Verdünnung gegeben ist. So lange aber in der Anodenlösung Hypochloritsauerstoff vorhanden ist, dessen Anwesenheit die Erörterungen des vorigen Abschnittes schon sehr wahrscheinlich machen, bleibt die Konzentration der Wasserstoffionen eine so geringe, dals ihre Beteiligung an der Stromleitung vernachlässigt werden darf. Sobald allerdings freie Salzsäure in irgend erheblicher Menge in der Anodenlösung verharren könnte, würde sie sich allmählich auch anreichern und schlielslich nach dem Kathodenraum dringen, und infolge der besonders grofsen Wanderungsgeschwindigkeiten der $\stackrel{+}{\mathrm{H}}$-Ionen hier die Alkalistromausbeute stärker vermindern, als es durch das Auswandern der $\mathrm{OH}$-Ionen der Fall gewesen wäre.

Ein Diaphragma mufs nun aber eine nicht geringe Widerstandsfähigkeit gegen mechanische und chemische Einflüsse besitzen. In Wirklichkeit kann also unsere obige Voraussetzung von einem unendlich dünnen Diaphragma niemals zutreffen, sondern ein. solches wird stets eine endliche und zwar meist nicht unbeträchtliche Wandstärke besitzen. Alsdann aber wird auch der Gesamtquersohnitt aller Poren nicht mehr so klein sein, wie er bei unserem idealen Diaphragma vorausgesetzt war, dafs durch ihn bei einer bestimmten Stromstärke eben nur die den Stromtransport bewirkenden Ionen hindurch können.

Wie in dieser Hinsicht die Dinge bei der praktisch benutzten Diaphragmen liegen, kann man leicht durch folgende des Beispiels wegen durchgeführte Rechnung erfahren, bei der wir die bei unseren späteren Versuchen meist innegehaltenen Versuchsbedingungen voraussetzen wollen. Es fliefsen dabei durch $100 \mathrm{qcm}$ Diaphragmenfläche bei $0.4 \mathrm{~cm}$ Wandstärke des Diaphragmas $1.6 \mathrm{Amp}$., und wir kommen der Wahrheit nahe, wenn wir annehmen, dafs das Spannungsgefälle zwischen beiden Grenzflächen des Diaphragmas 1 Volt beträgt. Fliefst ein Coulomb durch einen Querschnitt einer Chlorkaliumlösung, so müssen dazu die Ionen von $0.77 \mathrm{mg} \mathrm{KCl}$ diesen Querschnitt durchwandern; bei einer Stromstärke von 1,6 Ampère gehen also in jeder Sekunde $1.6 \times 0.77 \mathrm{mg} \mathrm{KCl}$ durch jeden Querschnitt. Bei 1 Volt Spannungsgefälle über $1 \mathrm{~cm}$ ist die Wanderungsgeschwindigkeit:

$$
\begin{aligned}
\text { des Chlorions } & =0.00069 \mathrm{~cm} / \text { Sek. } \\
" \text { Kaliumions } & =0.00067 \quad "
\end{aligned}
$$

Herrscht der Spannungsabfall von 1 Volt über $0.4 \mathrm{~cm}$, so sind diese Geschwindigkeiten: 


$$
\begin{gathered}
-174- \\
\text { für das Chlorion }=0.00172 \mathrm{~cm} / \text { Sek. } \\
" \quad, \text { Kaliumion }=0.00168 \quad "
\end{gathered}
$$

d. h. die Ionen des Chlorkaliums können insgesamt unter diesen Bedingungen $0.0034 \mathrm{~cm}$ in einer Sekunde zurücklegen. Damit nun $1.6 \times 0.77 \mathrm{mg} \mathrm{KCl}$ in jeder Sekunde durch $2 \mathrm{um} 0.4 \mathrm{~cm}$ voneinander entfernte Querschnitte hindurchwandern können, müssen zwischen diesen Querschnitten:

$$
\frac{0.4}{0.0034} \times 1.6 \times 0.77 \mathrm{mg} \mathrm{KCl}=0.145 \mathrm{~g} \mathrm{KCl}
$$

auf der Wanderung, d. h. an der Stromleitung beteiligt sein.

Da nun das Porenvolumen der von uns benutzten Pukaul'schen Thonmasse durch Wägen der absorbierten Wassermenge zu etwa $20 \%$ bestimmt wurde, so sind in einem Diaphragmenabschnitt von $100 \mathrm{qcm} \times 0.4 \mathrm{~cm}=40 \mathrm{ccm}$ Volumen $8 \mathrm{ccm}$ der Lösung absorbiert. Ist diese, wie bei unseren Versuchen, anfangs etwa 20-prozentig, so sind $1.6 \mathrm{~g} \mathrm{KCl}$ in dem betrachteten Diaphragmenabschnitt vorhanden, von denen im vorliegenden Falle etwa 67 v. H. dissoziiert sind, d. h. es sind insgesamt $1.07 \mathrm{~g} \mathrm{Kalium-} \mathrm{und} \mathrm{Chlorionen} \mathrm{vor-}$ handen, von denen aber nur $0.145 \mathrm{~g}$, also $13.5 \%$, zur Stromleitung benutzt werden.

Diese Rechnung hat zur Voraussetzung, dafs die absoluten Wanderungsgeschwindigkeiten der Ionen in einem porösen Diaphragma denen in der Lösung gleich sind. Das wird aber wohl kaum der Fall sein, sondern dort werden der Fortbewegung der Ionen jedenfalls auch gröfsere Reibungswiderstände im Wege stehen als hier. Dazu kommt, dals die Wege der Ionen im allgemeinen eine grölsere Länge besitzen dürften, als der Wandstürke des Diaphragmas entspricht, da ja die Porenkanäle wohl nur zum geringsten Teil senkrecht, zumeist wohl schräg gegen die Grenzfläche des Diaphragmas gerichtet und in ihrem Lauf auch vielfach gewunden sein werden. Dadurch erscheint der oben berechnete Bruchteil der die Stromleitung bei unseren Versuchen bewirkenden Ionen als ein unterer Grenzwert.

In jedem Falle befinden sich im Diaphragma, und natürlicherweise auch im freien Elektrolyten Ionen, welche an der Stromleitung unbeteiligt sind, und sich unabhängig von dieser bewegen können. Sobald einmal die Poren des Diaphragmas sich mit Unterstützung der Kapillarität mit dem Elektrolyten gefüllt haben, so 
werden neben den Überführungserscheinungen durch den Strom auch die Vorgänge der gewöhnlichen Diffusion zwischen Kathodenraum und Diaphragma einerseits und diesem und dem Anodenraum andererseits Platz greifen können.

Die auf diesem Wege durch einen Querschnitt hindurchdringenden Salzmengen sind gegeben:

1. Durch die Gröfse dieses Querschnittes selbst;

2. durch den zwischen beiden Seiten des Querschnitts herrschenden Unterschied in der Konzentration des betreffenden Salzes, durch das Konzentrationsgefälle;

3. durch den Diffusionskoëffizienten des betreffenden Salzes; und

4. durch die für den Vorgang zur Verfügung stehende Zeit.

Es entsteht nun zunächst die Frage, ob und inwieweit etwa zwischen den im Kathodenraum auftretenden verschiedenen Stoffen bei derselben Elektrolyse Unterschiede hinsichtlich ihrer Beteiligung an den Diffusionsvorgängen zu erwarten sind. Die Anodenlösung mag hier wieder als reine Chloridlösung betrachtet werden, da die Diffusion der Chlorsauerstoffsalze jedenfalls kaum von wesentlicher Bedeutung für das Ergebnis der Elektrolyse sein wird. Haben wir es mit einem gegebenen Diaphragma, also einem konstanten Querschnitt zu thun, so sind während desselben Zeitabschnittes für den Verlauf der Diffusion gemischter Lösungen die unter Nr. 2 und 3 genannten Faktoren malsgebend, von deren letzterem NERNST ja nachgewiesen hat, dafs der bei Elektrolyten mit deren Wanderungserscheinungen in engstem Zusammenhange steht. Daher hesitzen Alkalihydrate wegen der grölseren Beweglichkeit des Hydroxylions einen höheren Diffusionskoëffizienten als die entsprechenden Chloride. Dieser Unterschied kommt hier aber verhältnismälsig wenig in Betracht, in Anbetracht der folgenden Umstände.

Zwischen den Chloridkonzentrationen im Kathoden und Anodenraum läfst man beim Diaphragmenprozef's nicht gern sehr grofse Differenzen bestehen; hier ist das Konzentrationsgefälle im allgemeinen nicht erheblich und wirkt dahin, im Diaphragma eine Chloridkonzentration zu erhalten, welche zwischen der im Kathoden- und im Anodenraum jeweilig herrschenden etwa in der Mitte liegt.

Ganz anders aber ist es mit dem rom Kathodenraum durch das Diaphragma nach der Anodenzelle herüberdiffundierenden Alkali- 
hydrat. Da hier jedes eindringende Hydroxyd sofort verschwindet, besteht auch hier kein der weiteren Diffusion entgegenwirkender osmotischer Druck; es wird also hier mit Zunahme des Alkalis im Kathodenraum und entsprechend reichlicherem Einwandern desselben in die Poren des Diaphragmas zwischen diesem und dem Anodenraum ein immer grölseres Konzentrationsgefälle für das Alkali sich herausstellen, und demgemäls seine freie Diffusion in die Anodenlösung hinein immer umfangreicher werden.

Werden also nicht nur durch die Stromleitnng, sondern auch durch Diffusionsvorgänge die Verminderungen der Alkali- und der Chlorausbeute herbeigeführt, so entsteht die weitere Frage, in welchem Umfange jeder dieser Faktoren an den auftretenden Verlusten beteiligt ist. Hierüber lälst sich Bestimmtes nicht sagen, sondern nur soviel, dafs ein stärkeres Hervortreten der im allgemeinen nur geringfügigen Diffusion wesentlich durch zwei Dinge begünstigt werden wird: Sie wird, wie es aus der oben angeführten Rechnung ohne weiteres folgt, einerseits umsomehr Bedeutung erlangen, je mehr Ionen für die Vorgänge der Diffusion zur Verfügung stehen, d. h. je grölser das relative Porenvolumen verschiedener Diaphragmen ${ }^{1}$ oder aber je grölser bei gleichem relativen Porenvolumen die von einem Strome von gegebener Stärke durchflossene Diaphramenfläche, je geringer also die auf das Diaphragma bezogene Stromdichte ist. Andererseits aber werden die Diffusionsvorgänge umsomehr hervortreten, in je längerer Zeit mit demselben Diaphragma eine bestimmte Alkalikonzentration im Kathodenraum erreicht werden soll, je gröfser also z. B. das Volumen der Kathodenflüssigkeit ist, oder mit je geringerer Stromstärke, also wiederum mit je kleinerer, auf das Diaphragma bezogener Stromdichte man arbeitet. Die letztere Grölse ist also für die Ergebnisse des in Rede stehenden elektrolytischen Prozesses von besonderem Interesse, während die kathodische Stromdichte hierfür von gar keinem, die anodische, wie wir sahen, von nur geringfügigem Einflufs ist.

Die oben für die Alkalistromausbeute gegebene Formel (b) kann, wie nan sieht, da sie nur einem Teile der Alkaliverluste Rechnung trägt,

1 Dasselbe wurde bei gewöhnlichen Thonzellen zu 35-40\% gefunden.

$" \quad " \quad$ " $\quad$ "Puralin'scher Thonmasse zu $20 \%$ "


für die wirklich erzielte Stromausbeute nicht uneingeschränkt mafsgebend sein. Ihre Anwendung wird noch dadurch erschwert, dals die in die Formel einzusetzenden Molekularkonzentrationen von Alkalichlorid und -hydrat bei einem Diaphragma von endlicher Dicke offenbar nicht mehr diejenigen sind, welche in der Kathodenzelle herrschen, sondern die, welche in der an den Anodenraum angrenzenden Diaphragmenschicht bestehen, denn nur die von hier in den Anodenraum eindringenden Hydroxylmengen entsprechen wirklich den Alkaliverlusten. Die Chloridkonzentration wird in diesen Schichten derjenigen, welche im Anodenraum herrscht, um so ähnlicher sein, je dicker das Diaphragma ist, und insofern könnte das Aufrechterhalten einer konzentrierten Anodenlösung auch die Alkaliausbeute günstig beeinflussen. Die durchschnittliche Hydroxydkonzentration im Diaphragma wird hinter derjenigen in der Kathodenzelle etwas zurückbleiben, da ja immer nur ein Teil ihrer hier durch den Strom bewirkten Konzentrationsvermehrung mittels Wanderung der im Diaphragma befindlichen Lösung sich mitteilt, und da es ja stets einige Zeit erfordert, bis das bei einer bestimmten im Kathodenraum herrschenden Alkalikonzentration in das Diaphragma eingedrungeneHydroxyd dieses auch durchwandert hat. Dieses Zurückbleiben der im Diaphragma vorhandenen Hydroxydkonzentration wird nun aber umsomehr ausgeglichen werden, je mehr Zeit für die freiwillige Diffusion zur Verfügung steht. Alle diese Verhältnisse sind so verwickelt, dafs sie in ihrem Zusammenwirken kaum genügend übersehen werden können; es kann daher die Formel (b) weniger zur genauen Berechnung der Ausbeuten benutzt werden, als zur vergleichsweisen Schätzung des Einflusses dieser oder jener Änderung in den Versuchsbedingungen auf unter bestimmten Verhältnissen gewonnene Ergebnisse.

Mit diesen Darlegungen ist nun aber die Bedeutung des Diaphragmas für elektrolytische Prozesse nicht erschöpft. Denn es gesellt sich zu den bisher betrachteten Erscheinungen noch diejenige der schon vor vielen Jahren von G. Wiedemasn und von Quincke etwas näher untersuchten, sogenannten elektrischen Endosmose. ${ }^{1}$ Es besteht die Thatsache, dals wenn die Bahn eines einen wässerigen Elektrolyten durchfliefsenden Stromes an einer Stelle kapillar verengt ist, dadurch in der Richtung des positiven Stromes, also von der Auoden- nach der Kathodenabteilung ein Strömen der Anoden-

1 Vgl. Wuedemand, Elektrizität, 2. Aufl, 1, $993 \mathrm{ff}$. Z. snorg. Chem. XXIII. 
lösung erfolgt. Das gleiche tritt natürlich ein, wenn statt einer einzigen Kapillare ein ganzes System von solchen, wie es in einem porösen Diaphragma vorliegt, zwischen die Elektroden eingeführt wird. Diese Strömung der Anodenlösung wirkt also dem die Stromverluste bedingenden Übertritt von Teilen des Elektrolyten aus dem Kathodenraum nach dem Anodenraum entgegen, ist also geeignet, die Stromausbeute zu erhöhen.

Die elektrische Endosmose treibt so lange Teile des Elektrolyten in den Kathodenraum, bis das Niveau der Kathodenlösung so hoch über das der Anodenlösung gestiegen ist, dals der hydrostatische Druck dieser Flüssigkeitssäule ihr das Gleichgewicht hält. Der so erreichte Druckwert kann ein verschiedener sein, je nach dem Material des Diaphragmas; er ist proportional dessen Dicke und umgekehrt proportional dem Quadrat des Querschnittes jeder einzelnen Kapillare; er wird also auch bei Diaphragmen aus dem gleichen Material verschieden sein können. Ferner ist dieser Druck proportional der Stromstärke und ungekehrt proportional der Leitfähigkeit der Kathoden- wie der Anodenlauge, soweit-die bisher für Kupfer- und Zinkvitriollösungen ausgeführten Versuche hierüber ein Urteil ermöglichen.

Wir haben also beim Diaphragmenprozels in der Alkaliausbeute das Endresultat dreier neben- und gegeneinander wirkender Einflüsse, von denen jeder wieder von den Versuchsbedingungen in besonderer Weise abhängt. Die Chlorausbeute ist gegeben durch die Alkaliausbeute, und erfährt noch durch die im Anodenraum sich abspielenden rein chemischen, bezw. elektrochemischen Vorgänge besondere Veränderungen.

\section{Experimenteller Teil.}

Sollten die schon der Theorie nach sehr verwickelten Verhältnisse bei der Alkalichloridelektrolyse mit Diaphragma durch Versuche näher geprüft werden, so war dazu nötig, dafs wir uns durch dieselben eine möglichst eingehende Kenntnis von dem zeitlichen Verlauf des in Rede stehenden Vorganges erwarben, und zwar durch analytische Feststellung der Konzentrations- und Mengenänderungen aller bei dem Vorgang in Betracht kommenden Stoffe. Wir haben unsere hierauf zielenden Versuchsreiben vorderhand auf die Verhältnisse bei gewöhnlicher 'Temperatur beschränkt; dabei 
dienten zunächst Platiniridiumplatten als Anoden, wie solche auch bei den theoretischen Erwägungen vorausgesetzt waren, und erst in einer späteren Versuchsreihe wurde der besondere Einflufs von Kohlenanoden einer näheren Prüfung unterzogen. Bei allen Versuchen bestanden die Diaphragmen aus Pukall'scher Thonmasse; unsere Ergebnisse dürfen also nicht ohne Vorsicht auf andere Diaphragmen, z. B. solche aus Cement, übertragen werden.

\section{A) Versuche mit Platiniridiumanoden.}

a) Die angewandten analytischen Verfahren.

1. Untersuchung der Kathodenlösung. In der Kathodenflüssigkeit waren Alkalihydrat und Alkalichlorid zu bestimmen, was durch Titration mit Normalschwefelsäure, bezw. mit Silbernitrat- und Rhodanammoniumlösung leicht geschehen konnte.

2. Untersuchung der Anodenlösung. Schwieriger gestaltete sich eine genaue Analyse der nach einer bestimmten Stromwirkung verbleibenden Anodenlauge. In dieser war aufser freiem Chlor zu erwarten: entweder Chlorid neben Salzsäure und vielleicht etwas Chlorat, oder Chlorid neben unterchloriger Säure (vielleicht etwas Hypochlorit) und Chlorat. Vorversuche entschieden für die letztere Möglichkeit.

Das freie Chlor lälst sich, wie vielfache Versuche dargethan haben, und es auch lange bekannt ist, aus seinen wässerigen Lösungen durch Einblasen eines kräftigen Luftstromes in 15-20 Minuten vollständig verjagen; riecht eine Lösung auch nach dieser Behandlung noch nach Chlor, so entsteht dieses dauernd in ihr durch chemische Prozesse. Da das freie Chlor für uns nur insofern Wert hatte, als es zur Chlorausbeute hinzugehörte, so haben wir es stets, ehe wir die Analyse begannen, aus der Lösung vertrieben und in den zur Bestimmung der Chlorausbeute dienenden Vorlagen aufgefangen.

Die Bestimmung des Hypochloritsauerstoffes geschieht sehr genau und zuverlässig nach dem Verfahren von PENoT mittels arseniger Säure. In der bei dieser Operation erhaltenen Lösung kann man nun alsbald, nach Ansäuerung mit chlorfreier Salpetersäure, die Chloridtitration nach Vourand vornehmen. Man findet hierbei neben dem ursprünglich vorhandenen Chlorid auch dasjenige, welches aus dem Hypochlorit bei dessen Reduktion durch die arsenige Säure 
entstanden ist. Stellt man letztere so ein, dals $1 \mathrm{ccm} 0.1 \mathrm{mg}$-Äquivalent Sauerstoff entspricht, so hat man, da nach der Gleichung:

$$
2 \mathrm{ROCl}+\mathrm{As}_{2} \mathrm{O}_{3}=2 \mathrm{RCl}+\mathrm{As}_{2} \mathrm{O}_{5}
$$

aus 2 Äquivalenten Hypochloritsauerstoff 1 Äquivalent Chloridchlor entsteht, von der Zahl der verbrauchten Kubikcentimeter 0.1-norm. Silberlösung die Hälfte der aufgewandten Kubikcentimeter Arsenigsäurelösung abzuziehen, um das wirklich vorhandene Chlorid finden zu können.

Die Chloratbestimmung geschieht mit einer für unsere Zwecke hinreichenden Genauigkeit durch Destillation der Lösung mit Salzsäure und Auffangen des entweichenden Chlors durch Jodkalium-

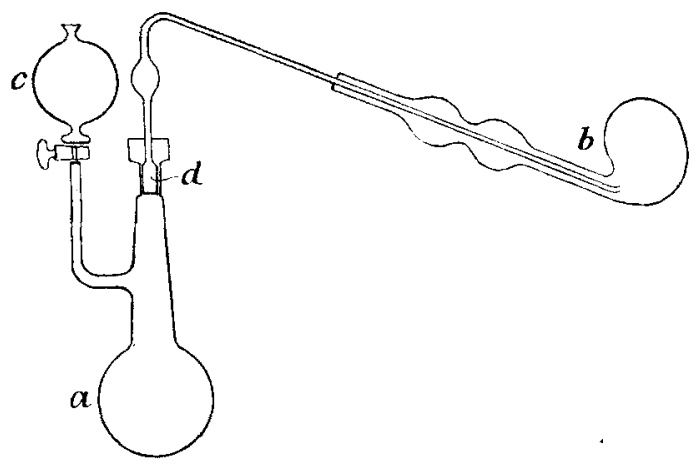

Fig. 1.

a) Zersetzungskolben; b) Absorptionsretorte; c) Trichter zur Aufnahme der für die Zersetzung notwendigen konz. $\mathrm{HCl}$; d) Eingeschliffenes Ableitungsrohr.

lösung in dem durch nebenstehende Zeichnung (Fig. 1) wiedergegebenen Apparat. Durch Abzug des für die geeiche Lösungsmenge gefundenen Hypochloritsauerstoffes von dem dem ausgeschiedenen Jod äquivalenten Gesamtsauerstoff ergiebt sich der Chloratsauerstoff.

Von grofser Bedeutung war es für die Prüfung der Theorie, ein Verfahren zu besitzen, durch welches man unterchlorige Säure von ihren Salzen unterscheiden und eventuell neben ihnen bestimmen konnte, durch welches man also feststellen konnte, ob wirlich, wie die Theorie verlangt, aller Hypochloritsauerstoff als freie unterchlorige Säure in der Anodenlösung vorhanden war. Auf gewöhnlichem acidimetrischen Wege ist dies wegen der Zerstörung der Indikatoren durch die unterchlorige Säure nicht möglich. Leicht aber lief's sich das Ziel erreichen durch Benutzung 
der bekannten, von LuNGE zur gasanalytischen Untersuchung des Chlorkalks benutzten Umsetzung, welche unterchlorige Säure oder ihre Salze mit Wasserstoffsuperoxyd geben. Dies vollzieht sich bei gewöhnlicher Temperatur momentan und glatt nach folgenden Gleichungen:

$$
\left.\begin{array}{l}
\mathrm{ROCl}+\mathrm{H}_{2} \mathrm{O}_{2}=\mathrm{RCl}+\mathrm{O}_{2}+\mathrm{H}_{2} \mathrm{O}, \\
\mathrm{HOCl}+\mathrm{H}_{2} \mathrm{O}_{2}=\mathrm{HCl}+\mathrm{O}_{2}+\mathrm{H}_{2} \mathrm{O} .
\end{array}\right\}
$$

Es ist dazu nur nötig, dafs man einen Überschufs der etwa $3 \%$ igen Wasserstoffsuperoxydlösung des Handels schnell und unter lebhaftem Umrühren mit der Hypochloritlösung vermischt; in wenigen Augenblicken ist die Entwickelung des Sauerstoffes vollendet, den man auffangen und messen kann, wodurch man für die Bestimmung des Hypochloritsauerstoffes eine Kontrolle gewinnt.

War die Lösung des Wasserstoffsuperoxyds neutral, bezw. vor der Benutzung neutralisiert, so erhält man nach der Umsetzung eine der ursprünglich vorhandenen unterchlorigen Säure genau äquivalente Menge von Salzsäure, welche durch 0.1-norm. Natronlauge zu messen ist. Da auf zwei als unterchlorige Säure vorhandene Äquivalente Hypochloritsauerstoff 1 Äquivalent Natronlauge verbraucht wird, so hat man nur die doppelte Zahl der von letzterer angewandten Kubikcentimeter von derjenigen abzuziehen, welche vorher an Arsenigsäurelösung der oben erwähnten Konzentration nötig gewesen, um zu wissen, wieviel des Hypochloritsauerstoffes etwa in Gestalt von neutralem Hypochlorit vorlag.

Die folgenden Versuche lassen die Zuverlässigkeit des Verfahrens beurteilen. Dabei wurden je $5 \mathrm{ccm}$ der zu untersuchenden Hypochloritlösung in ein kurzes Reagensglas gebracht, welches mit einem ein Gasableitungsrohr und eine kleine Hahnbürette tragenden Kork verschlossen war. Jenes mündete unter einem Gasmefsrohr; aus dieser liefs man jedesmal 2 ccm 3\% iger neutraler Wasserstoffsuperoxydlösung schnell und unter lebhaftem Schütteln in das Reagensglas einflielsen. War die Gasentwickelung beendet, so wurde das Gas in einer HEMPeL'schen Bürette gemessen. Abzüglich der zugeflossenen $2 \mathrm{ccm}$ entsprach nach obigen Gleichungen die Hälfte des entwichenen Gases dem vorhandenen Hypochloritsauerstoff.

1. Eine durch Einleiten von Chlor in Natronlauge hergestellte und möglichst neutrale Hypochloritlösung, welche nach dem Ergebnis der Titration nach Penot 0.3024 g Hypochloritsauerstoff in $100 \mathrm{ccm}$ enthielt, gab bei der oben beschriebenen Analyse folgende Werte: 


$\begin{array}{ccccc}\begin{array}{c}\text { Vełsuch Nr. } \\ \text { g Hypochloritsauerstoff } \\ \text { in } 100 \mathrm{ccm}\end{array} & \mathbf{0 . 3 0 6 2} & \mathbf{0 . 3 1 3 2} & 0.3117 & 0.3103\end{array}$

Die erhaltene Lösung war genau neutral.

2. Eine nach BALARD hergestellte Lösung von freier unterchloriger Säure, welche nach der Titration $0.350 \mathrm{~g}$ Hypochloritsauerstoff in $100 \mathrm{ccm}$ enthielt und demnach zur Neutralisation von $5 \mathrm{ccm}$ $1.09 \mathrm{ccm} 1 / 10^{-n o r m}$. Natronlauge brauchen würde, gab folgende Ergebnisse:

Versuch Nr. g Hypochloritsauerstoff in $100 \mathrm{~cm}$

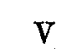

0.345

1.10

\section{VI}

0.347

1.09
VII

Liefs man das Wasserstoffsuperoxyd nicht schnell, sondern nur langsam einflielsen, so wurde zu wenig Sauerstoff gefunden und zu wenig Natronlauge verbraucht:

$\begin{array}{cccc}\begin{array}{c}\text { Versuch Nr. } \\ \text { g Hypochloritsauerstoff } \\ \text { in } 100 \text { ccm }\end{array} & \text { VIII } & \text { IX } & X \\ \begin{array}{c}\text { cem } n / 10-\mathrm{NaOH} \text { verbraucht } \\ \text { auf } 5 \text { ccm der Lösung }\end{array} & 0.27 & 0.30 & 0.25 \\ & 0.85 & 0.95 & -\end{array}$

Der Grund dafür liegt darin, dafs bei zu langsamem Zuflufs von Wasserstoffsuperoxyd die entstehende Salzsäure Zeit und Gelegenheit hat, mit noch vorhandener unterchloriger Säure nach der Gleichung $\mathrm{HCl}+\mathrm{HOCl}=\mathrm{H}_{2} \mathrm{O}+\mathrm{Cl}_{2}$ freies Chlor zu bilden. In der That roch bei den fehlerhaften Analysen das aufgesammelte Gas stets nach Chlor, und hierin hat man ein Kriterium für die Richtigkeit der Analyse. Bei neutralen oder alkalischen Hypochloritlösungen spielt demnach, wie es auch der Versuch zeigt, die Geschwindigkeit, mit der das Wasserstoffsuperoxyd zufliefst, für das Ergebnis keine Rolle.

3. Untersuchung der aus der Anodenzelle entweichenden Gase. Unter den beim Diaphragmenprozefs auftretenden Gasen können diejenigen der Kathodenzelle ununtersucht bleiben, da kein Einflufs da ist, die Reinheit und die der Stromstärke entsprechende Menge des hier auftretenden Wasserstoffes zu stören. Dagegen besteht das aus der Anodenzelle sich entwickelnde Gas aus einem in der Zusammensetzung wechselnden Gemenge von Chlor und Sauerstoff. Wenn, wie die theoretischen Erörterungen in Abschnitt $2 \mathrm{~A}$ 
ohne weiteres erkenneñ lassen, dessen Analyse und der Vergleich seiner Menge mit dem gleichzeitig in einem Knallgasvoltameter entwickelten Sauerstoff auch nicht, wie in anderen Fällen, zur Bestimmung der jeweiligen Stromausbeute dienen kann, so ist dieselbe, wie sich zeigen wird, doch nach anderer Richtung nicht ohne Vorteil. Man führt sie mit einer einfachen Hemper'schen Gaspipette aus, welche mit starker Natronlauge beschickt ist. So lange diese noch nicht allzuweit mit Chlor gesättigt ist, sind die gewonnenen Ergebnisse sehr genau. Den im wesentlichen aus Sauerstoff bestehenden Gasrest führt man in die Kupferpipette über und bringt eine etwa verbleibende kleine Stickstoffmenge als Luft vom Gesamtgas in Abzug.

b) Die Versuchsanordnung.

Die in diesem Teil beschriebenen Versuche wurden ausschliefslich mit Chlorkaliumlösungen ausgeführt. Als Gefäfs zu ihrer Elektrolyse wurde ein $20 \mathrm{~cm}$ hoher, $13 \mathrm{~cm}$ breiter und $8 \mathrm{~cm}$ tiefer rechteckiger Glastrog benutzt, dessen innere Breitseiten von zwei gut anliegenden, die Kathode bildenden Eisenblechen bedeckt waren. Zwischen sie wurde eine schmale, rechteckige, $16 \mathrm{~cm}$ hohe, $11 \mathrm{~cm}$ breite und $4.5 \mathrm{~cm}$ tiefe Thonzelle von $4 \mathrm{~mm}$ Wandstärke eingestellt und in ihr die Anoden angebracht. Zum zeitweisen Umrühren der Kathodenlauge diente ein die Anodenzelle gabelförmig umfassender Glasstab.

Als Anoden wurden je zwei $4.5 \times 12.0 \mathrm{~cm}$ grolse Bleche aus Platiniridium senkrecht nebeneinander in die Thonzelle eingehängt, und diese wurde durch ein eingepalstes dickes Stück Gummi dicht verschlossen. Letzteres hatte vier Durchbohrungen: durch zwei derselben gingen die Glasröhren, in welche die Zuleitungen zur Anode eingeschmolzen waren, durch die dritte das Gasableitungsrohr und durch die vierte ein bis auf den Boden der Zelle reichendes Glasrohr, durch welches im erwünschten Augenblick zur Vertreibung des Chlors aus der Lösung ein Luftstrom in die Anodenzelle geblasen werden konnte.

Die so vorgerichtete Zelle wurde mit Kupfervoltameter, Stromund Spannungsmesser in einen von einer Akkumulatorenbatterie gespeisten Stromkreis eingeschaltet.

Die aus der Zelle tretenden Gase gelangten, wenn die Chlorausbeute bestimmt werden sollte, in eine mit starker Natronlauge beschickte Vorlage, oder aber, wenn das nicht beabsichtigt wurde, 
in eine Art von Chlorkalkkammer. Eine solche stellt man sich, wie es schon gelegentlich beschrieben ist, leicht her, wenn man einen Trichter oder den oberen abgesprengten Teil einer Flasche mit der weiten Öffnung nach unten, z. B. in einer geeignet grolsen Kiste, auf eine Unterlage von grob zerkleinerter Holzkohle stellt, am Stiel des Trichters oder im Hals der Flasche ein aus der Kiste herausragendes Glasrohr befestigt und im übrigen die Kiste mit abwechselnden Schichten von gelöschtem Kalk und Holzkohle anfüllt. Eine solche Einrichtung erlaubt, grofse Mengen Chlor ohne die geringste Belästigung zu beseitigen und machte bei unserer Arbeit die Benutzung des Abzuges völlig entbehrlich.

Diese Vorlage wurde benutzt, wenn das aus der Anodenzelle austretende Gas zur Analyse aufgefangen werden sollte. Sie wurde

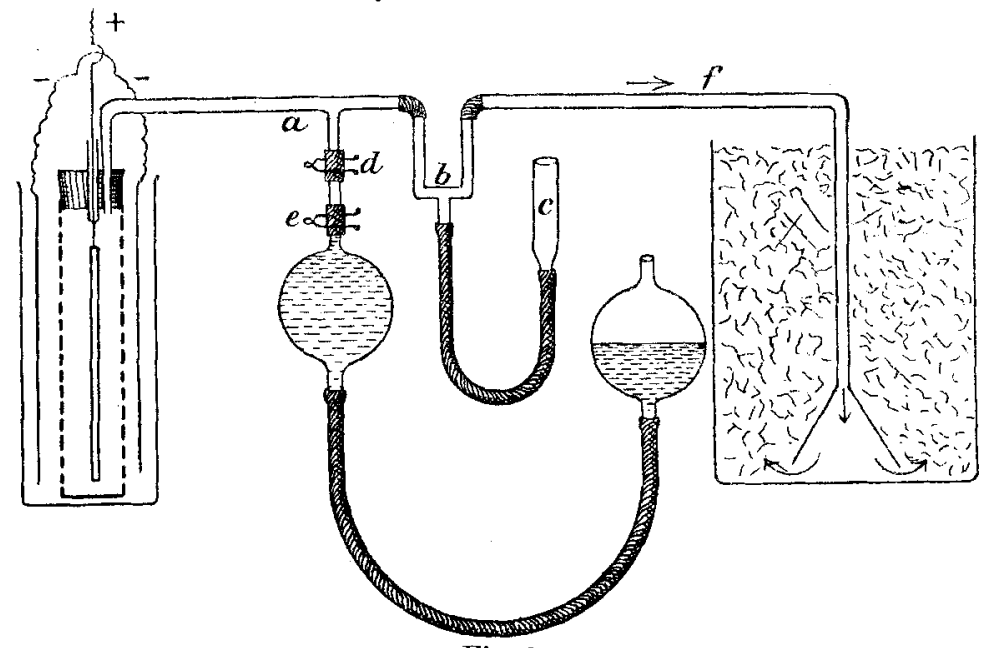

Fig. 2.

mit der Anodenzelle durch ein gläsernes T-Stück $a$ (in nebenstehender Fig. 2) verbunden, und zwar so, dals zwischen diesem und der Kalkvorlage ein starker, durch einen Quetschhahn zu schliefsender Gummischlauch oder, wie Herr stud. GräFE es bei seinen später zu beschreibenden Versuchen als zweckmäfsig fand, der Wasserverschlufs $b$ eingeschaltet war, welcher durch Heben und Senken des Niveaurohres $e$ geschlossen und geöffnet werden kann und gleichzeitig den Gasdruck in der Anodenzelle anzeigt.

Das untere Ende des T-Stückes konnte mit dem zum Aufsammeln der Gase dienenden Apparat verbunden werden und trug dazu an einem kurzen, durch den Quetschbahn $d$ zu schliefsenden 
Gummischlauch ein kleines und enges Ansatzröhrchen, welches mit dem den Gassammelapparat durch den Quetschhahn $e$ abschliefsenden Gummischlauchstück zu verbinden war. Jener Apparat bestand aus einer $500 \mathrm{ccm}$ fassenden Glaskugel, an welche oben ein mit dem T-Stück zu verbindendes Kapillarrohr, unten ein weiteres, die Marke tragendes und ein Niveaugefäls führendes Glasrohr angeschmolzen war. Vor der Gasentnahme wurde der Apparat mit durch Chlor nahezu gesättigter Kochsalzlösung beschickt.

Zum Zweck der Gasentnahme wurde die Verbindung der Anodenzelle mit der Kalkvorlage geschlossen und im nächsten Augenblick durch Öffnen der Hähne $d$ und $e$ diejenige nach dem Gassammelgefäls geöffnet; durch langsames Senken des Niveaugefälses wurde dafür gesorgt, dafs während der Gasentnahme der Druck in der Anodenzelle möglichst konstant blieb. War die Operation beendet, so wurden die Hähne $d$ und $e$ schnell geschlossen und sofort die Verbindung nach der Kalkvorlage wieder freigegeben.

Da mit dieser Versuchsanordnung ja, wie erwähnt, im wesentlichen der zeitliche Verlauf des Diaphragmenprozesses festgestellt werden sollte, wurde fast ausschliefslich mit einer bestimmten konstanten Stromstärke gearbeitet. Als solche wurde 5 Amp. gewählt, wodurch eine Stromdichte von $0.023 \mathrm{Amp} / \mathrm{qcm}$ an der. Anode und von $0.016 \mathrm{Amp} / \mathrm{qcm}$, bezogen auf die wirksame Diaphragmenfläche, gegeben war. Die Spannung betrug dabei gewöhnlich 3.6 Volt, konnte aber, wenn die Anodenlösung stark erschöft war, auf 4.0 bis 4.5 Volt ansteigen.

In der Anodenzelle wurde, um die Versuche möglichst lange fortsetzen zu können, von einer bei gewöhnlicher Temperatur nahezu gesättigten Chlorkaliumlösung ausgegangen; die Konzentration der Kathodenlösung wurde so gewählt, dals diese die gleiche Menge Chlorkalium enthalten sollte, wie die Anodenlösung. Demgemäls wurde jede Elektrolyse, bei der nicht gerade der Einflufs von Änderungen in der Chloridkonzentration untersucht werden sollte, begonnen mit

$500 \mathrm{ccm}$ Anodenlösung, welche in $100 \mathrm{ccm} 28 \mathrm{~g} \mathrm{KCl}$ enthielt, und $700 \mathrm{ccm}$ Kathodenlösung, welche in $100 \mathrm{ccm} 20 \mathrm{~g} \mathrm{KCl}$ enthielt.

c) Die Ausführung der Versuche und ihre Ergebnisse.

Es bestand ursprünglich die Absicht, während einer Elelstrolyse in bestimmten Zeitabschnitten, womöglich von Stunde zu Stunde, Bestimmungen aller bei der Elektrolyse entstehender Stoffe vorzu- 
nehmen. Doch erwies es sich als eine, zumal bei längeren Versuchen, äufserst anstrengende Arbeit, die nötige Zahl von Werten mit wünschenswerter Genauigkeit zu erhalten. Besonders erschwert wurde dies durch die infolge der elektrischen Endosmose dauernd sich vollziehende Vermehrung der Kathoden- und Verminderung der Anodenlauge. Beider Volumina mufsten in jedem Augenblick aber bekannt sein, um die mit aliquoten Teilen der Lösung gewonnenen Titrationsergebnisse auf das Gesamtvolumen umrechnen zu können. Während eine Aichung des Kathodengefälses die Ausdehnung der Kathodenlauge ungefähr zu verfolgen gestattete, entzog sich die Volumenänderung der Anodenlauge der Wahrnehmung.

Nach den Vorversuchen wurde daher bei der ersten endgültigen Versuchsreihe, der Reihe A, so verfahren, dafs von Zeit zu Zeit die Kathodenlauge untersucht wurde. Tauschte man jedesmal im Augenblick der Probenahme die Kathode im Kupfervoltameter gegen eine neue aus, und geschah das gleiche mit einer zur Aufsammlung des entweichenden Chlors bestimmten, mit Natronlauge beschickten Vorlage, so konnte die in jedem Zeitabschnitt erhalten Alkali- und der Chlorausbeute bestimmt werden. Die Zusammensetzung der Anodenlauge konnte dann freilich erst am Schlufs jedes der Versuche festgestellt werden. Liefs man diese aber verschieden lange Zeiten dauern, so konnte damit doch auch die Frage nach dem zeitlichen Verlauf der Änderungen in der Anodenlauge beantwortet werden. Die so gewonnenen Ergebnisse zeigen die folgenden $\mathrm{Zu}$ sammenstellungen.

\section{Versuchsreihe A.}

I. Untersuchungen in der Kathodenzelle.

a) Veränderungen im Chlorkaliumgehalt.

\begin{tabular}{|c|c|c|c|c|c|c|c|c|c|}
\hline \multirow{2}{*}{\multicolumn{2}{|c|}{ Versuch $\mathrm{Nr}$. }} & \multicolumn{4}{|c|}{$\begin{array}{c}\text { Gesamtmenge des Chlor- } \\
\text { kaliums in der Kathodenlauge } \\
\text { in } \mathrm{g}\end{array}$} & \multicolumn{4}{|c|}{$\begin{array}{c}\text { Konzentration des Chlor- } \\
\text { kaliums in } \mathrm{g} \text { auf } \\
100 \mathrm{ccm}\end{array}$} \\
\hline & & 1 & 2 & 3 & 4 & 1 & 2 & 3 & 4 \\
\hline $\begin{array}{l}\text { Vor der } \\
\text { Versuch }\end{array}$ & em & 141.9 & 143.9 & 147.1 & 140.1 & 20.27 & 20.55 & 21.01 & 20.01 \\
\hline Nach $2 \mathrm{~S}$ & Std. & - & - & 134.9 & - & - & - & 17.75 & - \\
\hline$" 4$ & $"$ & 128.8 & 122.8 & 125.9 & 123.0 & 16.2 & 16.2 & 16.57 & 16.18 \\
\hline 6 & $"$ & - & 118.7 & 118.7 & - & - & 15.6 & 15.62 & 一 \\
\hline$" 8$ & $"$ & - & - & 116.9 & 113.9 & - & - & 15.39 & 14.99 \\
\hline$n 10$ & $"$ & - & - & - & 112.8 & - & - & - & 14.84 \\
\hline
\end{tabular}


b) Der Zuwachs an Kalihydrat.

\begin{tabular}{|c|c|c|c|c|c|c|c|c|}
\hline \multirow[b]{2}{*}{ Versuch $\mathrm{Nr}$. } & \multicolumn{4}{|c|}{$\begin{array}{c}\text { Gesamtmenge des } \\
\text { entstandenen Kalihydrats } \\
\text { in } \mathrm{g}\end{array}$} & \multicolumn{4}{|c|}{$\begin{array}{l}\text { Konzentration des Kali- } \\
\text { hydrats in } \mathrm{g} \text { auf } \\
100 \mathrm{ccm}\end{array}$} \\
\hline & 1 & 2 & 3 & 4 & 1 & 2 & 3 & 4 \\
\hline Nach 2 Std. & 19.62 & - & 17.8 & - & 2.58 & - & 2.34 & - \\
\hline, $4 n$ & 33.6 & 33.1 & 32.1 & 33.2 & 4.4 & 4.2 & 4.21 & 4.48 \\
\hline $6 "$ & - & 47.0 & 45.7 & -- & - & 6.1 & 6.09 & - \\
\hline$" 1$ & - & - & 56.8 & 60.1 & - & - & 7.47 & 7.91 \\
\hline$" 10 "$ & - & 一 & - & 70.6 & - & - & - & 9.29 \\
\hline
\end{tabular}

c) Stromausbeute an Kalihydrat.

\begin{tabular}{|c|c|c|c|c|c|c|c|c|c|}
\hline \multirow[b]{2}{*}{ Versucl } & \multirow[b]{2}{*}{ Nr. } & \multicolumn{4}{|c|}{$\begin{array}{l}\text { Während der Bildung des } \\
\text { Kalihydrats im Kupfervolta- } \\
\text { meter abgeschiedene g Kupfer }\end{array}$} & \multicolumn{4}{|c|}{$\begin{array}{l}\text { Gesamtstromausbeute an } \\
\text { Alkali in Hundertteilen der } \\
\text { theoretischen }\end{array}$} \\
\hline & & 1 & 2 & 3 & 4 & 1 & 2 & 3 & 4 \\
\hline Nach 2 & Std. & 12.86 & - & 11.47 & - & 86.5 & - & 88.0 & - \\
\hline$\Rightarrow 4$ & $"$ & 23.99 & 24.13 & 23.18 & 23.60 & 79.5 & 78.3 & 76.5 & 79.7 \\
\hline 6 & " & - & 36.10 & 34.79 & - & - & 74.0 & 74.6 & - \\
\hline$" 8$ & $"$ & - & - & 46.64 & 46.49 & - & - & 69.1 & 73.4 \\
\hline$\Rightarrow 10$ & " & - & - & $\rightarrow$ & 58.32 & - & - & - & 68.7 \\
\hline
\end{tabular}

II. Untersuchungen über die Anodenzelle.

a) Stromausbeute an Chlor.

\begin{tabular}{|c|c|c|c|c|c|c|c|c|c|}
\hline \multirow{2}{*}{\multicolumn{2}{|c|}{ Versuch $\mathrm{Nr}$. }} & \multicolumn{4}{|c|}{$\begin{array}{l}\text { Chlormenge, die in } \\
\text { der Zelle entwiekelt wurde } \\
\text { in } g\end{array}$} & \multicolumn{4}{|c|}{$\begin{array}{l}\text { Gesamtchlorausbente } \\
\text { in Hundertteilen der } \\
\text { theoretischen }\end{array}$} \\
\hline & & 1 & 2 & 3 & 4 & 1 & 2 & 3 & 4 \\
\hline Nach 2 & Std. & 11.71 & - & 9.35 & - & 81.6 & - & 73.0 & - \\
\hline$n \quad 4$ & 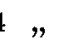 & 20.48 & 19.01 & - & 18.74 & $82.8 ?$ & 70.5 & - & 71.1 \\
\hline$"$ & $"$ & - & 27.77 & 28,1 & - & - & 68.8 & 70.2 & - \\
\hline$" 8$ & $"$ & - & - & 35.05 & 36.4 & - & - & 67.3 & 70.2 \\
\hline$" 10$ & $n$ & - & - & $\ldots$ & 45.3 & - & - & - & 69.6 \\
\hline
\end{tabular}


b) Zusammensetzung der Anodenlauge (500 ccm)

\begin{tabular}{|c|c|c|c|c|c|c|c|}
\hline 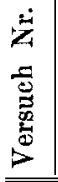 & $\begin{array}{c}\text { Zeitdauer } \\
\text { des } \\
\text { Versuchs }\end{array}$ & $\begin{array}{c}\text { Chlorid- } \\
\text { menge vor } \\
\text { dem Ver- } \\
\text { such in } \\
g\end{array}$ & $\begin{array}{c}\text { Chlorid- } \\
\text { menge } \\
\text { nach dem } \\
\text { Versuch } \\
\text { in g }\end{array}$ & $\begin{array}{l}\text { Chlorat- } \\
\text { menge } \\
\text { nach dem } \\
\text { Versuch } \\
\text { in } g\end{array}$ & $\begin{array}{l}\text { Menge der } \\
\text { unterchlo- } \\
\text { rigen Säure } \\
\text { nach dem } \\
\text { Versuch in } \mathrm{g}\end{array}$ & $\begin{array}{c}\text { Culorat- } \\
\text { sauerstoff } \\
\text { in } 100 \mathrm{ccm} \\
\text { in } \mathrm{g}\end{array}$ & $\begin{array}{l}\text { Hypo- } \\
\text { chlorit- } \\
\text { sauerstoff } \\
\text { in } 100 \mathrm{ccm} \\
\text { in } \mathrm{g}\end{array}$ \\
\hline 1 & 4 Std. & 141.9 & 108.0 & 0.313 & 4.080 & 0.0243 & 0.252 \\
\hline 2 & $6 \quad "$ & 143.9 & 91.14 & 1.206 & 5.788 & 0.0945 & 0.352 \\
\hline 3 & 8 & 147.1 & 82.3 & 2.705 & 6.541 & 0.212 & 0.399 \\
\hline 4 & $10 "$ & 140.1 & 56.9 & 4.723 & 5.407 & 0.370 & 0.329 \\
\hline
\end{tabular}

III. Zusammenstellung der Mittelwerte für die erhaltenen Ausbeuten.

\begin{tabular}{|c|c|c|c|c|}
\hline \multirow{2}{*}{\multicolumn{2}{|c|}{$\begin{array}{l}\text { Zeit nach } \\
\text { Beginn der } \\
\text { Elektrolyse }\end{array}$}} & \multirow{2}{*}{$\begin{array}{l}\text { Alkalikonzen- } \\
\text { tration in } \mathrm{g} \text { auf } \\
100 \mathrm{ccm}\end{array}$} & Alkaliausbeuto & Chlorausbeute \\
\hline & & & \multicolumn{2}{|c|}{ in Hundertteilen der theoretischen } \\
\hline & Stunden & 2.46 & 87.2 & 77.3 \\
\hline &, & 4.32 & 78.5 & 70.8 \\
\hline 6 & $"$ & 6.10 & 74.3 & 69.5 \\
\hline 8 & $"$ & 7.69 & 71.2 & 68.7 \\
\hline & $"$ & 9.29 & 68.7 & 69.6 \\
\hline
\end{tabular}

Diese Versuche waren insofern noch mangelhaft, als die wiederholte Entnahme von Proben aus dem Kathodenraum sowie die in einzelnen Abschnitten erfolgende Bestimmung der Chlorausbeute mancherlei Genauigkeitsstörungen im Gefolge hatte. Auch waren die Versuche, da sie mit etwas wechselnden Chloridkonzentrationen begonnen wurden, nicht ganz streng untereinander vergleichbar. Deshalb wurde eine neue Versuchsreihe eingeleitet, bei der auf jede Entnahme von Flüssigkeitsproben während der Elektrolyse verzichtet wurde. Es wurden die einzelnen Versuche verschieden lange Zeit fortgesetzt; nach Schluls jedes derselben wurde die Kathodenlauge gemessen, auf $1000 \mathrm{ccm}$ aufgefüllt und analysiert, die Anodenlange zunächst durch Einblasen von Luft während 20 Minuten von gelöstem Chlor befreit, dann auf $500 \mathrm{ccm}$ aufgefüllt und genau analysiert. Hierbei wurde die Chlorausbeute durch Auffangen der während der Elektrolyse und dem nachherigen Lufteinblasen entweichenden Chlormenge in starker Natronlauge und Analyse eines aliquoten Teiles derselben bestimmt.

Ganz streng exakt sind auch diese Versuche nicht; denn wenn nur die Kathodenlauge und die Anodenlauge analysiert werden, so 
bleiben die vom Diaphragma aufgenommenen Flüssigkeitsteile unberücksichtigt; diese sind aber nicht ganz gering, da das Porenvolumen des bei den folgenden Versuchen benutzten Diaphragmas durch Wägen des absorbierten Wassers zu etwa $40 \mathrm{ccm}$ gefunden wurde. Die darin befindlichen Teile von Salzlösungen sind nur durch langes Auswässern zu entfernen, zum grölsten Teil freilich schon durch etwa 12 stündige Behandlung mit grofsen Wassermengen. Daher haben wir, um stets dasselbe Diaphragma anwenden zu können, dieses stets nach Schlufs eines Versuches über Nacht möglichst ausgewaschen, aber die in jedem Falle sicher ungenaue Bestimmung der ausgezogenen Salzmengen unterlassen und die Waschflüssigkeit verworfen. Diese Arbeitsweise hat zur Folge, dals die beobachteten Alkaliverluste etwas grölser sind, als die wirklich aufgetretenen, und dals zwischen der angewandten Chloridmenge einerseits und der am Schlufs jedes Versuches noch vorhandenen und der in seinem Verlauf zersetzten andererseits eine nahezu konstante kleine Differenz hervortritt. Für unsere Ergebnisse freilich waren diese Fehler ohne Bedeutung, und daher haben wir uns nicht bemüht, sie zu vermeiden.

\section{Versuchsreihe B.}

I. Untersuchungen in der Kathodenflüssigkeit.

\begin{tabular}{|c|c|c|c|c|c|c|c|}
\hline \multirow[b]{2}{*}{ 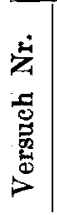 } & \multirow[b]{2}{*}{ 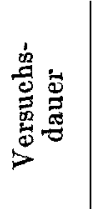 } & \multicolumn{2}{|c|}{ Kaliumchlorid } & \multicolumn{2}{|c|}{ Kalihydrat } & \multirow[b]{2}{*}{$\begin{array}{l}\text { Im Kupfer- } \\
\text { voltameter } \\
\text { während des } \\
\text { Versuchs ab- } \\
\text { geschiedenes } \\
\text { Kupfer in } g\end{array}$} & \multirow[b]{2}{*}{$\begin{array}{l}\text { Alkali- } \\
\text { ausbeute in } \\
\text { Hundert- } \\
\text { teilen der } \\
\text { theore- } \\
\text { tischen }\end{array}$} \\
\hline & & $\begin{array}{c}\text { zu } \\
\text { Beginn } \\
\text { des } \\
\text { Versuchs } \\
\text { in } g\end{array}$ & $\begin{array}{l}\text { am } \\
\text { Schlufs } \\
\text { des } \\
\text { Versuchs } \\
\text { in } g\end{array}$ & $\begin{array}{l}\text { Ent- } \\
\text { standene } \\
\text { Gesamt- } \\
\text { menge } \\
\text { in } \mathrm{g}\end{array}$ & $\begin{array}{c}\text { in } 100 \mathrm{cem} \\
\text { ent- } \\
\text { standenen } \\
\text { Menge } \\
\text { in } \mathrm{g}\end{array}$ & & \\
\hline 5 & $2 \mathrm{Std}$ & 146.2 & 135.0 & 18.4 & 2.6 & 12.0 & 87.2 \\
\hline 6 & & 146.2 & 126 & & & & \\
\hline 7 & $6 \%$ & 146.2 & 122.8 & 48.0 & 6.32 & 35.76 & 76.2 \\
\hline 8 & & 146.2 & 117.1 & 63.05 & 8.3 & & 72. \\
\hline 9 & $10 "$ & 146.2 & 116.6 & 77.71 & 10.2 & & 72.5 \\
\hline 10 & 12 & 146.2 & 113.4 & 87.16 & 11.2 & 72.32 & 68.4 \\
\hline 11 & $17 "$ & 143.0 & 116.6 & 116.9 & 13.9 & 100.91 & 65.6 \\
\hline
\end{tabular}

II. Untersuchungen über die Vorgänge in der Anodenzelle. a) Chlorausbeute.

\begin{tabular}{c||c|c|c|c|c|c|c}
\hline \hline Versuch Nr. & 5 & 6 & 7 & 8 & 9 & 10 & 11 \\
\hline Versuchsdauer & 2 Std. & 4 Std. & 6 Std. & 8 Std. & 10 Std. & 12 Std. & 17 Std. \\
\hline \hline $\begin{array}{c}\text { Menge des entwickeiten } \\
\text { Chlors in g }\end{array}$ & 10.53 & 19.82 & 29.22 & 37.87 & 47.97 & 54.50 & 78.02 \\
$\begin{array}{c}\text { Stromausbeute an Chlor } \\
\text { in Hundertteilen der } \\
\text { theoretischen }\end{array}$ & 78.7 & 75.2 & 73.2 & 69.1 & 71.4 & 69.3 & 69.3 \\
\hline
\end{tabular}


b) Zusammensetzung der Anodenlauge (500 ccm)

\begin{tabular}{|c|c|c|c|c|c|c|c|}
\hline 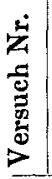 & 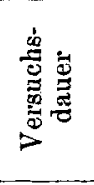 & $\begin{array}{l}\text { Chlor } \\
\text { zu Beginn } \\
\text { des Ver- } \\
\text { suchs in g }\end{array}$ & $\begin{array}{l}\text { kalium } \\
\text { nachSchlufs } \\
\text { des Ver- } \\
\text { suches ing }\end{array}$ & $\begin{array}{l}\text { Kalium- } \\
\text { chlorat am } \\
\text { Schlufs des } \\
\text { Versuches } \\
\text { in g }\end{array}$ & $\begin{array}{l}\text { Unterchlo- } \\
\text { rige Säure } \\
\text { am Schlufs } \\
\text { des Vers. } \\
\text { in } g\end{array}$ & $\begin{array}{l}\text { Chlorat- } \\
\text { sauerstoff } \\
\text { in } \mathrm{g} \\
\text { auf } \\
100 \mathrm{ccm}\end{array}$ & $\begin{array}{c}\text { Hypochlo- } \\
\text { ritsauer- } \\
\text { stoff in } \mathrm{g} \\
\text { auf } \\
100 \mathrm{ccm}\end{array}$ \\
\hline 5 & 2 Std. & 146.2 & 119.7 & 0.09 & 1.26 & 0.0067 & 0.0769 \\
\hline 6 & $4 \%$ & 146.2 & 106.4 & 0.83 & 3.80 & 0.025 & 0.232 \\
\hline 7 & 6 & 146.2 & 93.15 & 1.18 & 4.73 & 0.091 & 0.289 \\
\hline 8 & $8 "$ & 146.2 & 75.08 & 2.31 & 6.92 & 0.178 & 0.422 \\
\hline $\mathbf{9}$ & $10 "$ & 146.2 & 56.37 & 4.04 & 6.20 & 0.314 & 0.378 \\
\hline 10 & 12, & 146.2 & 46.37 & 6.53 & 5.86 & 0.509 & 0.314 \\
\hline 11 & 17 & 143.0 & 1.24 & 11.71 & 1.48 & 1.31 & 0.13 \\
\hline
\end{tabular}

Bei den bisherigen Versuchen wurde zur Bestimmung der Chlorausbeute das aus der Anodenzelle austretende Gas in Natronlange geleitet und dabei tanchte das Einleitungsrohr $4-5 \mathrm{~cm}$ in diese ein. Der Druck dieser Flüssigkeitssäule addierte sich zu dem ohnehin schon von der Anoden- nach der Kathodenzelle wirkenden Druck der elektrischen Endosmose. Um diese Störung auszuschalten, bezw. ihre Wirkung kennen zu lernen, wurden mehrere Versuche der Reihe B wiederholt, mit dem einzigen Unterschiede, dals das Chlor hier in der Kalkvorlage aufgefangen wurde. Bei dieser Reihe $\mathrm{C}$ wurde also auf die Bestimmung der Chlorausbeute verzichtet, dafür bot sich Gelegenheit, das aus der Anodenzelle entweichende Gas zur Analyse aufzufangen.

\section{Versuchsreihe C.}

I. Untersuchungen in der Kathodenflüssigkeit.

\begin{tabular}{|c|c|c|c|c|c|c|c|}
\hline \multirow[b]{2}{*}{ 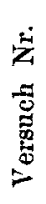 } & \multirow[b]{2}{*}{ 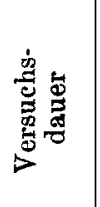 } & \multicolumn{2}{|c|}{ Chlorkalium } & \multicolumn{2}{|c|}{ Kalihydrat } & \multirow[b]{2}{*}{$\begin{array}{l}\text { Im Kupfer- } \\
\text { voltameter } \\
\text { während des } \\
\text { Versuchs ab- } \\
\text { geschiedenes } \\
\text { Kupfer in g }\end{array}$} & \multirow[b]{2}{*}{$\begin{array}{l}\text { Strornaus- } \\
\text { beute an } \\
\text { Alkali in } \\
\text { Hundert- } \\
\text { teilen der } \\
\text { theoretischen }\end{array}$} \\
\hline & & $\begin{array}{c}\text { vor } \\
\text { dem } \\
\text { Versuch } \\
\text { in } \\
\mathrm{g}\end{array}$ & $\begin{array}{c}\text { nach } \\
\text { dem } \\
\text { Versuch } \\
\text { in } \\
\text { g }\end{array}$ & $\begin{array}{l}\text { ent- } \\
\text { standene } \\
\text { Gesamt- } \\
\text { menge } \\
\text { in g }\end{array}$ & $\begin{array}{c}\text { in } 100 \mathrm{ccm} \\
\text { vor- } \\
\text { handenen } \\
\text { Menge } \\
\text { in } \mathrm{g}\end{array}$ & & \\
\hline 12 & $10 \mathrm{std}$. & 144.6 & 111.8 & 74.06 & 9.87 & 59.9 & 69.9 \\
\hline 13 & $17 \%$ & 143.0 & 104.2 & 114.8 & 15.3 & 101.49 & 64.0 \\
\hline
\end{tabular}


II. Zusammensetzung der Anodenlauge (500 ccm).

\begin{tabular}{|c|c|c|c|c|c|c|c|}
\hline \multirow{2}{*}{ 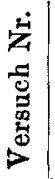 } & \multirow{2}{*}{ 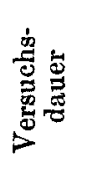 } & \multicolumn{2}{|c|}{ Chlorkalium } & \multirow{2}{*}{$\begin{array}{c}\text { Kalium- } \\
\text { chlorat } \\
\text { nach dem } \\
\text { Versuch } \\
\text { in } g\end{array}$} & \multirow{2}{*}{\begin{tabular}{|c|} 
Unter- \\
chlorige \\
Saure nach \\
dem Versuche \\
in $\mathrm{g}$
\end{tabular}} & \multirow{2}{*}{$\begin{array}{l}\text { Chlorat- } \\
\text { sauerstoff } \\
\text { in g } \\
\text { auf } \\
100 \mathrm{ccm}\end{array}$} & \multirow{2}{*}{$\begin{array}{c}\text { Hypo- } \\
\text { chlorit- } \\
\text { sauerstoff } \\
\text { in } \mathrm{g} \mathrm{auf} \\
100 \mathrm{ccm}\end{array}$} \\
\hline & & $\begin{array}{l}\text { vor dem } \\
\text { Versuch } \\
\text { in } g\end{array}$ & $\begin{array}{l}\text { nach dem } \\
\text { Versuch } \\
\text { in } g\end{array}$ & & & & \\
\hline & & & & & & & \\
\hline & 17 & 143.0 & 20.0 & 13.41 & 5.13 & 1.358 & 0.313 \\
\hline
\end{tabular}

III. Zusammensetzung der aus der Anodenzelle entweichenden Gase.

\begin{tabular}{c|r|r|r|r|r|r|r|r|r}
\hline $\begin{array}{c}\text { Zeit nach Beginn } \\
\text { der Elektrolyse }\end{array}$ & 2 Std. & 4 Std. & 7 Std. & 9 Std. & $9 \% / 4$ Std. & 14 Std. & 15 Std. & 16 Std. \\
\hline$\%$ \% Sauerstoff & 0.54 & 1.9 & 5.4 & 7.1 & 7.6 & 10.3 & 10.6 & 12.1 \\
$\%$ Chlor & 99.46 & 98.1 & 94.6 & 92.9 & 92.4 & 89.7 & 89.4 & 87.9
\end{tabular}

War durch die vorangehenden Versuchsreihen der zeitliche Verlauf des Diaphragmenprozesses bei gewöhnlicher Temperatur klargestellt, so war schliefslich nur noch zu untersuchen, welchen Einflufs eine Abänderung der bei den vorigen Versuchen konstant gehaltenen Arbeitsbedingungen, der Chloridkonzentrationen im Kathoden- und im Anodenraum oder der Stromstärke, auf die Erscheinungen haben würde. Dies geschah durch die Versuche der Reihe $\mathrm{D}$, welche im übrigen ganz so wie die der Reihe $\mathrm{C}$ durchgeführt wurden.

\section{Versuchsreihe D.}

I. Untersuchungen in der Kathodenflüssigkeit.

\begin{tabular}{|c|c|c|c|c|c|c|c|}
\hline \multirow{2}{*}{ 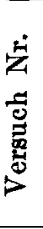 } & \multirow[b]{2}{*}{$\begin{array}{c}\text { Versuchs- } \\
\text { bedingungen }\end{array}$} & \multicolumn{2}{|c|}{ Chlorkalium } & \multicolumn{2}{|c|}{ Kalihydrat } & \multirow{2}{*}{\begin{tabular}{|} 
Im \\
Kupfer- \\
voltamet. \\
abge- \\
schiedene \\
Menge Cu \\
in g
\end{tabular}} & \multirow{2}{*}{$\begin{array}{l}\text { Stromaus- } \\
\text { beute an } \\
\text { Alkali in } \\
\text { Hundert- } \\
\text { teilen der } \\
\text { theo- } \\
\text { retischen }\end{array}$} \\
\hline & & $\begin{array}{l}\text { yor dem } \\
\text { Versuch } \\
\text { in } \mathbf{g}\end{array}$ & $\begin{array}{l}\text { nach dem } \\
\text { Versuch } \\
\text { in } g\end{array}$ & $\begin{array}{l}\text { ent- } \\
\text { standene } \\
\text { Gesamt- } \\
\text { menge } \\
\text { in g }\end{array}$ & $\begin{array}{c}\text { in } 100 \mathrm{ccm} \\
\text { vor- } \\
\text { handene } \\
\text { Menge } \\
\text { in } \mathrm{g}\end{array}$ & & \\
\hline 14 & $\begin{array}{l}10 \text { Std. mit } 5 \text { Amp. } \\
\text { u. auf die Hälfte } \\
\text { verminderter Kon- } \\
\text { zentration der Ka- } \\
\text { thodenlauge }\end{array}$ & 72.3 & 41.9 & 67.11 & 9.4 & 60.23 & 63.1 \\
\hline 15 & $\begin{array}{l}10 \text { Std. mit } 5 \text { Amp. } \\
\text { u. auf die Hälfte } \\
\text { verminderter Kon- } \\
\text { zentration der } \\
\text { Anodenlauge }\end{array}$ & 144.6 & 109.3 & 71.32 & 9.5 & 60.03 & 67.2 \\
\hline 16 & $\left.\begin{array}{c}50 \text { Std. mit } 1 \mathrm{Amp} . \\
\text { u. den früher be- } \\
\text { nutzten Konzen- } \\
\text { trationsverhält- } \\
\text { nissen }\end{array}\right\}$ & 143.0 & 113.5 & 70.46 & 9.8 & 67.00 & 59.3 \\
\hline
\end{tabular}


II. Zusammensetzung der Anodenlauge.

\begin{tabular}{|c|c|c|c|c|c|c|c|}
\hline \multirow{2}{*}{ 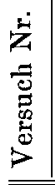 } & \multirow[b]{2}{*}{$\begin{array}{l}\text { Versuchs- } \\
\text { bedingungen }\end{array}$} & \multicolumn{2}{|c|}{ Chlorkalium } & \multirow{2}{*}{$\begin{array}{c}\text { Kalium- } \\
\text { chlorat } \\
\text { nach dem } \\
\text { Vers. in } \\
\mathrm{g}\end{array}$} & \multirow{2}{*}{$\begin{array}{l}\text { Unter- } \\
\text { ehlorige } \\
\text { Säure } \\
\text { nach dem } \\
\text { Vers.in g }\end{array}$} & \multirow{2}{*}{$\begin{array}{l}\text { Chlorat- } \\
\text { sauer- } \\
\text { stoff in } \\
\mathrm{g} \text { auf } \\
100 \mathrm{ccm}\end{array}$} & \multirow{2}{*}{$\begin{array}{l}\text { Hypo- } \\
\text { chlorit- } \\
\text { sauerstoff } \\
\text { in g anf } \\
100 \mathrm{ccm}\end{array}$} \\
\hline & & $\begin{array}{l}\text { vor dem } \\
\text { Versuch } \\
\text { in } g\end{array}$ & $\begin{array}{l}\text { nach dem } \\
\text { Versuch } \\
\text { in } g\end{array}$ & & & & \\
\hline 14 & $\begin{array}{c}\text { Mit halber Konzen- } \\
\text { tration der Katho- } \\
\text { denlauge }\end{array}$ & 144.6 & 66.07 & 7.23 & 5.94 & 0.567 & 0.362 \\
\hline 15 & $\begin{array}{c}\text { Mit halber Konzen- } \\
\text { tration d. Anoden- } \\
\text { lauge }\end{array}$ & 72.3 & 3.24 & 6.02 & 1.26 & 0.472 & 0.077 \\
\hline 16 & $\begin{array}{l}\text { Mit } 1 \text { Amp. wäh- } \\
\text { rend } 50 \text { Std. }\end{array}$ & 143.0 & 64.5 & 6.86 & $4: 95$ & 0.537 & 0.302 \\
\hline
\end{tabular}

III. Sauerstoffgehalt des aus der Anodenzelle entweichenden Gases in $\%$.

\begin{tabular}{|c|c|c|c|c|c|}
\hline $\begin{array}{c}\text { Versuch } \\
\text { Nr. }\end{array}$ & Nach 2 Std. & Nach 4 Std. & Nach 7 Std. & Nach 9 Std. & Nach $9^{3} /{ }_{4}$ Std. \\
\hline 14 & 0.66 & 3.24 & 7.00 & 8.10 & - \\
\hline 15 & 0.90 & 3.32 & 8.3 & $\begin{array}{c}14.4 \\
\text { Nach } 45 \text { Std. }\end{array}$ & 16.3 \\
\hline 16 & - & - & - & 12.3 & - \\
\hline
\end{tabular}

a) Erörterung der Versuchsergebnisse.

Die Betrachtung der in der Reihe A gewonnenen Zahlen, sowie ein Vergleich der entsprechenden der Reihe B zeigt, dals die unter gleichen Bedingungen gefundenen Werte nicht immer völlig miteinander übereinstimmten. Das darf aber bei Zahlen, welche von so mannigfachen Einflüssen gleichzeitig abhängen wie die obigen, und bei deren Bestimmung stets von kleinen Lösungsproben auf grolse Volumina gerechnet werden mulste, nicht Wunder nehmen. Die unter Weglassung offenbar fehlerhafter, in obigen Übersichten mit ? bezeichneter Zahlen gewonnenen Mittelwerte der Reihe A stimmen mit den Ergebnissen der Reihe $B$ genügend überein, um gemeinsam für den Verlauf der hier in Rede stehenden Erscheinungsreihen als mafsgebend gelten zu können.

\section{Die Alkaliausbeute}

nimmt ihrem Gesamtwert nach immer mehr ab, je mehr im Kathodenraum die Konzentration des Alkalihydrats wächst. Diese von der Theorie vorausgesehene Thatsache, die auch die Fogr'schen wie die 
WINTELER'schen Versuche bestätigen, ist ja, wie wohl allgemein bekannt, der grolse, dem Diaphragmenprozels anhaftende Mangel.

Wie oben gezeigt, rührt diese Erscheinung daher, dafs die Einzelalkaliausbeuten in verschiedenen aufeinander folgenden Zeitabschnitten derselben Elektrolyse um so kleiner werden, je mehr vorher schon die Konzentration des Alkalihydrats in der Kathodenlösung gewachsen war. Die folgende Übersicht soll die bei Versuch 3 nacheinander betrachteten Einzelausbeuten an Alkalihydrat zeigen. Gleichzeitig enthält sie die Werte der Stromausbeute, welche nach der Formel $\left(b_{z}\right)$ aus den am Ende eines jeden Zeitabschnitts in der Kathodenlauge herrschenden Konzentrationsverhültnissen eben für diesen Augenblick berechnet wurden. Die Werte von $c_{1}$ und $\alpha_{1}$ beziehen sich auf das Chlorid, von $c_{2}$ und $\alpha_{2}$ auf das Hydrat; sie haben die ihnen oben gegebene Bedeutung.

\begin{tabular}{|c|c|c|c|c|c|c|c|c|}
\hline $\begin{array}{c}\text { Zeit- } \\
\text { abschnitt } \\
\text { des Ver- } \\
\text { suches }\end{array}$ & $\begin{array}{l}\text { Ent- } \\
\text { standene } \\
\text { Alkali- } \\
\text { menge } \\
\text { in } \mathrm{g}\end{array}$ & \begin{tabular}{|} 
Gleich- \\
zeitig vom \\
Strom \\
niederge- \\
schlag. \\
Cu in g
\end{tabular} & $\begin{array}{c}\text { Alkali- } \\
\text { stromaus- } \\
\text { beute in } \\
\text { dem betr. } \\
\text { Zeit- } \\
\text { abschnitt }\end{array}$ & $c_{1}$ & $\alpha_{1}{ }^{1}$ & $c_{2}$ & $\alpha_{g}{ }^{1}$ & $\begin{array}{c}\text { Berechnete } \\
\text { Stromaus- } \\
\text { beute am } \\
\text { Ende des } \\
\text { Zeit- } \\
\text { abschnitts }\end{array}$ \\
\hline $\begin{array}{l}\text { die ersten } \\
2 \text { Std. }\end{array}$ & 17.78 & 11.47 & 88.06 & 0.2382 & 0.69 & 0.0418 & 0.85 & $79.2 \%$ \\
\hline $\begin{array}{c}\text { die zweit. } \\
\text { 2 Std. }\end{array}$ & 14.29 & 11.71 & 69.30 & 0.2224 & 0.69 & 0.0754 & 0.80 & 69.3 \\
\hline $\begin{array}{l}\text { die dritten } \\
\text { 2 Std. }\end{array}$ & 13.60 & 11.61 & 66.50 & 0.2096 & 0.70 & 0.1071 & 0.78 & $62.6 "$ \\
\hline $\begin{array}{c}\text { die vierten } \\
2 \text { Std. }\end{array}$ & 11.11 & 11.85 & 58.02 & 0.2066 & 0.70 & 0.1331 & 0.74 & $55.0 "$ \\
\hline
\end{tabular}

Gesamte Alkaliausbeute gefunden: $69.1 \%$.

berechnet: 70.0 ,"

Man bemerkt, wenn man von dem offenbar zu niedrig gefundenen Wert im zweiten Zeitabschnitt absieht, dals die beobachteten Zahlen sich zwischen den Werten der Ausbeute halten, welche die Rechnung für den Anfang und das Ende des betreffenden Zeitabschnittes erwarten lärst.

Ähnliche Ergebnisse liefern andere Versuche der Reihe A. Man könnte daraus schlielsen, dafs die der Formel (b) zu Grunde liegen-

${ }^{2}$ Die Werte von $\alpha_{1}$ und $\alpha_{2}$ wurden nach den oben angegebenen graphisch interpoliert.

2 Setzt man willkürlich $\frac{\alpha_{1}}{\alpha_{2}}=1$, so berechnen sich die Stromausbeuten zu $81.3 ; 70.4 ; 62.6$ bezw. $55.0 \%$. 
den Uberführungsverhältnisse doch nahezu ausschliefslich bestimmend wären für die Alkaliausbeute und demnach den ganzen Verlauf des Diaphragmenprozesses.

Dennoch aber handelt es sich hier wohl nur um eine zufällige Ubereinstimmung, indem unter den in den Reihen A und B eingehaltenen Versuchsbedingungen die gegen einander wirkenden Einflüsse der freiwilligen Diffusion und der elektrischen Endosmose sieh ungefähr aufgehoben haben. Wie die Theorie lehrt, wird aber mit abnehmender Stromstärke unter sonst gleichen Bedingungen der Einflufs der Diffusion besonders herrortreten, um so mehr als auch dann der Druck der elektrischen Endosmose sich vermindert.

Dies lebrt besonders auffallend ein Vergleich von Versuch 12 und 16. Am Schlufs herrschte bei ihnen im Kathodenraum nahezu die gleiche Konzentration für Alkalichlorid und Alkalihydrat, und doch ist bei Versuch 12 die Alkaliausbeute $69.9 \%$, bei Versuch 16 aber, wo nur mit $1 / 5$ der Stromstärke die gleiche Alkalimenge erreicht wurde, $59.3 \% 0^{.}$

Vergleicht man aber mit diesen Stromausbeuten die Spannungen, mit denen sie erhalten wurden, so ergiebt sich, dals die Verbesserung jener durch Erhöhung der Stromstärke verhältnismälsig geringer war, als der dazu nötige Mehraufwand an Spannung.

Diese war bei Versuch $12 \mathrm{im} \mathrm{Mittel}=3.7 \mathrm{Volt} ; 10$ Wattstunden $=3.94 \mathrm{~g} \mathrm{KOH}$ und $" \quad 16, \quad "=2.85 " 10 \quad, \quad=4.38, "$,

Man sieht also, dafs es keineswegs günstig ist, den Diaphragmenprozels mit sehr hoher Stromdichte am Diaphragma zu betreiben, und dal's es nur gerechtfertigt ist, wenn die Technik, wie verlautet, diese Stromdichte auf $0.01 \mathrm{Amp} . / \mathrm{qcm}$ herabsetzt. Da ja mit zunehmen-

1 Um einen ungefähren Überschlag über den Grad der Steigerung der durch die freiwillige Diffussion hervorgebrachten Alkaliverluste zu erhalten, wurde eine Purans'sche Thonzelle mit Normal-Kalilauge so beschickt, dafs diese auch ihre Poren entfällte, und dann in eine grofse Mengen lebhaft bewegten Wassers eingestellt. Als dann verliefsen durch jedes Quadratdezimeter der Oberfläche in der ersten Stunde $0.14 \mathrm{~g} \mathrm{KOH}$ die Zelle. Würde man durch Elektrolyse eine Normal-Kalilauge erhalten haben, und würde diese sich während einer Stunde durch die weitere Elektrolyse nur unbedeutend weiter konzentrieren, so wurde bei $1.6 \mathrm{Amp} / \mathrm{qdm}$. der durch Wanderung vor sich gehende Alkaliverlust nach der Formel $\left(b_{2}\right) 1.17 \mathrm{~g} \mathrm{KOH}$ betragen und die Diffusion würde das in der Kathodenzelle neu verbleibende Alkali um $7 \%$ vermindern. Bei 2-fach normaler Kalilauge ergaben sich die entsprechend bestimmten Werte zu $1.59 \mathrm{~g}$ Kaliverlust dürch Wanderung and $0.24 \mathrm{~g}$ Kaliverlust durch Diffussion, was durch die Alkaliausbeute in der hier in Betracht gezogenen Stunde einen Verlust von 14\% ihres Wertes erleidet. Beträgt dieser Verlust $100 \%$ der nach den Überführungsverhältnissen zu erwartenden Stromausbeute, so ist die wirkliche Alkaliausbeute gleich Null. 
der Alkalität im Kathodenraum auch das den Diffusionsvorgang beherrsehende Konzentrationsgefälle des Alkalis steigt, so wird; wenn man anf eine geringere Alkalikonzentration, als sie bei Versuch 12 und 16 erreicht wurde, hinarbeitet, der Einflufs der Diffusion und damit die Verminderung der Stromausbeute durch Anwendung kleinerer Stromstärken geringer als in obigem Beispiel: Andererseits wird bei immer weiter abnehmender Stromstärke die Verminderung der Spannung verhältnismäfsig immer kleiner, indem diese sich dem Werte der Polarisation der Zelle, 2.3 Volt in unserem Falle, immer mehr nähert. Alsdann werden die immer gröfser werdenden Stromverluste durch Diffusion schliefslich auch die Energieausbeute herabsetzen; man wird also allzu niedrige Stromdichten am Diaphragma vermeiden, was für praktische $Z$ wecke sich ja ohnedies von selbst versteht.

Dafs auch das im Kathodenraum herrschende Verhältnis der Chlorid- zur Hydratkonzentration nicht in dem Umfange mafsgebend ist, wie es die Formel $\left(b_{2}\right)$ verlangt, zeigen ferner die Versuche 12 und 14. Denn während dort am Schlufs des Versuchs ist: $c_{1}: c_{2}=$ $0.2001: 01762$ und danach eine Stromausbeute von $52.5 \%$ in den letzten Stadien des Versuchs noch herrschen mülste, ist hier, infolge der geringen anfänglichen Chloridkonzentration im Kathodenranm, schliefslich $c_{1}: c_{2}=0.054: 0.168$, und danach dürfte die Endausbeute nur $28 \%$ betragen. Die beobachtete Verminderung der Gesamtalkaliausbeute von 69.9 auf $63.1 \%$ erscheint demgegenüber verhältnismälsig geringfügig; sie erklärt sich, wenn man bedenkt, dals bei Versuch 14 am Schlufs in der Anodenzelle noch eine ziemlich hohe Chloridkonzentration herrschte, demgemäls auch im Diaphragma diese erheblich gröfser sein mufste, als im Kathodenraum. Man wird natürlich Ausbeuteverluste durch allzu starke Verminderung der kathodischen Chloridkonzentration möglichst vermeiden und letztere zu Anfang zweckmälsig so hoch wählen, dals auch nach Erreichung der gewünschten Alkalikonzentration das Verhältnis $\frac{c_{1}}{c_{2}}$ immer noch gröfser ist als 1 ; geht man von 2-2.5 fach normalen Chloridlösungen aus, so ist bei unserer Versuchsanordnung dieser Bedingung für die mit befriedigender Stromausbeute zu erzielenden Alkalikonzentrationen in jedem Falle genügt.

Wird, wie bei Versuch 15, die Chloridmenge in der Anodenzelle von vornherein niedrig gewählt, so ist zwar im Diaphragma eine ähnliche Chloridkonzentration zu erwarten wie bei Versuch 14; 
aber hier wandert, da im Kathodenraum die gewöhnliche Chloridmenge vorhanden ist, weniger Hydroxyl als dort in das Diaphragma ein, und daher wird hier auch die Chloridausbeute nur von 69.9 auf $67 \%$ herabgesetzt.

Aus allen diesen Vergleichen folgt, dafs je mehr man eine sehr grofse Verminderung der Chloridkonzentration im Anoden- und Kathodenraum vermeidet, und je weniger weit man die Alkalikonzentration in diesem etwa über die einer Normallösung herauftreibt, um so eher man sich der Formel (b) zur ungefähren Orientierung über die zu erwartenden Alkaliausbeuten wird bedienen dürfen. Hierbei ist immer vorausgesetzt, dafs die von uns getroffene einfache Versuchsanordnung herrscht und keine besonderen Vorkehrungen benutzt sind, um die Alkaliverluste einzuschränken.

Die ungefähre Übereinstimmung der von uns in der Reihe A und $\mathrm{B}$ beobachteten Stromausbeuten an Alkalihydrat mit den aus den Überführungsverhältnissen berechneten zeigt, dafs wir den für die betreffenden Konzentrationsverhältnisse ohne besondere Vorkehrungen zu erreichenden Ausbeuten ziemlich nahe gekommen sind. Auch Winteler hat mit Diaphragmen aus Pukall'scher Thonmasse gearbeitet und ist von 20\% iger Chlorkaliumlösung ausgegangen. Soweit ein Vergleich seiner Ergebnisse mit den unseren möglich ist, zeigt sich, dafs beide Versuchsreihen ungefähr übereinstimmen:

\begin{tabular}{|c|c|c|c|}
\hline $\begin{array}{l}\text { WIN'ELLer erhielt } \\
\text { eine Kathoden- } \\
\text { lauge von }\end{array}$ & $\begin{array}{c}\text { mit einer } \\
\text { Stromausbeute }\end{array}$ & $\begin{array}{c}\text { Wir erhielten } \\
\text { eineKathoden- } \\
\text { lauge von }\end{array}$ & $\begin{array}{l}\text { mit einer Strom- } \\
\text { ausbeute von }\end{array}$ \\
\hline $5.26 \% \mathrm{KOH}$ & $85.1 \%$ & $4.3 \%$ & $78.4 \%$ \\
\hline $8.03 "$, & $70.7 \%$ & $8.3 "$ & 72.6, \\
\hline 11.37, & 68.9, & 11.2, & 68.4, \\
\hline
\end{tabular}

Beim Arbeiten mit Diaphragmen von weniger günstigen Eigenschaften als sie gerade die Puratu'sche Thonmasse für unseren Zweck liefert, dürften die gleichen Alkalikonzentrationen wohl mit etwas geringerer Stromausbeute erreicht werden.

\section{Die Chlorausbeute}

ist, wie die Versuchsreihen $\mathrm{A}$ und $\mathrm{B}$ übereinstimmend zeigen und die Theorie es verlangt, fast ausnahmslos niedriger als die Alkaliausbeute. Besonders im ersten Stadium der Elektrolyse tritt dies sehr deutlich hervor, solange noch im wesentlichen Hypochloritsauerstoff und nur ganz wenig Chloratsauerstoff in der Anodenzelle entsteht. Alsdann, wenn die Chloratbildung an Umfang gewinnt, und die Chloridkonzentration immer mehr sich Werten nähert, bei denen 
eine erheblichere Salzsäurebildung in Frage kommen kann, nimmt der Unterschied zwischen beiden Ausbeuten immer mehr ab, um schliefslich zu verschwinden.

Die Chloridkonzentration im Kathoden- und im Anodenranm ist besonders von der Einwirkung der elektrischen Endosmose betroffen.

Würde kein Alkalihydrat sich an der Stromleitung bethätigen, so mülsten in je 2 Stunden unter den in Reihe A und B innegehaltenen Versuchsbedingungen, also auf je 10 Ampèrestunden, aus der Anoden- und Kathodenlösung zusammen $27.76 \mathrm{~g}$ Chlorkalium verschwinden, und zwar, wie die Theorie lehrte, aus jeder von ihnen etwa die Hälfte dieses Betrages. Das letztere mülste nach den früheren Darlegungen auch noch, wenigstens annähernd, zutreffen, wenn infolge der Anteilnahme der Hydroxylionen an den Wanderungsvorgängen, weniger als $27.76 \mathrm{~g}$ Chlorkalium in 2 Stunden verbraucht werden. In Wirklichkeit aber liegen bei unseren Versuchen die Dinge ganz anders; es betrug nämlich z. B. in der Reihe B der Verlust an Chlorkalium

$\begin{array}{cccc} & & \text { für die Kathodenlauge } & \text { für die Anodenlauge } \\ \text { in den zweiten 2 Std. } & 8.3 \mathrm{~g} & 13.3 \mathrm{~g} \\ \text { " " dritten } " & 4.0 " & 13.35 " \\ " \text { " vierten } " & 5.6, & 18.07 " \\ " \text { " fünften } " & 0.5 " & 18.71 "\end{array}$

Es nahm also die Chloridmenge im Anodenraum viel stärker ab als im Kathodenraum und wurde hier sogar schliefslich fast konstant. Das kann nur daher rühren, dafs der durch elektrische Endosmose aus der Anodenzelle zugeführte Betrag an Chlorkalium den aus dem Kathodenraum wegwandernden immer vollständiger zu ergänzen vermag.

In der That stieg auch bei den Versuchen der Reihe $\mathrm{E}$ und B stets das anfängliche Volumen der Kathodenlösung von $700 \mathrm{ccm}$ anf 740-760 $\mathrm{ccm}$, und um die gleichen Beträge sank die Menge der Anodenlauge. Schon bald nach Beginn der Elektrolyse stellt sich ein Niveauunterschied zwischen Kathoden- und Anodenraum heraus; er steigert sich dauernd, da mit abnehmender Konzentration der Anodenlauge ihre Neigung, nach dem Kathodenraum zu strömen, zunimmt. Bei Versuch 11 war schliefslich nach 17 stündiger Elektrolyse die Kathodenlauge auf $850 \mathrm{~cm}$ angewachsen und die Chloridmenge in ihr höher als bei dem um 5 Stunden kürzeren Versuch 10, während im Anodenraum die Lauge nur noch $0.35 \mathrm{~g} \mathrm{KCl}$ in $100 \mathrm{ccm}$ enthielt. Wurde nun bei Versuch 13 die Anodenlauge 
von dem Druck der bei den Reihen A und B vorgelegten Natronlauge befreit, so war die Menge der aus der Anodenzelle austretenden Chloridlösung erheblich niedriger; die Kathodenlauge stieg nur noch auf $750 \mathrm{ccm}$ an, verlor in den letzten 7 Stunden der Elektrolyse noch $7.6 \mathrm{~g} \mathrm{KCl}$, und in der Anodenlauge fanden sich dementsprechend am Schlufs des Versuchs noch reichliche Chloridmengen, $4 \mathrm{~g} \mathrm{KCl}$ in $100 \mathrm{ccm}$, vor. Geringer ist der Einflufs, den die Vertauschung der zur Chlorabsorption hestimmten Natronlauge mit der Kalkvorlage ausübt, bei 10 stündiger Elektrolyse, wenngleich auch hier die dadurch hervorgebrachte auf den ersten Blick befremdende, aber nach dem Gesagten selbstverständliche Wirkung einer kleinen Verminderung in der Alkaliausbeute deutlich hervortritt. Die beobachteten Unterschiede sind aber so kleine, dafs wir nicht zu zögern brauchen, die bei den Reihen $\mathrm{B}$ und $\mathrm{C}$ gewonnenen Ergebnisse miteinander zu verknüpfen, besonders die bei der letzteren erhaltenen Werte für die Zusammensetzung der aus der Anodenzelle entweichenden Gase mit den bei Reihe $\mathrm{B}$ gefundenen Änderungen in den Bestandteilen der Anodenlauge in Beziehung setzen dürfen.

\section{Die Chlorsanerstoffverbindungen in der Anodenzelle}

bestehen, in voller Übereinstimmung mit der Theorie, aus freier unterchloriger Säure und chlorsaurem Salz. Alle Versuche ergaben übereinstimmend, dafs sehr nahe die gesamte Menge des in der Anodenlösung rorhandenen Hypochloritsauerstoffes als freie unterchlorige Säure vorlag. Die etwa vorhandene Hypochloritmenge lag den durch die Fehler des Verfahrens gezogenen Grenzen sehr nahe. Folgende Übersicht soll diese für den Diaphragmenprozefs sehr wichtigen Verhältnisse kennzeichnen; sie giebt für eine Anzahl obiger Versuche die für $10 \mathrm{ccm}$ der Anodenlösung verbrauchten Mengen einer Lösung von arseniger Säure $(1 \mathrm{ccm}=$ $0.0008 \mathrm{~g} \mathrm{O}$ ), sowie die nach Umsetzung der gleichen Lösungsmenge mit Wasserstoffsuperoxyd zur Neutralisation benutzte Menge von Normalnatronlauge an, welche ja, wenn reine unterchlorige Säure vorlag, $1 / 20$ von jener betragen mufste.

$\begin{array}{cccc}\begin{array}{c}\text { Versuch } \\ \text { Nr. }\end{array} & \begin{array}{c}\text { Verbrauchte } \\ \text { cem- } \mathrm{As}_{\mathbf{2}} \mathrm{O}_{\mathbf{3}} \text {-Lösung }\end{array} & \begin{array}{c}\text { Verbrauchte ccm } \\ \text { gef. }\end{array} & \begin{array}{c}\text { Natronlauge } \\ \text { ber. }\end{array} \\ 5 & 9.6 & 0.59 & 0.48 \\ 6 & 29.0 & 1.38 & 1.45 \\ 7 & 36.15 & 1.70 & 1.81 \\ 8 & 52.8 & 2.56 & 2.64 \\ 9 & 47.3 & 2.34 & 2.36 \\ 10 & 39.3 & 1.86 & 1.96 \\ 11 & 11.07 & 0.60 & 0.55\end{array}$


Da die Anodenlauge unterchlorige. Säure enthält, so wird sie auch nach Schluls der Elektrolyse ihre Zusammensetzung noch ändern, indem jene dem vorhandenen Chlorid gegenüber ihre chloratbildende Thätigkeit fortsetzt. Dabei mufs nach den Gleichungen (3) und (4) ebensoviel Hypochloritsauerstoff in Chloratsauerstoff übergehen, als durch Entweichen von freiem Chlor an aktivem Sauerstoft aus der Lösung verloren wird. Wird also die Anodenlauge auch als bald nach Schlufs der Elektrolyse durch längeres Einblasen eines Luftstromes von Chlor befreit, so entsteht dieses doch bald wieder von neuem. Die folgende Übersicht zeigt die Änderungen der Anodenlauge, welche sich nach 20-stündigem Stehen bei gewöhnlicher Temperatur und unter Lichtabschlufs vollzogen.

\begin{tabular}{|c|c|c|c|c|c|c|}
\hline \multirow{2}{*}{ 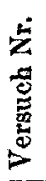 } & \multicolumn{2}{|c|}{$\begin{array}{c}\text { Am Schlufse der } \\
\text { Elektrolyse }\end{array}$} & \multicolumn{2}{|c|}{$\begin{array}{cl}\text { Nach } & 20 \text {-stündigem } \\
\text { Stehen }\end{array}$} & \multirow{2}{*}{$\begin{array}{l}\text { Zunahme } \\
\text { des } \\
\text { Chlorat- } \\
\text { sauerstoffes } \\
\text { in } \mathrm{g}\end{array}$} & \multirow{2}{*}{$\begin{array}{c}\text { Abnahme } \\
\text { des gesamten } \\
\text { aktiven } \\
\text { Sanerstoffes } \\
\text { in } g\end{array}$} \\
\hline & $\begin{array}{l}\text { g Hypo- } \\
\text { chlorit- } \\
\text { sauerstoff }\end{array}$ & $\begin{array}{c}\mathrm{g} \\
\text { Chlorat- } \\
\text { sauerstoff }\end{array}$ & $\begin{array}{l}\text { g Hypo- } \\
\text { chlorit- } \\
\text { sauerstoff }\end{array}$ & $\begin{array}{c}\text { Chlorat- } \\
\text { sauerstoff }\end{array}$ & & \\
\hline 5 & 0.0769 & 0.0067 & 0.0587 & 0.0163 & 0.0096 & 0.0091 \\
\hline 6 & 0.232 & 0.025 & 0.174 & 0.0491 & 0.024 & 0.034 \\
\hline 7 & 0.289 & 0.091 & 0.193 & 0.124 & 0.033 & 0.065 \\
\hline 8 & 0.422 & 0.178 & 0.254 & 0.243 & 0.065 & 0.103 \\
\hline 9 & 0.878 & 0.314 & 0.211 & 0.385 & 0.071 & 0.096 \\
\hline 10 & 0.314 & 0.509 & 0.221 & 0.561 & 0.059 & 0.044 \\
\hline
\end{tabular}

Berücksichtigt man, dals beim Abblasen des in der Lauge gelösten Chlors stets auch etwas unterchlorige Säure sich verflüchtigt, so kann man diese Beobachtungsreihe als weitere Bestätigung der Thatsache ansehen, dafs der Hypochloritsauerstoff beim Diaphragmenprozefs in der Anodenlösung fast ausschliefslich in der Form von freier unterchloriger Säure zugegen ist.

Die Menge des in der Anodenlösung vorhandenen gesamten aktiven Sauerstoffes könnte man versucht sein, mit der aus. der Kathodenlösung verschwundenen Alkalimenge in Vergleich zu setzen, da die Theorie lehrt, dafs 1 Atom des Hypochloritsauerstoffes ans einem, 1 Atom Chloratsauerstoff aber aus zwei in den Anodenraum gelangten Hydroxylen entstanden ist. Eine solche Rechnung ist aber vorderhand nicht durchführbar. Denn abgesehen davon, dafs der Alkaliverlust infolge der Vernachlässigung der im Diaphragma verbliebenen Lösungsmenge bei unseren Versuchen etwas zu hoch erscheint, mufs der in der Lösung gefundene aktive Sauerstoff nur 
ein Teil des wirklich entstandenen sein, da er mancherlei dauernde Verminderungen erfährt, und zwar

1. durch die oxydierende Bethätigung der unterchlorigen Säure gegenüber dem Chloridgehalt der Lösung;

2. durch anodische Salzsäureentwickelung;

3. durch Verflüchtigung von unterchloriger Säure.

Der Verlust aus dem ersten Grunde kann, wie die letzte Übersicht lehrt, in 20 Stunden etwa 10 v. H. des gesamten aktiven Sauerstoffes betragen.

Die Verflüchtigung der unterchlorigen Säure wird durch das aus der Lösung entweichende Chlorgas befördert; sie wird, da bei ihrer sehr geringen elektrolytischen Dissoziation die unterchlorige Säure dem HenrY'schen Gesetz folgen muls, bei gleich lebhafter Chlorentwickelung in gleichen Zeiten sich immer auf gleiche Bruchteile der vorhandenen unterchlorigen Säure erstrecken. Bei der grofsen Löslichkeit der letzteren in Wasser sind diese bei gewöhnlicher Temperatur nur geringe: eine etwa $0.5 \mathrm{~g}$ aktiven Sauerstoff in $100 \mathrm{ccm}$ enthaltende Lösung von freier unterchloriger Säure verlor, bei $18^{\circ}$ vou einem Luftstrom lebhaft durchblasen, in je 2 Stunden etwa 3 v. H. ihres Gehalts. Bei den für den Diaphragmenprozels technisch viel verwendeten höheren Temperaturen sind diese Verluste jedenfalls sehr viel bedeutender, und der dadurch dem elektrolytisch entwickelten Chlor erteilte Gehalt an unterchloriger Säure ist vielleicht für manche, z. B. bei organischen Chlorierungen, sich bemerkbar machenden Eigentümlichkeiten des auf die genannte Weise gewonnenen Chlors verantwortlich zu machen.

Am wenigsten läfst sich zur Zeit Bestimmtes über den möglichen Umfang der durch die anodische Salzsäurebildung veranlafsten Verluste an aktivem Sauerstoff sagen. Unsere hier mitgeteilten Versuche geben nach dieser Richtung hin noch keinen sicheren Anhalt. Da aber diese Frage nach mehrfachen Seiten hin von Bedeutung ist, hat es Herr Dr. SonNeborn im hiesigen Laboratorium übernommen, ibre Beantwortung auf experimentellem Wege zu versuchen, und zwar unter Benutzung der von BEIN ${ }^{2}$ für diese Fälle als ,typisch" bezeichneten Versuchsanordnung mit einer den Kathodenund Anodenraum trennenden Flüssigkeitsschicht. Neuerdings hat ja diese Arbeitsweise auch ein grofses technisches Interesse gewonnen. ${ }^{2}$

1 Zeitschr. Eleletrochem. (1896).

2 Vgl. Patent des Österreichischen Vereins für chemische und elektrometallurgische Produktion. Zeitschr. Eleltrochem. 5. 407. 
Es hat sich dabei ergeben, dafs eine auf anodischer Hydroxylentladung beruhende Salzeäurebildung in der That schon bei den höchst konzentrierten Chloridlösungen eintritt, dals ihr Umfang aber ein recht geringfügiger ist, so lange der Chloridgehalt der Anodenlösung noch über demjenigen einer Normallösung liegt. Nähere Mitteilungen hierüber sollen baldmöglichst erfolgen.

Der zeitliche Verlauf der Bildung von unterchloriger Säure wird auf beistehender Kurventafel (Fig. 3) durch Kurve I wiedergegeben, wobei die Abscissen die Zeiten, die Ordinaten die Mengen an Hypo-

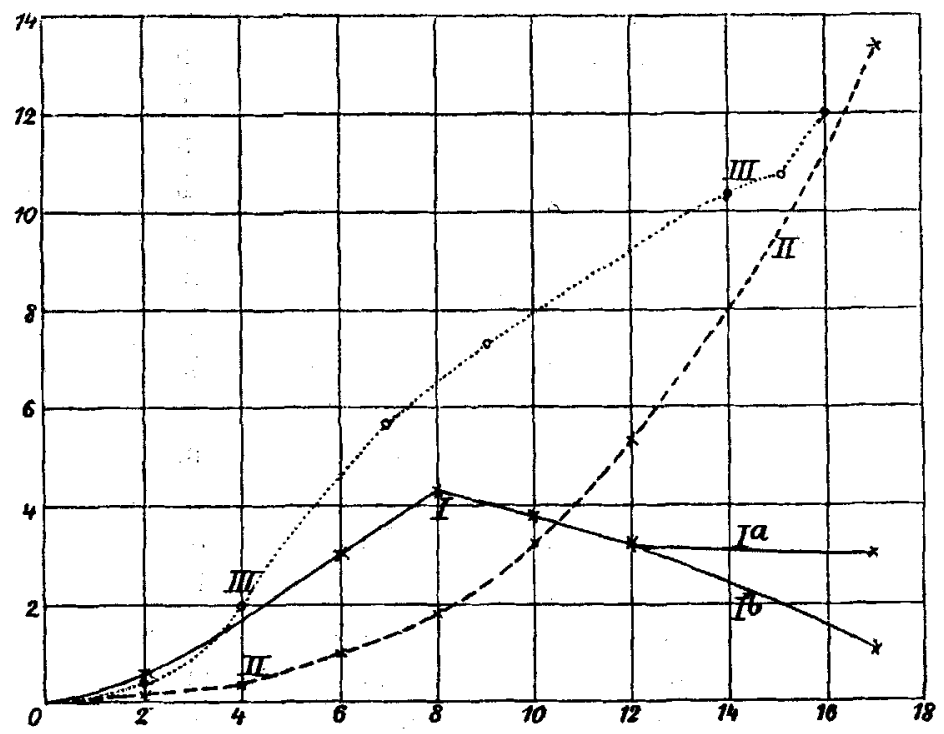

Fig. 3.

chloritsauerstoff in $100 \mathrm{ccm}$, ausgedrückt in Dezigrammen, bedeuten. Man sieht, der Theorie entsprechend, erreicht diese Kurve ein Maximum, und zwar bei Reihe A und B ubereinstimmend dann, wenn die Kathodenlösung in Bezug auf freies Alkali 1.4-1.5 fach normal, die Anodenlösung in Bezug auf Alkalichlorid etwa 2 fach normal war. Bis dahin steigt die Kurve ziemlich geradlinig an, infolge des von der Theorie angezeigten Umstandes, dafs mit der Zeit zwar immer mehr Hydroxyl in die Anodenzelle dringt, dieses aber auch immer weniger zur Steigerung des Gehalts an unterchloriger Säure beiträgt. Ist das Maximum erreicht, so fällt nun die. Hypochloritmenge langsam wieder ab. Inwieweit hiervon, aufser dem von der Theorie schon gegebenen Grunde auch eine durch die Abnahme der Chloridkonzentration bedingte, gesteigerte, anodische 
Salisäurebildung die Schuld trägt, mag vorläufig dahingestelit bleiben.

Unzweifelhaft aber tritt in erheblichem Umfange Salzsäurebildung ein, wenn, wie bei Versuch 11 oder 15, die Anodenlauge in Bezug auf Chlorid nur noch $1 / 30-1 / 10$ normal ist. Dann erfolgt ein sehr viel stärkerer Rückgang in der Menge der in der Anodenzelle gefundenen unterchlorigen Säure, als er unter sonst gleichen Verhältnissen eintritt, wenn die Chloridkonzentration in der Anodenlauge weniger tief herabgeht. Der mit Ib bezeichnete, auf Versuch 11 bezügliche Kurventeil bringt die bei grofser Erschöpfung des Chlorids in der Anodenzelle schliefslich auftretenden Änderungen des Hypochloridgehaltes zur Anschauung, während der Ast Ia sich auf Verhältnisse bezieht, bei denen die Chloridkonzentrationen der Anodenlauge noch über derjenigen einer $1 / 2$-normalen Chlorkaliumlösung bleibt. Aber selbst bei stärkstem Rückgange des Chlorids blieb, wie man sieht, niemals freie Salzsäure bei unseren Versuchen in der Anodenlauge bestehen.

Während zufolge der grofsen Verschiedenheit der Entstehungsbedingungen der zeitliche Verlauf der Bildung von Hypochloritsauerstoff beim Diaphragmenprozefs sehr stark von dem von E. MÜLuER ${ }^{1}$ bei der diaphragmenlosen Elektrolyse von Chloralkalilösungen festgestellten abweicht, besteht für die Chloratbildung ein solcher Unterschied nioht. Kurve II zeigt den Verlauf der Zunahme des Chloratsauerstoffes während der fortschreitenden Elektrolyse; als Ordinaten sind wieder die in $100 \mathrm{ccm}$ der Lösung vorhandenen Mengen von Chloratsauerstoff in Dezigrammen aufgetragen. Diese nahmen, ganz wie bei der diaphragmenlosen Alkalichloridelektrolyse anfangs nur langsam, allmählich schneller und schliefslich etwa proportional der Zeit zu. Diese Übereinstimmung ist darauf zurückführbar, dafs in beiden Fällen steigende Mengen von unterchloriger Säure immer wachsenden Konzentrationen von Hypochloriten entgegengeführt werden, und so die Chloratbildung fortschreitet.

In engstem Zusammenhange mit den in der Anodenlösung auftretenden Mengen an unterchloriger Säure steht nach der Theorie auch

\section{der Sauerstoffgehalt des ans der Anodenzelle austretenden Gases.}

Die Änderung desselben im Verlauf einer Elektrolyse, wie sie bei der Versuchsreihe $\mathrm{C}$ gefunden wurde, ist durch Kurve III in obiger Tafel zur Anschauung gebracht; die Ordinaten bedeuten

1 Z. anorg. Chem. 22, 38. 
Hundertteile des Anodengases an Sauerstoff. Man sieht, mit fortschreitender Elektrolyse steigt der Sauerstoffgehalt in dem aus der Anodenzelle entweichenden Gase stetig an.

Für seine Entstehung kommen, wenn man von der nur ausnahmsweise möglichen Beteiligung von $\mathrm{ClO}_{3}$-Ionen an den Anodenvorgängen absieht, nach der Theorie zwei Gründe in Betracht: die anodische Entladung von ClŌ-Ionen oder diejenige von $\mathrm{OH}$-Ionen. Fände die erstere ausschliefslich statt, so würde von dem Zeitpunkte an, wo die Hypochloritkonzentration in der Anodenlauge nicht mehr wächst, der Sauerstoffgehalt in dem an der Anode entwickelten Gase ziemlich konstant bleiben müssen, so lange der Hypochloritsauerstoff sich nicht stärker ändert, als es der Kurve Ia entspricht. Mag auch gleichzeitig die Chloridmenge von $75 \mathrm{~g} \mathrm{KCl}$, welche die Anodenlauge nach 8 Stunden am Schlufs von Versuch 8 aufweist, auf $20 \mathrm{~g} \mathrm{KCl}$, wie sie nach 17 Stunden bei Versuch 13 noch vorhanden waren, herabgehen, so wird das nach den Errahrungen MüLLER's den Betrag der anodischen Sauerstoffentwickelung nur wenig ändern. Freilich ist hier, da die Konzentration der ClÖ. Ionen viel geringer ist, als sie bei gleichem Hypochloritsauerstoffgehalt für die diaphragmenlose Alkalichloridelektrolyse in Betracht kommt, auch trotz der sehr niedrigen anodischen Stromdichte der zur Entladung von ClŌ-Ionen verbrauchte Teil der Stromarbeit viel kleiner, als er ohne Diaphragma für die hier beobachteten Gehalte an Hypochloritsauerstoff gefunden wurde.

Hierbei ist aber zu beachten, dafs, wenn das in der Anodenzelle auftretende Hydroxyd immer freies Chlor bindet, die Zusammensetzung des aus der Anodenzelle entweichenden Gases derjenigen des an der Anode entwickelten Gases nicht entspricht, sondern dafs, auch wenn dieses einen konstanten Sauerstoffgehalt aufweist, derselbe in jenem doch im Verlauf der Elektrolyse dauernd steigen mufs, da immer gröfsere Anteile des Chlors zurückgehalten werden.

Würde die Sauerstoffentwickelung lediglich von einer Entladung von Hydroxylionen herrühren, so mufste diese mit fortschreitender Elektrolyse, also bei abnehmender Chloridkonzentration in der Anodenzelle, immer mehr an Umfang gewinnen, die Sauerstoffmenge im Anodengase also dauernd ansteigen. Die hierbei frei werdende Salzsäure mülste in der Nähe der Anode unterchlorige Säure zerstören; also auch, wenn diese in der übrigen Lösung bestehen bleibt, braucht sie an den anodischen Vorgängen nicht teilzunehmen; ihre Entstehung erfolgt ja am Diaphragma. 
Rührt schliefslich der Sauerstoff des Anodengases gleichzeitig von der Entladung von $\mathrm{ClO}$ - und $\mathrm{O} \overline{\mathrm{H}}$-Ionen her, so wird seine Menge im Anodengase natürlich auch stetig ansteigen, in dem Mafse, als die Elektrolyse fortschreitet.

Es ist also auch aus der Untersuchung des Anodengases kein sicherer Schlufs dahingehend zu ziehen, ob überhaupt und in welchem Umfange etwa Salzsäure an der Anode entsteht, so lange sich noch reichliche Mengen von Hypochloritsauerstoff in der Anodenlauge vorfinden, ihre Chloridkonzentration noch mindestens $1 / 2$ - bis $1 / 4$-norm. ist. Wird aber die Chloridlösung in der Anodenzelle schliêslich sehr verdünnt, wie z. B. bei Versuch 15, so steigt, zumal im letzten Stadium der Elektrolyse, im Anodengase der Sauerstoffgehalt besonders hoch, während die Hypochloritmenge stark abnimmt. Dies bestätigt also nur die aus der letzterwähnten Thatsache schon vorhin gezogene Schlufsfolgerung, dafs unter diesen Bedingungen reichliche Hydroxylentladung an der Anode stattfindet.

Da Haber und Grinberg stets, wenn bei der Elektrolyse von Salzsäure Sauerstoff auftrat, auch eine primäre elektrolytische Bildung von Chlorsäure feststellen konnten, so dürfte auch im vorliegenden Falle, sobald reichliche Hydroxylentladung eintritt, an Stelle der anfangs sekundären eine primäre Chloratbildung erfolgen, also dann, wenn die für jene bestimmende freie unterchlorige Säure eine starke Verminderung erfährt.

\section{B) Versuche mit Kohlenanoden}

(ausgeführt von den Herren Dr. Sieverts und stud. GräFE).

Im vorangehenden war der allgemeine Verlauf der Alkalichloridelektrolyse mit Diaphragma einigermalsen festgestellt, und es konnte nunmehr der Frage nähergetreten werden, inwiefern die bei Anwendung von Platiniridiumanoden beoachteten Erscheinungen eine Änderung erfahren können, wenn jene durch die in der Technik fast ausschliefslich gebrauchten Kohlenanoden ersetzt werden.

\section{a) Theoretische Erörterungen.}

Die Anwendung von Koblenanoden kann naturgemäls nur auf die Erscheinungen in der Anodenzelle von Einflufs sein. Hier entsteht wieder freie unterchlorige Säure, welche jetzt aber aufser gegen das Hypochlorit und Chlorid in der Lösung auch gegen die Substanz der Anode ihre stark oxydierende Wirkung ausüben und 
zur Entstehung von Kohlensäure - in untergeordnetem Mafse wobl auch von Mellitsäure und ähnlichen orgauischen Säuren - Veranlussung geben mufs. Je nach den Oxydationsgeschwindigkeiten durch unterchlorige Säure wird sich deren Wirkung auf das Hypochlorit, das Chlorid und die Kohle verteilen. Es ist aber bekannt, wie aufserordentlich verschieden die chemische Widerstandsfähigkeit der zu Anoden benutzten Kohlensorten ist, je nach ihrer physikalischen Beschaffenheit und dem Grade, in dem sie sich ihrer chemischen Zusammensetzung nach dem reinen Kohlenstoff nähern. Wir werden daher bei wechselndem Kohlenmaterial Erscheinungen zu erwarten haben, welche bald mehr, bald weniger von den an unangreifbaren Elektroden beobachteten sich entfernen.

Je mehr sich die unterchlorige Säure den Kohlen gegenüber bethätigt, um so mehr Salzsäure entsteht aus ihr und kann entweder die erstere aus Hypochlorit wieder erzeugen oder mit anderer unterchloriger Säure freies Chlor geben. Je angreifbarer also die Kohlenanoden sind, um so mehr wird die Menge des in der Anodenlösung verbleibenden aktiven Sauerstoffes abnehmen und statt seiner in den aus der Anodenzelle entweichenden Gasen Kohlensäure auftreten. Je mehr aber die unterchlorige Säure in der Lösung verschwindet, um so weniger wird auch die Chlorausbeute hinter der Alkaliausbeute zurückbleiben.

Die Sauerstoffentwickelung an der Anode wird, soweit sie von der Entladung von ClÖ-Ionen herrührt, sich vermindern, wenn die Hypochloritkonzentration in der Lösung geringer wird; soweit sie von den Anionen des Wassers ausgeht, dürfte sie durch den Austausch von Platiniridiumanoden gegen Kohlenanoden keine merkliche Beeinträchtigung erfahren. Ein meist sehr beträchtlicher Teil des an Kohlenannoden frei werdenden Sauerstoffes entweicht als solcher, der Rest erzeugt Kohlensäure; immerhin werden die Kohlen um so stärker zerstört, je mehr Sauerstoff an ihnen entsteht. So fand ZöLLNRR, ${ }^{1}$ dals in der stark anodischen Sauerstoff entwickelnden $1 \%$ igen Chlornatriumlösung der Angriff verschiedener Kohlen viel lebhafter war, als wenn die Lösung $5 \%$ ig oder gesättigt an Chlornatrium war.

Da nun aber, wie oben dargethan, die anodische Sauerstoffentwickelung in stärkeren Chloridlösungen nur geringe Beträge erreicht, so ist der Schlufs geboten, dafs bei der Elektrolyse

1 Zeitschr. Elektrochem. 5, 454. Die dort für die erwähnte Erscheinung gegebene Erklärung übersieht die Thatsache, dafs in verdünnter Kochsalz. lösung anodisch sehr stark Sauerstoff entwickelt wird. 
nioht allzu stark verdünnter Chloridlösungen die Zerstörung der Anodenkohlen im wesentlichen der Einwirkung freier unterchloriger Säure zur Last zu legen ist.

Dem widerspricht auch nicht die von dem Einen von uns beob. achtete Thatsache, ${ }^{1}$ dals bei der Elektrolyse heifser und starker Nickelchloridlösungen mit Kohlenanoden diese sehr stark angegriffen wurden, obgleich hier weder von der Kathode kommendes Hydroxyl zur Bildung von Hypochlorit oder unterchloriger Säure Anlafs gab, noch auch eine starke Entladung der Anionen des Wassers in Betracht zu ziehen ist.

Diese Erscheinung erhält aber leicht ihre Erklärung durch die schönen Versuchsreihen JAkowkIN's, ${ }^{2}$ welcher nachwies, dafs in Wasser oder wässerigen Lösungen enthaltenes Chlor mit dem Wasser folgendes Gleichgewicht giebt:

$$
\mathrm{H}_{2} \mathrm{O}+\mathrm{Cl}_{2} \rightleftarrows \mathrm{HCl}+\mathrm{HOCl} \text {. }
$$

Bei Anwesenheit von Chloriden in der Lösung wird es nicht ausgeschlossen, sondern nur in dem Malse zu Ungunsten der unterchlorigen Säure verändert, wie es die herrschende Chloridkonzentration dem Massenwirkungsgesetz zufolge erheischt. An Platinanoden wird durch diese immerhin nur geringfügige Hydrolyse des Chlors beim Diaphragmenprozefs die Menge der ohnedies in der Anodenlauge entstehenden unterchlorigen Säure keine erhebliche Vermehrung erfahren. Erfolgt an Kohlenanoden die Einwirkung des Chlors auf Wasser und bethätigt sich hier $1 \mathrm{Mol}$. der dabei entstandenen unterchlorigen Säure, indem sie Kohlensäure erzeugt, so hinterbleiben $2 \mathrm{Mol}$. Salzsäure in der Lösung, von denen die eine $1 \mathrm{Mol}$. der vom Diaphragma kommenden unterchlorigen Säure zerstört, die andere aber auch zurückgeblieben wäre, wenn die letztere von der Anodenkohle reduziert worden wäre. Das Endergebnis dieser Vorgänge ist also dasselbe, als wenn gar keine unterchlorige Säure durch Hydrolyse von gelöstem Chlor entstanden wäre. Dies bleibt so lange richtig, als in der Zeit, in welcher ein aus Chlor und Wasser entstandenes Molekül $\mathrm{HOCl}$ an der Anode verschwindet, am Diaphragma mindestens ein neues davon entsteht. Geschieht dies nicht mehr in genügendem Umfange, so entsteht freie Salzsäure in der Anodenlauge und beeinträchtigt stark die weitere Hydrolyse des Chlors.

1 Zeitschr. Elektrochem. 4, 164.

${ }^{2}$ Zeitschr. phys. Chem. 29, 613. 
Wenn nun gar keine Hydroxyle von der Kathode herandringen und andererseits : die Chloridkonzentration eine irgend erhebliche Beteiligung der OH-Ionen des Wassers an den anodischen Entladungsvorgängen aussehliefst, so ist nur die durch Einwirkung von Chlor auf Wasser entehendo unterohlorige Säure die Veranlassung zum Angriff der Kohlenanoden. Daher sind diese bei der Elektrolyse starker Salzsäure so beständig, da hier auch die Hydrolyse des Chlors nur sehr geringfügig sein kann. Da andererseits dieser Vorgang als endothermischer mit steigender Temperatur seine Geschwindigkeit steigert und auch die Kohle von unterchloriger Säure dann lebhafter oxydiert wird, so unterliegt es keinem Zweifel, dafs man den Zerfall der Anodenkohlen bei der Elektrolyse heifser Nickelchloridlösung im wesentlichen auch der Einwirkung der unterchlorigen Säure, und zwar der durch Hydrolyse des frei gewordenen Chlors entstandenen, zuschreiben mul's.

Mag nun beim Diaphragmenprozefs die unterchlorige Säure auf dem einen oder dem anderen W.ege entstehen, so ergiebt sich doch, dals die Summe des in der Anodenflüssigkeit vorhandenen aktiven (Hypochlorit- und Chlorat-) Sauerstoffes und des aus diesem hervorgegangenen Sauerstoffes der im Anodengase entweichenden Kohlensäure im Verlaufe einer Elektrolyse dauernd ansteigen muls in dem Mafse, als immer mehr Hydroxyle aus dem Kathodenraum durch das Diaphragma dringen und hier zur Bildung von aktivem Sauerstoff führen.

Diese Folgerung steht im Gegensatz zu Beobachtungen, welche WiNTELER $^{1}$ vor einiger Zeit veröffentlicht hat. Bei Benutzung von künstlichen Kohlenanoden fand er, als er Chlorkaliumlösung mit Diaphragma elektrolysierte, dafs in der Anodenlauge niemals Hypochlorit- oder Chloratsauerstoff entstanden war, sondern nur kleine Mengen freier Salzsäure hier anftraten. Er glaubt, die Entstehung der letzteren durch die allen chemischen Analogien widersprechende Gleichung

$$
\stackrel{+}{\mathrm{H}} \stackrel{+}{\mathrm{H}} \overline{\mathrm{O}}+\mathrm{Cl}_{2}=\stackrel{+}{\mathrm{H}} \stackrel{+}{\mathrm{H}} \overline{\mathrm{Cl}} \overline{\mathrm{Cl}}+0
$$

deuten zu dürfen; die hiernach frei werdende Salzsäure soll dann das durch das Diaphragma dringende Hydroxyl immer neutralisieren und damit wäre der Bildung aktiven Sauerstoffes der Boden ent. zogen. Zu dieser Deutung aber stehen Wrntelek's eigene Ver-

1 Zeitschr: Elektrochem. 5, 10. 
suche in auffallendem Widerspruch. Denn wenn wirklich immer so viel Salzsäure entstehen sollte, als Hydroxyl einwandert, so mülste doch in dem Malse, als das letztere reichlicher erfolgt, bei fortschreitender Elektrolyse im Anodengase Sauerstoff bezw. Sauerstoff und Kohlensäure sich anreichern. Thatsächlich aber fand WinTELER die Zusammensetzung des Anodengases wie folgt:

Nach 6-stündigem Versuch und bei
85.1\% Alkaliausbeute
Cl 95.2 ;
$\mathrm{CO}_{2} 1.2$
$\mathrm{O}_{2} 3.4 \%$

Nach 18-stüudigem Versuch und bei $68.9 \%$ Alkaliausbeute

Cl $95.3 ; \quad \mathrm{CO}_{2} 1.0 ; \quad \mathrm{O}_{2} 3.4$,

Diese auf Versuchsfehler wohl kaum zurückführbaren Ergebnisse zeigen, dafs an Kohlenanoden Salzsäure auch entstehen kann, ohne dafs gleichzeitig Sauerstoff auftritt. Dafs eine solche Möglichkeit thatsächlich vorliegt, wurde dem Einen von uns von befreundeter Seite mitgeteilt. Es giebt nämlich künstliche Anodenkohlen, welche soviel asphaltartige Kohlenwasserstoffe enthalten, dals sie durch das an ihnen freiwerdende Chlor in erheblichem Malse der Chlorierung anheimfallen. Diese verläuft im Sinne der Gleichung

$$
\mathrm{C}_{m} \mathrm{H}_{n}+\mathrm{Cl}_{2}=\mathrm{C}_{m} \mathrm{H}_{n-1} \mathrm{Cl}+\mathrm{HCl}
$$

und wird sich mit fortschreitender Elektrolyse auf immer grölsere Teile der Kohlenanode erstrecken, je mehr ein vorangehender Angriff deren Gefüge gelockert hat.

Auf einen solchen Vorgang dürften die in der That mit einer künstlichen Anodenkohle durchgeführten WiNTELER'schen Beobachtungen zurückzuführen sein; dafür spricht auch der Umstand, dafs bei lange fortgesetzter Elektrolyse WINTELER eine stark braun gefärbte Anodenlauge erhielt, während eine solche bei normalem Verlaufe des Diaphragmenprozesses auch nach weitgehender Erschöpfung der Anodenlauge nicht eintritt. Die Anwendung angreifbarer Kohlen zu Anoden mufs aber bei der Alkalichloridelektrolyse unter allen Umständen vermieden werden, da, wie Gleichung (8) lehrt, aufser dem Verlust an Kohlenmaterial eine eintretende Chlorierung auch eine erhebliche Verschlechterung der Chlorausbeute herbeiführen mufs; die organischen Chlorverbindungen oder deren unter dem Einflufs der Salzsäure gebildete Unwandlungsprodukte können durch Diffusion in die Kathodenlauge gelangen, und diese, zumal beim Eindampfen, dunkel färben, und endlich kann in der Anodenlauge mehr freie Salzsäure entstehen, als Hydroxyl durch das Diaphragma 
dringt. So läfst sich die gelegentlich unter ungünstigen Verhältnissen in der Technik gemachte Beobachtung deuten, dafs, je schneller die Kohlen zerstört werden, umsoweniger auch die dem Angriff der Salzsäure unterliegenden Cementdiaphragmen balten.

Sieht man von den bitumenreichen, für die Chloridelektrolyse ungeeigneten künstlichen Anodenkohlen ab, so bleibt doch für die besseren, nur sehr wenig Wasserstoff noch enthaltenden Kohlen zwar auch die Möglichkeit noch bestehen, dafs sie der Einwirkung des freien Chlors in geringem Umfange unterliegen, aber im wesentlichen wird es, wie schon gesagt, die unterchlorige Säure sein, welche sie angreift. Die Betrachtungen im ersten Teil dieser Arbeit lehren aber, dafs die Theorie ein einfaches Mittel an die Hand giebt, die störende Substanz zu beseitigen, nämlich der Anodenlauge fortdauernd soviel Salzsäure zuzuführen, als Hydroxyl durch das Diaphragma dringt. Dieses Mittel verspricht nicht nur hohe Ausbeuten an sehr reinem Chlor, sondern auch möglichste Schonung der Anodenkohlen. Eine experimentelle Prüfung dieser Folgerung aus der Theorie wäre sehr wertvoll, vor der Hand mufsten wir davon absehen.

\section{b) Die Versuchsanordnung.}

Der Zweck unserer Versuche war wieder lediglich der, den allgemeinen Gang der Chloralkalielektrolyse mit Diaphragma bei Anwendung von Kohlenanoden und bei gewöhnlicher Temperatur zu verfolgen.

Nach den vorangehenden Überlegungen war es zur Gewinnung allgemeiner gültiger Ergebnisse von grolser Wichtigkeit, dafs zur Herstellung der Anoden kein allzu weiches und angreifbares Kohlenmaterial genommen wurde. Es wurde bester Gasretortengraphit der hiesigen Firma OTTo WinkLER gewählt und aus ihm $0.6 \mathrm{~mm}$ starke Platten von $4.5 \mathrm{~cm}$ Breite und $18.0 \mathrm{~cm}$ Länge geschnitten, welche an ihrem oberen Ende etwas breiter wurden und hier einen $1 \mathrm{~cm}$ starken zylindrischen Schaft trugen, welcher durch den die Anodenzelle abschlielsenden Gummistopfen geführt und oberhalb desselben mit der Stromzuführung verbunden wurde.

Um mit solchen Anoden arbeiten zu können, von denen immer zwei neben einander benutzt wurden, bedurften wir erheblich gröfserer Anoden- und Kathodenzellen, als sie bei den früheren Versuchen angewandt wurden, wollten wir, wie es des Vergleichs wegen nötig war, die dort befolgte allgemeine Versuchsanordnung beibehalten.

z. anorg. Chem. XXII. 
Durch das freundliche Entgegenkommen der Berliner Porzellanfabrik erhielten wir aus Pukaru'scher Masse gefertigte schmale, rechteckige Thonzellen von $0.4 \mathrm{~cm}$ Wandstärke, $21 \mathrm{~cm}$ Höhe, $14.5 \mathrm{~cm}$ Breite und $3.5 \mathrm{~cm}$ Tiefe; in ihnen hatten neben den Kohlenanoden $700 \mathrm{ccm}$ der Anodenlauge Platz. Der rechteckige Glaskasten, in welchen die Anodenzelle eingestellt wurde, fafste über 3 Liter und erhielt eine Beschickung mit $2200 \mathrm{ccm}$ der Kathodenlauge, welche die Anodenzelle bis $2 \mathrm{~cm}$ unter ihrem Rande bespülte. Zu ihrer gleichmälsigen Durchmischung diente ein Mrulus-Fromm'sches Rührwerk, von welchem aus ein Steigrohr auch in das Kupfervoltameter tauchte, um hier die in der Zeit bis zur genügenden Alkalianreicherung in der so umfangreichen Kathodenlauge auftretenden Konzentrationsänderungen auszugleichen.

Mit diesem Apparat wurde ganz so gearbeitet, wie es oben bei der Versuchsreihe $\mathrm{C}$ geschah, da es weniger auf eine Feststellung der Chlorausbeute, als auf die analytische Verfolgung der Zusammensetzung des Anodengases ankam.

c) Analyse der Chlor, Kohlensäure und Sauerstoff enthaltenden Anodengase.

Während im übrigen die sämtlichen Bestandteile der Anodenlauge nach den früher beschriebenen Verfahren zu bestimmen waren, bedurfte bei den jetzigen Versuchen die Analyse der aus der Anodenzelle entweichenden, Chlor, Kohlensäure und Sauerstoff neben kleinen Mengen von Kohlenoxydstickstoff führenden Gase besonderer Aufmerksamkeit.

Man fübrt diese meist so aus, daf́s das zu analysierende Gas in eine mit Jodkalium- oder Zinnchlorürlösung gefüllte einfache HeMPEL'scbe Gaspipette übergetrieben und hier vom Chlor befreit wird, worauf im verbleibenden Gasrest Kohlensäure, Sauerstoff und Kohlenoxyd in der üblichen Weise bestimmt werden. Dieses Verfahren ist, da Kohlensäure in beiden genannten Lösungen nicht unerheblich löslich ist, nicht ohne Fehler, die um so bedeutender sind, je geringer der Kohlensäuregehalt des Gases und je frischer die Pipettenfüllung ist.

Diese Fehler aber lassen sich sehr einschränken, wenn man die Analyse nach dem für diesen Fall von Hemper angegebenen Verfahren ${ }^{1}$ durchführt. Es dient dazu eine gewöhnliche HeMPEL'sche Bürette, bei welcher über den nach dem Niveaurohr fübrenden

1 Gasanalytische Methoden, 3. Aufl. 276. 
Gummischlauch ein MонR'scher Quetschhahn gezogen ist. Man füllt sie mit Wasser, dessen spezifisches Gewicht durch etwas Kochsalz ein wenig erhöht ist, und saugt von obenher $1-2 \mathrm{ccm}$ Chlorwasser in die Bürette ein, welche während des Aufsammelns des zu analysierenden Gases auf der Kochsalzlösung verharren und die Absorption des Chlors durch die Sperrflüssigkeit verhindern. Ist die Bürette mit dem Gase gefüllt, so stellt man in ihr einen geringen Unterdruck her, schliefst dann die Verbindung mit dem Niveaurohr durch den Quetschhahn ab und lärst von oben her $2-3 \mathrm{ccm}$ $50 \%$ ige Jodkaliumlösung in die Bürette eintreten. Durch mehrmaliges langsames Neigen derselben vollendet man die Absorption des Chlors. Dabei vermindert sich der Druck in der Bürette so stark, dals eine nennenswerte Aufnahme der Kohlensäure seitens der Jodkaliumlösung unterbleibt. Stellt man nun rorsichtig die Verbindung nach dem Niveaugefäls her, so ist es nur noch die kleine Oberfläche der Sperrflüssigkeit, welche Kohlensäure zu absorbieren vermag und dies in der Zeit einer Gasanalyse bekanntlich nur in sehr geringem Mafse thut. Man treibt nun sofort den Gasrest nach einander in die zur Absorption der Kohlensäure und des Sauerstoffes (bei ganz sorgfältigen Analysen auch des nie ganz fehlenden Kohlenoxyds) geeigneten Pipetten über und rechnet schlielslich einen etwa verbleibenden kleinen Stickstoffrest auf Luft um, die man vom Gesamtgase in Abzug bringt. Dieses Verfahren ist bei der Möglichkeit, die HEMPEL'sche Gasbürette schnell gut zu reinigen, sehr bequem und hat sich auch zur technischen Betriebsüberwachung als höchst wertroll erwiesen.

Im vorliegenden Falle wurde es, zumal, wenn sehr kleine Mengen Kohlensäure im Chlor zu erwarten waren, durch eine umständlichere Arbeitsweise ersetzt. Mit dem früher beschriebenen Sammelgefäls wurden jedesmal $500 \mathrm{ccm}$ des Anodengases aufgefangen und dann in eine einfache, und zwar mit Quecksilber gefüllte Gaspipette übergetrieben, in welche zuvor soviel Jodkalium in böchst konzentrierter wässeriger Lösung eingebracht war, dafs $1000 \mathrm{ccm}$ reinen Chlors von ihm absorbiert werden konnten. Die Lösung wurde hierbei mit Kohlensäure unter dem von ihr gerade im Gasrest ausgeübten Partialdruck gesättigt, und diente nunmehr zur Ausführung der Analyse einer unmittelbar nach der ersten entnommenen Gasprobe, deren Ergebnis erst als endgültig angesehen wurde. Hierauf wurde die Quecksilberpipette gereinigt und für die nächste Analyse mit frischer Jodkaliumlösung beschickt. 
Wir glauben, auf diese Weise unsere gasanalytisch erhaltenen Werte nach Möglichkeit gesichert zu haben; da wo beide Verfahren auf dieselbe Gasprobe angewandt wurden, lieferten sie übereinstimmende Ergebnisse. So wurde in einem Gase gefunden:

bei Untersuchung in der HEMPEL'schen Bürette 9.50\% $\mathrm{CO}_{9}$;

" " "Quecksilberpipette $9.54 "$ ".

Die stets nur sehr kleinen, höchstens einige Zehntelprozente betragenden Kohlenoxydmenge wurden bei unseren Analysen vernachlässigt.

\section{d) Versuchsergebnisse.}

Die Versuche wurden zunächst mit der früher bei den Versuchsreihen $\mathrm{A}$ bis $\mathrm{C}$ benutzten anodischen Stromdichte von $0.023 \mathrm{Amp} / \mathrm{qcm}$ und mit einer solchen von $0.012 \mathrm{Amp} / \mathrm{qcm}$ am Diaphragma, d. $h$. mit einer Stromstärke von 6.2-6.3 Amp., durchgeführt, und zwar solange, bis die Kathodenlauge in Bezug auf freies Alkali ungefähr normal war. Sie erstreckten sich auf Chlorkalium wie auf Chlornatrium. Die Ergebnisse sind in der folgenden Übersicht als Versuchsreihe $\mathbf{E}$ zusammengestellt, und zwar so, dafs zunächst die Änderung des Alkalititers der Kathodenlauge und der Zusammensetzung des Anodengases im Verlauf einer Elektrolyse angegeben und alsdann die Resultate der vollständigen Analysen der Kathodenund der Anodenlauge zu Anfang und am Schlufs des Versuches verzeichnet sind.

Versuchsreihe E.

Versuch 17. Die Kathodenlauge enthielt $179 \mathrm{~g} \mathrm{KCl}$ in 1 Liter Die Anodenlauge enthielt $290 \mathrm{~g}, " 1$,

\begin{tabular}{|c|c|c|c|c|c|}
\hline \multirow{2}{*}{$\begin{array}{c}\text { Zeit nach } \\
\text { Beginn } \\
\text { der } \\
\text { Elektrolyse }\end{array}$} & \multirow{2}{*}{$\begin{array}{c}\text { cem } n-\mathrm{H}_{2} \mathrm{SO}_{4} \\
\text { welche } 25 \mathrm{ccm} \\
\text { der } \mathrm{Ka} \text { - } \\
\text { thodenlauge } \\
\text { neutralisierten }\end{array}$} & \multirow{2}{*}{$\begin{array}{c}\text { Spannung } \\
\text { am } \\
\text { Bade }\end{array}$} & \multirow{2}{*}{$\begin{array}{c}\text { Temperatur } \\
\text { der } \\
\text { Kathoden- } \\
\text { lauge }\end{array}$} & \multicolumn{2}{|c|}{$\begin{array}{l}\text { Zusammensetzung } \\
\text { des Anodengases }\end{array}$} \\
\hline & & & & $\% \quad \mathrm{CO}_{2}$ & $\% \mathrm{O}_{2}$ \\
\hline 1 Std. & 2.64 & 3.85 Volt & $23.5^{\circ}$ & $\ldots$ & - \\
\hline $3 \quad$ & 7.15 & 3.76, & $26^{\circ}$ & - & - \\
\hline $41 / 4$, & - & $3.80 "$ & $27.5^{\circ}$ & 2.48 & 0.74 \\
\hline & 11.54 & $3.76 "$ & $28^{\circ}$ & - & - \\
\hline $6^{1 / 4}$, & - & $3.78 "$ & $28^{\circ}$ & 2.62 & 1.12 \\
\hline 7 & 15.40 & $3.78 "$ & $28^{\circ}$ & - & - \\
\hline $8 \%$ & -- & $3.77 "$ & $28^{\circ}$ & 2.74 & 2.00 \\
\hline $91 / 4$, & 19.55 & $3.80 "$ & $28^{\circ}$ & - & - \\
\hline $10^{1} / 2$, & - & $3.89 "$ & $28.5^{\circ}$ & 3.80 & 2.62 \\
\hline $11 "$ & 22.20 & 3.90 & $29.0^{\circ}$ & - & - \\
\hline
\end{tabular}


Versuch 18. Die Kathodenlange enthielt $114 \mathrm{~g} \mathrm{NaCl}$ in 1 Liter Die Anodenlauge $230 \mathrm{~g}, ", 1$, .

\begin{tabular}{|c|c|c|c|c|c|}
\hline $\begin{array}{l}\text { Zeit nach } \\
\text { Beginn } \\
\text { der } \\
\text { Elektrolyse }\end{array}$ & $\begin{array}{c}\text { ccm } n-\mathrm{H}_{8} \mathrm{SO}_{4} \\
\text { welche } 25 \mathrm{ccm} \\
\text { der } \mathrm{Ka}- \\
\text { thodenlauge } \\
\text { neutralisierten }\end{array}$ & $\begin{array}{c}\text { Spannung } \\
\text { Bam } \\
\text { Bade }\end{array}$ & Temperatur & $\begin{array}{l}\begin{array}{c}\text { Zusamn } \\
\text { des Ax }\end{array} \\
\% \mathrm{CO}_{8}\end{array}$ & $\begin{array}{l}\text { isetzung } \\
\text { engases } \\
\% \mathrm{O}_{2}\end{array}$ \\
\hline 1 Std. & 2.65 & 4.29 Volt & $24^{\circ}$ & - & - \\
\hline $2 "$ & - & 4.20 & $26^{\circ}$ & 1.46 & 0.62 \\
\hline 3 & 7.08 & $4.19 "$ & $27^{\circ}$ & - & - \\
\hline $4^{1 / 4}$, & - & $4.16 "$ & $28^{\circ}$ & 2.26 & 1.36 \\
\hline 5 & 11.14 & $4.12 "$ & $29^{\circ}$ & - & - \\
\hline $61 / 4$, & - & $4.15 "$ & $30^{\circ}$ & 3.20 & 2.82 \\
\hline $7 \%$ & 14.6 & $4.12 "$ & $30.5^{\circ}$ & - & - \\
\hline $8 \quad$, & - & - & -- & 3.78 & 4.24 \\
\hline $91 / \%$ & 18.2 & 4.15 & $31.5^{\circ}$ & - & - \\
\hline $101 / 2$, & - & $4.19 "$ & $31.5^{0}$ & 5.22 & 5.0 \\
\hline $11 \%$ & 20.87 & $4.23 "$ & $32^{0}$ & - & - \\
\hline
\end{tabular}

Gesamtänderungen in der Zusammensetzung der Kathodenlauge und Ausbeute an Alkali.

\begin{tabular}{|c|c|c|c|c|c|c|c|c|c|c|c|}
\hline \multirow{3}{*}{ 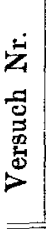 } & \multicolumn{6}{|c|}{ Chloridmenge } & \multirow{2}{*}{\multicolumn{3}{|c|}{$\begin{array}{l}\text { Alkalimenge am } \\
\text { Schlufs d. Versuchs }\end{array}$}} & \multirow{3}{*}{ 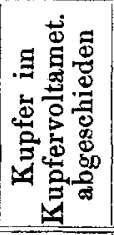 } & \multirow{3}{*}{ 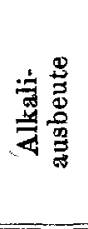 } \\
\hline & \multicolumn{3}{|c|}{ vor dem Versuch } & \multirow{2}{*}{ 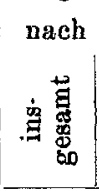 } & \multicolumn{2}{|c|}{ dem Versuch } & & & & & \\
\hline & 点泀 & 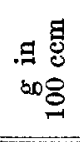 & 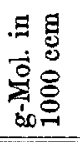 & & 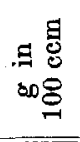 & 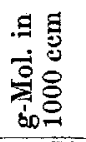 & م. & 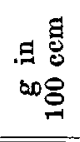 & 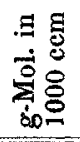 & & \\
\hline 17 & $\begin{array}{c}394 \mathrm{~g} \\
\mathrm{KCl}\end{array}$ & 17.9 & 2.403 & $355.6 \mathrm{~g}$ & 15.4 & 2.063 & $\begin{array}{c}118.5 \mathrm{~g} \\
\mathrm{KOH}\end{array}$ & 4.97 & 0.888 & 78.0 & $86.0 \%$ \\
\hline 18 & $\begin{array}{l}253 \mathrm{~g} \\
\mathrm{NaCl}\end{array}$ & 11.4 & 1.95 & $228.6 \mathrm{~g}$ & 10.2 & 1.744 & $\begin{array}{l}77.28 \mathrm{~g} \\
\mathrm{NaOH}\end{array}$ & 3.34 & 0.818 & 78.8 & 77.6 \\
\hline
\end{tabular}

Gesamtänderungen der Anodenlauge.

\begin{tabular}{|c|c|c|c|c|c|c|c|c|c|c|c|c|}
\hline \multirow{3}{*}{ 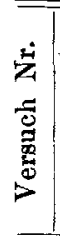 } & \multirow{2}{*}{\multicolumn{2}{|c|}{$\begin{array}{l}\text { Volumen der } \\
\text { Anodenlauge }\end{array}$}} & \multicolumn{6}{|c|}{ Chloridmenge } & \multirow{3}{*}{ 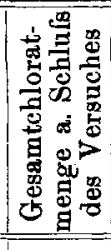 } & \multirow{3}{*}{ 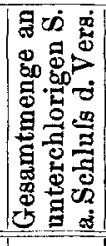 } & \multirow{3}{*}{ 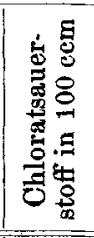 } & \multirow{3}{*}{ 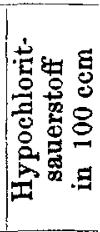 } \\
\hline & & & \multirow{2}{*}{ 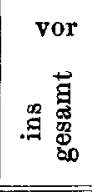 } & \multicolumn{2}{|c|}{ lem Versuch } & \multicolumn{3}{|c|}{ nach dem Versuch } & & & & \\
\hline & 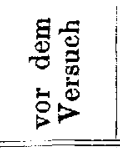 & 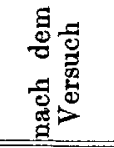 & & 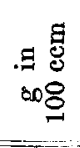 & 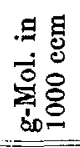 & 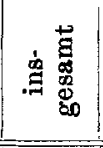 & 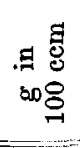 & 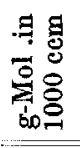 & & & & \\
\hline 17 & $700 \mathrm{ccm}$ & $480 \mathrm{ccm}$ & $209 \mathrm{~g}$ & 29 & 3.89 & $64.15 \mathrm{~g}$ & 13.4 & 1.80 & $\begin{array}{l}1.184 \mathrm{~g} \\
\mathrm{KClO}\end{array}$ & $0.473 \mathrm{~g}$ & 0.097 & \\
\hline 18 & $700 "$ & 510, & $\underset{\mathrm{NaCl}}{161} \mathrm{~g}$ & 23 & 3.93 & 67.86, & 13.0 & 2.22 & 2.183, & 1.53 & 0.189 & \\
\hline
\end{tabular}


Da bei dieser Versuchsreihe die Anfangskonzentrationen der Kathodenlauge bei Versuch 17 und 18 nicht einander äquivalent waren, andererseits die Möglichkeit des Einwandes bestand, dafs die von den WINTELER'schen abweichenden Ergebnisse darauf zurückführbar seien, dals die anodische Stromdichte nicht die von ihm benutzte von $0.01 \mathrm{Amp} . / \mathrm{qm}$ war, so wurde eine neue Versuchsreihe F vorgenommen, bei welcher mit äquivalent zusammengesetzten Chlorkalium- und Chlornatriumlösungen und mit einer Anodenstromdichte von $0.01 \mathrm{Amp} . / \mathrm{qcm}$ gearbeitet wurde. Die Stromstärke betrug $2.8 \mathrm{Amp}$, wodurch am Diaphragma eine Stromdichte von $0.005 \mathrm{Amp} / \mathrm{qcm}$ gegeben war, sowie die Notwendigkeit, den Versuch 30 Stunden fortzusetzen, um etwa normale Alkalilauge in der Kathodenzelle zu erzielen. Die Ergebnisse waren die folgenden:

\section{Versuchsreihe F.}

Versuch 19. Die Kathodenlauge enthielt $176 \mathrm{~g} \mathrm{KCl}$ in 1 Liter. Die Anodenlauge " $280, ", 1$,

\begin{tabular}{|c|c|c|c|c|c|c|}
\hline \multirow{2}{*}{\multicolumn{2}{|c|}{$\begin{array}{l}\text { Zeit nach } \\
\text { Begin der } \\
\text { Elektrolyse }\end{array}$}} & \multirow{2}{*}{$\begin{array}{c}\text { cem } n-\mathrm{H}_{2} \mathrm{SO}_{4} \\
\text { welche } 25 \mathrm{ccm} \\
\text { der Kathoden- } \\
\text { lauge neu- } \\
\text { tralisierten }\end{array}$} & \multirow[t]{2}{*}{$\begin{array}{c}\text { Spannung } \\
\text { am } \\
\text { Bade }\end{array}$} & \multirow[t]{2}{*}{$\begin{array}{c}\text { Temperatur } \\
\text { der } \\
\text { Kathoden- } \\
\text { lauge }\end{array}$} & \multicolumn{2}{|c|}{$\begin{array}{l}\text { Zusammensetzung } \\
\text { des Anodengases }\end{array}$} \\
\hline & & & & & $\% \mathrm{CO}_{2}$ & $\% \quad \mathrm{O}_{2}$ \\
\hline & Std. & 3.5 & 3.32 Volt & $24.5^{\prime \prime}$ & - & - \\
\hline 4 & $"$ & - & 3.30, & $25^{\circ}$ & 0.92 & 0.57 \\
\hline 5 & " & 5.6 & 3.30 & $25^{n}$ & - & 一 \\
\hline 7 & $"$ & 7.4 & $3.30 "$ & $24^{\circ}$ & 1.04 & 0.80 \\
\hline 21 & $"$ & 20.0 & $3.42 "$ & $23.5^{0}$ & - & - \\
\hline 24 & $"$ & 22.3 & 3.46, & $23.5^{\circ}$ & 4.58 & 2.78 \\
\hline 28 & $"$ & 24.8 & $3.50 \%$ & $24.5^{\circ}$ & - & - \\
\hline 29 & $"$ & - & 3.52, & $24.5^{\circ}$ & 7.38 & 4.50 \\
\hline 30 & , & 25.4 & $\ldots-$. & - & - & - \\
\hline
\end{tabular}


Versuch Nr. 20. Die Kathodenlauge enthielt $138.2 \mathrm{NaCl}$ in 1 Liter.

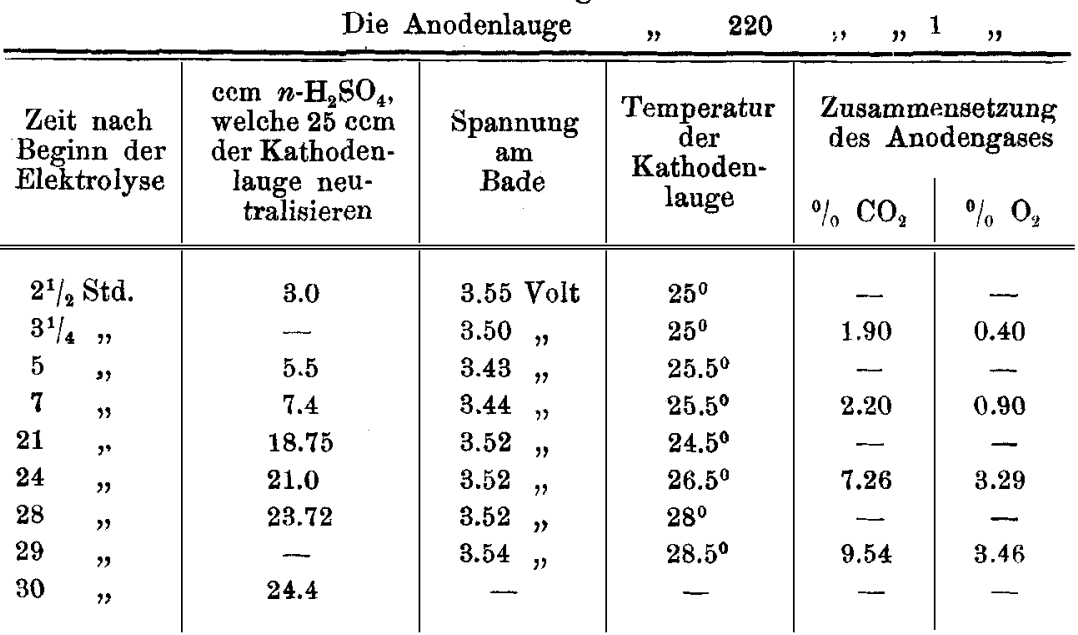

Gesamtänderung in der Zusammensetzung der Kathodenlauge und Alkaliausbeute.

\begin{tabular}{|c|c|c|c|c|c|c|c|c|c|c|c|}
\hline \multirow{3}{*}{ 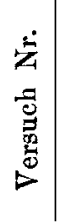 } & \multicolumn{6}{|c|}{ Chloridmenge } & \multirow{2}{*}{\multicolumn{3}{|c|}{$\begin{array}{l}\text { Alkalimenge am } \\
\text { Schlufs d. Versuchs }\end{array}$}} & \multirow{3}{*}{ 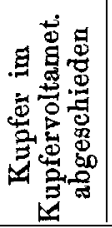 } & \multirow{3}{*}{ 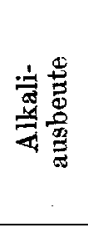 } \\
\hline & \multirow{2}{*}{ 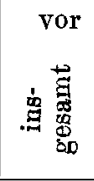 } & \multicolumn{2}{|c|}{ dem Versuch } & \multirow{2}{*}{ 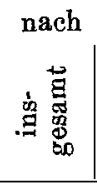 } & \multicolumn{2}{|c|}{ dem Versuch } & & & & & \\
\hline & & $\begin{array}{r} \\
. \\
.8 \\
.08 \\
8\end{array}$ & 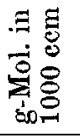 & & $\begin{array}{l}. \approx \\
.08 \\
008\end{array}$ & 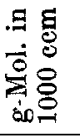 & 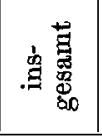 & $\begin{array}{l}\exists \\
. \exists \\
808\end{array}$ & 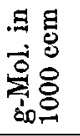 & & \\
\hline 19 & $\begin{array}{c}387.2 \mathrm{~g} \\
\mathrm{KCl}\end{array}$ & 17.6 & 2.37 & $324.3 \mathrm{~g}$ & 14.1 & 1.89 & $\begin{array}{c}130.9 \mathrm{~g} \\
\mathrm{KOH}\end{array}$ & 5.69 & 1.016 & $101 \mathrm{~g}$ & $73.3 \%$ \\
\hline 20 & $\begin{array}{c}304.0 \mathrm{~g} \\
\mathrm{NaCl}\end{array}$ & 13.8 & 2.37 & $245.6 \mathrm{~g}$ & 10.8 & 1.85 & $\begin{array}{l}89.0 \mathrm{~g} \\
\mathrm{NaOH}\end{array}$ & 3.90 & 0.976 & $100 \mathrm{~g}$ & 70.5 \\
\hline
\end{tabular}

Gesamtänderungen der Anodenlauge.

\begin{tabular}{|c|c|c|c|c|c|c|c|c|c|c|c|c|}
\hline \multirow{3}{*}{ 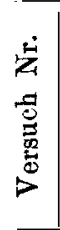 } & \multirow{2}{*}{\multicolumn{2}{|c|}{$\begin{array}{l}\text { Volumen der } \\
\text { Anodenlauge }\end{array}$}} & \multicolumn{6}{|c|}{ Chloridmenge } & \multirow{3}{*}{ 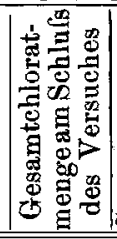 } & \multirow{3}{*}{ 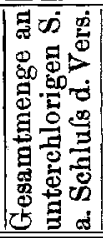 } & \multirow{3}{*}{ 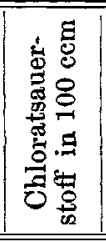 } & \multirow{3}{*}{ 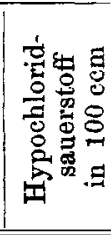 } \\
\hline & & & \multicolumn{3}{|c|}{ vor dem Versuch } & \multicolumn{3}{|c|}{ nach dem Versuch } & & & & \\
\hline & 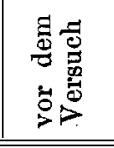 & 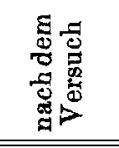 & 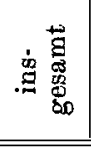 & 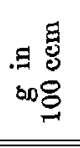 & 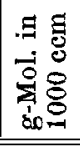 & 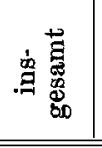 & 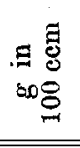 & 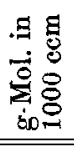 & & & & \\
\hline 19 & $700 \mathrm{cem}$ & $480 \mathrm{ccm}$ & $\begin{array}{l}196 \mathrm{~g} \\
\mathrm{KCl}\end{array}$ & 28 & 3.76 & $37.6 \mathrm{~g}$ & 7.8 & 1.05 & $\begin{array}{l}2.886 \mathrm{~g} \\
\mathrm{KClO} \\
\mathrm{B}\end{array}$ & & $0.215 \mathrm{~g}$ & 0.0 \\
\hline 20 & $700 "$ & $560 "$ & $\begin{array}{l}154 \mathrm{~g} \\
\mathrm{NaCl}\end{array}$ & 22 & 3.76 & $50.6 \mathrm{~g}$ & 9.0 & 1.54 & $\begin{array}{l}1.674 \mathrm{~g} \\
\mathrm{NaClO}_{8}\end{array}$ & $0.830 \mathrm{~g}$ & $0.145 \mathrm{~g}$ & 0.045 \\
\hline
\end{tabular}


Bei allen Versuchen erhielt die Anodenlauge höchstens eine ganz geringe gelbliche Färbung, welche wohl ausschliefslich von dem aus den Anoden herrührenden Eisenchlorid verursacht war der Angriff der Anoden zeigte sich daran, dals auf ihnen ein leicht entfernbares Pulver von Resten der zerstörten Kohlensubstanz hinterblieb; nur geringe Anteile desselben traten als Bodensatz in der Anodenzelle auf.

Übereinstimmend zeigen die Versuchsreihen $\mathrm{E}$ und $\mathrm{F}$, dals in der Anodenlauge aktiver Sauerstoff, Chlorat- und Hypochloritsauerstoff, auftritt, und zwar der letztere wieder in Gestalt von freier unterchloriger Säure. Zum Überflufs wurde in einem Falle, bei Versuch 18, durch Fällen der stark eingeengten Anodenlauge mit Chlorkalium, etwa $1 \mathrm{~g}$ reines Kaliumchlorat in Substanz abgeschieden. Vergleicht man die Menge des gesamten aktiven Sauerstoffes, welcher bei dem bis etwa zu der bei Versuch 17 erreichten kathodischen Alkalikonzentration fortgeführten Versuch 1 in der Anodenzelle auftrat $(0.276 \mathrm{~g}$ in $100 \mathrm{ccm})$, mit der hier gefundenen $(0.127 \mathrm{~g}$ in $100 \mathrm{ccm})$, so sieht man, dafs die letztere zumal hinsichtlich ihres Hypochloritsauerstoffes $(0.030 \mathrm{~g}$ in $100 \mathrm{ccm})$ hinter dem dort gefundenen Werte $(0.252 \mathrm{~g}$ in $100 \mathrm{ccm})$ sehr stark zurück blieb. Dafür erscheint aber hier der Sauerstoff der Kohlensäure im Anodengase. Seine, sowie des freien Sauerstoffes Menge wächst, je mehr die in den Anodenraum dringende Hydroxylmenge ansteigt; hierfür ist aulser dem Verlauf jeder einzelnen Elektrolyse zumal ein Vergleich der Versuch 17 und 18 interessant, da der letztere die kleinere Alkaliausbeute, dafür aber sowohl mehr aktiven Sauerstoff in der Anodenlauge als auch einen höheren Gehalt an Kohlensäure im Anodengase gab als der erstere.

Bei Versuch 19 sank die Chloridkonzentration in der Anodenlauge auf den Gehalt einer 1/1-norm. Lösung. Die unter solchen Bedingungen notwendigerweise schon entstehende Salzsäure hat hier die unterchlorige Säure vermindert, während der Sauerstoffgehalt des Anodengases - infolge der Hydroxylentladung - noch angestiegen ist. Bei der ohnehin geringen Menge von unterchloriger Säure, welche an Kohlenelektroden bestehen bleibt, wird der Punkt, an dem freie Salzsäure an der Anodenzelle verbleiben kann, in diesem Falle bei einer höheren Chloridkonzentration erreicht als an Platinanoden. Während bei deren Benutzung die Anodenlauge in Bezug auf $\mathrm{KCl}$ bis auf $1 / 10$ bis $1 / 30^{-n o r m}$. herabgehen konnte, ohne dafs der Hypochloritsauerstoff ganz aus der Lösung verschwand, war, als Herr Dr. SonNeborn an Kohlenelektroden Chlorkalium- 
lösung elektrolysierte, bis die Anodenlauge nicht mehr ganz $1 / 2^{-}$ normal in Bezug auf Cl-Ionen war, diese in Hinblick auf freie Säure schon etwa $1 / 5$-normal, sie enthielt kein Hypochlorit mehr und gab ein Gas, in welchem $21 \%-\mathrm{CO}_{2}$ und $14 \%-\mathrm{O}_{2}$ vorhanden waren; dementsprechend war jetzt der Angriff der Anoden sehr stark sichtbar geworden.

Die Vorgänge in der Anodenzelle sind also bei der Alkalielektrolyse mit Diaphragma im wesentlichen dieselben, ob Platiniridiumoder Kohlenanoden angewandt werden; die auftretenden Unterschiede sind keine anderen, als sie die Theorie voraussehen lälst. Die Beobachtungen WinTELERS sind hiermit als für die Beurteilung der allgemeinen Vorgänge des Diaphragmenprozesses ungeeignet erwiesen.

Schliefslich gestatten die zuletzt angeführten Versuchsreihen E und $F$ noch einige Bemerkungen über die für die Alkaliausbeuten malsgebenden Gesichtspunkte. Bei Versuch 19 wurde eine Kathodenlauge von $5.69 \mathrm{~g} \mathrm{KOH}$ in $100 \mathrm{ccm}$ mit einer Stromausnutzung von $73.3 \%$ erzielt, während bei den Versuchen 3 und 6 Alkaligehalte von 6.1 bezw. $6.3 \mathrm{~g} \mathrm{KOH}$ mit 74 bezw. $76 \%$ Stromausbeute erhalten wurden. Der Grund hierfür liegt darin, dafs Versuch 19 wegen der geringeren dabei angewandten Stromstärke und des grölseren Volumens der Kathodenflüssigkeit $5 \mathrm{mal}$ so lange fortgesetzt werdeu mulste, als die nur 6-stündigen Versuche 3 und 6 . Wenn nun aber hier der Alkaliverlust erheblich kleiner ist, als er früher zwischen den Versuchen 12 und 16 gefunden wurde, deren Versuchszeiten sich ebenfalls wie $1: 5$ verhielten, so ist das damit zu begründen, dals in diesem Falle eine viel stärkere, etwa $10 \mathrm{~g} \mathrm{KOH}$ in $100 \mathrm{ccm}$ enthaltende Kathodenlauge gewonnen wurde, mithin hier die bei längerer Versuchsdauer die Alkaliverluste vermehrende Diffusion infolge des höheren Konzentrationsgefälles mehr sich bethätigen mufste, als wenn nur etwa $6 \mathrm{~g} \mathrm{KOH}$ in $100 \mathrm{ccm}$ der Kathodenlauge enthalten waren. Man wird also, wenn man durch eine gegebene Diaphragmenfläche auf eine bestimmte Stromstärke angewiesen ist, zweckmäl'sig um so kleinere Kathodenräume anwenden, auf je höhere Alkalikonzentration man hinarbeitet, bezw. bei gegebenem Kathodengefäls durch Vergrölserung der Diaphragmenfläche, also wohl der Zahl der Anodenzellen, bestrebt sein, eine für das gegebene Volumen der Kathodenlauge günstige Stromstärke erreichen zu können.

Bei Versuch 19 wurde eine sehr viel gröfsere Gesamtalkalimenge mit besserer Strom- und Energieausbeute gewonnen als es bei Versuch 13 der Fall war, welcher bei den früheren Versuchsreihen das meiste 
Kalihydrat geliefert hatte. Die folgende Übersicht zeigt, dafs diese Ersparnis an elektrischer Energie geschieht auf Kosten von einer grofsen Menge von Chlorkalium, welche unverändert in der Kathodenlauge verblieb und als Ballast durch die Fabrikation hindurchgeführt werden mülste, noch dazu auf Kosten der Notwendigkeit grolse Flüssigkeitsmengen eindampfen zu müssen.

\begin{tabular}{|c|c|c|c|c|c|}
\hline $\begin{array}{c}\text { Versuch } \\
\text { Nr. }\end{array}$ & $\begin{array}{l}\text { Es wurden } \\
\text { gewonnen }\end{array}$ & $\begin{array}{l}\text { mit einer } \\
\text { Stromaus- } \\
\text { beute von }\end{array}$ & $\begin{array}{c}\text { mit einer } \\
\text { mittleren } \\
\text { Badspannung } \\
\text { von }\end{array}$ & $\begin{array}{c}\text { Gleichzeitig } \\
\text { waren in dex } \\
\text { Endlauge }\end{array}$ & $\begin{array}{l}\text { Volumen } \\
\text { der } \\
\text { Endlauge }\end{array}$ \\
\hline 19 & $130.9 \mathrm{~g} \mathrm{KOH}$ & $73.3 \%$ & 3.35 Volt & $324.3 \mathrm{~g} \mathrm{KCl}$ & $2300 \mathrm{ccm}$ \\
\hline 13 & $114.8, \quad n$ & $64.0 "$ & $3.75 \quad$ & $104.2, "$, & 750 \\
\hline
\end{tabular}

Es ist Sache der Technik, für gegebene Verhältnisse diejenigen Arbeitsbedingungen zu fipden, unter denen nach beiden Seiten hin mit möglichster Sparsamkeit die elektrolytische Alkalierzeugung nach dem Diaphragmenprozefs betrieben werden kann.

Endlich können aus den Versuchen 19 und 20 auch Chlorkalium und Chlornatrium hinsichtlich ihrer Brauchbarkeit für den Diaphragmenprozels mit einander verglichen werden. Es ergab sich, dafs aus Chlornatrium nicht nur wegen der Verschiedenheit der Atomgewichte von Natrium und Kalium mit Hilfe desselben Stromes eine kleinere Gewichtsmenge Alkalihydrat als aus Chlorkalium erzielt werden kann, sondern dafs auch die Stromausbeute an Natronhydrat unter sonst ganz gleichen Verbältnissen kleiner ist, als an Kalihydrat. Die Theorie liels dies nach den Überführungsverhältnissen voraussagen; hierzu kommt aber noch, dafs, wie unsere Versuche zeigen, die elektrische Endosmose bei den Chlornatriumlösungen schwächer war als bei äquivalenten Chlorkaliumlösungen; dort ist die den Anodenraum verlassende Flüssigkeitsmenge, mithin auch der den einwandernden Hydroxylen entgegenstehende Druck geringer als hier. Die beobachtete Verminderung der Stromausbeute bei den Natriumlösungen ist also wohl im wesetlichen, aber nicht allein auf die Verschiedenheit der Wanderungsgeschwindigkeiten des Natriumund Kaliumions zurückführbar. Diese bedingt freilich in unserem Falle auch noch einen weiteren Nachteil der Chlornatriumlösungen, denn sie bewirkt, dafs letztere, die zudem bei hoher Konzentration auch weniger starke elektrolytische Dissoziation zeigen als äquivalente Chlorkaliumlösungen, den Strom schlechter leiten, also eine etwas höhere Badspannung erfordern als diese. Zu Anfang der Ver- 
suche 19 und 20 herrschte die gleiche Temperatur von $25^{\circ}$, und da belief sich dieser Unterschied auf 0.2 Volt, d. h. für Chlornatrium war eine um $6 \%$ höhere Badspannung nötig als für Chlorkalium. Die Energieausbeute an Alkalihydrat beim Diaphragmenprofs wird also bei Benutzung von Chlornatrium nicht unerheblich hinter der durch Elektrolyse von Chlorkalium zu erzielenden zurückbleiben. Eine Temperaturerhöhung kann diesen Unterschied vermindern, wie die für heilse Chlornatriumlösungen von $\mathrm{BEIN}^{1}$ vorgenommenen Überführungsversuche vermuten lassen.

Die vorstehend mitgeteilten Untersuchungen dürfen nur als ein erster Versuch, die Eigenarten des Diaphragmenprozesses wissenschaftlich zu kennzeichnen, aufgefalst werden. Sie bedürfen noch nach mancher Seite hin der Ergänzung. Dals die anodische Salzsäurebildung noch genauer zu studieren ist, wurde oben betont; hierzu kommt die für die Technik so wichtige Frage des Einflusses der Temperatursteigerung auf den Verlauf der hier nur für gewöhnliche Temperatur erörterten Vorgänge, und schliefslich wird auch wohl manche Folgerung aus den vorangehenden Darlegungen bestätigt werden können, wenn man statt mit dauernd schwächer werdender, mit stets gesättigter Chloridlösung in der Anodenzelle arbeitet.

1.. a. 0 .

Dresden, Anorg.-chemisches Laboratorium der k. sächs. techn. Hochschule 27. Dezember 1899.

Bei der Redaktion eingegangen am 28. Dezember 1899. 